Pontifícia Universidade Católica $_{\text {ma }}$ DO RIO DE JANEIRO

Patricia Tainá da Silva Correa Antunes

Uso do Pavimento Permeável de Concreto para

Atenuação de Cheias Urbanas

Dissertação de Mestrado

Dissertação apresentada ao Programa de Pós-Graduação em Engenharia Urbana e Ambiental da PUC-Rio como requisito parcial para obtenção do grau de Mestre em Engenharia Urbana e Ambiental

Orientador: Prof. Antônio Roberto Martins Barboza de Oliveira

Rio de Janeiro

Dezembro de 2017 


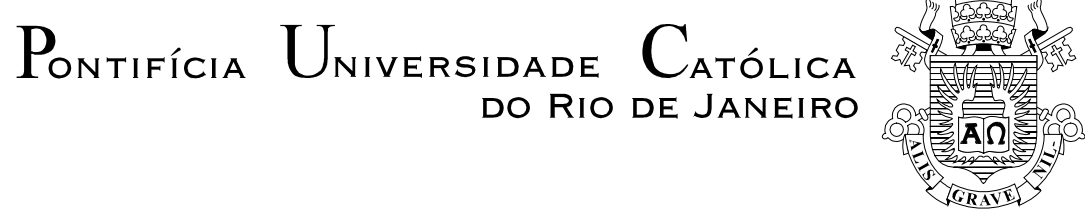

Patricia Taina da Silva C Antunes

\title{
Uso do pavimento permeável de concreto para atenuação de cheias urbanas
}

\begin{abstract}
Dissertação apresentada como requisito parcial para obtenção do grau de Mestre pelo Programa de Pós-Graduação em Engenharia Urbana e Ambiental da PÚC-Rio. Aprovada pela Comissão Examinadora abaixo assinada.
\end{abstract}

Prof. Antonio Roberto Martins Barboza de Oliveira Orientador Departamento de Engenharia Civil e Ambiental - PUC-Rio

Prof. - Thais Cristina Campos de Abreu Departamento de Engenharia Civil e Ambiental - PUC-Rio

Prof. Paulo Luiz da Fonseca Prefeitura da Cidade do Rio de Janeiro

Prof. Márcio da Silveira Carvalho

Coordenador Setorial do Centro

Técnico Científico - PUC-Rio

Rio de Janeiro, 11 de dezembro de 2017. 
Todos os direitos reservados. É proibida a reprodução total ou parcial do trabalho sem a autorização da universidade, do autor e do orientador.

\section{Patricia Tainá da Silva Correa Antunes}

Graduou-se em Engenharia Civil pela Universidade Federal do Rio de Janeiro em 2011. Atualmente, trabalha com projetos de hidráulica e hidrologia na área de petróleo e gás.

Ficha Catalográfica

Antunes, Patricia Tainá da Silva Correa

Uso do pavimento permeável de concreto para atenuação de cheias urbanas / Patricia Tainá da Silva Correa Antunes; orientador: Antônio Roberto Martins Barboza de Oliveira. - 2018.

132 f. : il. color. ; $30 \mathrm{~cm}$

Dissertação (mestrado)-Pontifícia Universidade Católica do Rio de Janeiro, Departamento de Engenharia Civil e Ambiental, Programa de Pós-Graduação em Engenharia Urbana e Ambiental, 2018.

Inclui bibliografia

1. Engenharia Civil - Teses. 2. Engenharia Urbana e Ambiental - Teses. 3. Drenagem urbana. 4. Pavimento permeável de concreto. 5. Atenuação de cheias. 6. Bacia Rio dos Macacos. 7. SWMM. I. Oliveira, Antônio Roberto Martins Barboza de. II. Pontifícia Universidade Católica do Rio de Janeiro. Programa de Pós-Graduação em Engenharia Urbana e Ambiental. III. Título.

CDD: 624 


\section{Agradecimentos}

À Deus, por ter me proporcionado essa oportunidade e ter me dado energia para chegar até o fim. Sem Ele certamente nada disso seria possível.

Aos meus pais, pela educação e amor incondicional.

Ao meu namorado, por todo incentivo para me inscrever no Mestrado e apoio ao longo de todo o curso.

Ao meu orientador, Antônio Roberto, por ter confiado na minha capacidade em desenvolver esse tema e pela orientação para a elaboração deste trabalho.

À equipe do Laboratório de Estruturas e Materiais (LEM) e a do Laboratório de Geotecnia e Meio Ambiente (LGMA), principalmente aos profissionais Amaury, Bruno, Euclides, Edson e José, pela orientação para realização dos ensaios.

Aos amigos que conheci no Mestrado, Bruno, Jéssica e Fabiana, por tornarem essa caminhada muito mais divertida.

Ao meu amigo César Sá, pelo incentivo constante, conselhos, companhia e amizade.

Aos amigos que também fizeram parte dessa história: Ana Maria, Cristiane, Cócis e Mourente. Especialmente, ao Mourente e à Ana, por terem incentivado esse projeto desde o início.

À Fabiane, por toda a torcida para terminar essa dissertação, pela constante disposição em compartilhar conhecimento e amizade.

À Flávia, por incentivar e compreender os momentos que tive que me ausentar para concluir o Mestrado.

A todos os professores do Mestrado em Engenharia Urbana e Ambiental e aos professores que participaram da banca, pelo valioso conhecimento transmitido. 


\section{Resumo}

Antunes, Patricia Tainá da Silva Correa; Oliveira, Antônio Roberto Martins Barboza (Orientador). Uso do Pavimento Permeável de Concreto para Atenuação de Cheias Urbanas. Rio de Janeiro, 2017. 132p. Dissertação de Mestrado - Departamento de Engenharia Civil e Ambiental, Pontifícia Universidade Católica do Rio de Janeiro.

A pesquisa analisou o material concreto permeável visando a sua aplicação como revestimento de pavimentos permeáveis para atenuação de cheias urbanas. Desta maneira, diversas misturas foram estudadas experimentalmente, objetivando determinar suas características hidráulicas e mecânicas. Com base nos resultados experimentais e no uso pretendido em calçadas, foi definida a mistura mais adequada. A fim de analisar o impacto desta solução no escoamento superficial, foi escolhida a bacia hidrográfica do Rio dos Macacos localizada no Bairro Jardim Botânico no Rio de Janeiro a qual apresenta problemas recorrentes de inundação. Em função das características da bacia e em critérios mecânicos e hidráulicos do pavimento permeável de concreto, foram escolhidas as áreas para a sua aplicação e o pavimento foi dimensionado. A bacia estudada foi modelada com auxílio do software Storm Water Management Model para os cenários antes e após a aplicação dos pavimentos permeáveis de concreto em calçadas. Por fim, foi estimado o custo direto da solução proposta. Os resultados do estudo experimental do concreto permeável demonstraram que o material possui permeabilidade e resistências mecânicas adequadas para aplicação em calçadas. Os resultados do modelo computacional, obtidos através da comparação de hidrogramas de cheia, evidenciaram satisfatório amortecimento. A análise de custo demonstrou que a solução é economicamente viável.

\section{Palavras-chave}

Drenagem urbana; pavimento permeável de concreto; atenuação de cheias; bacia Rio dos Macacos; SWMM. 


\section{Extended Abstract}

Antunes, Patricia Tainá da Silva Correa; Oliveira, Antônio Roberto Martins Barboza (Advisor); The use of permeable concrete pavement for the attenuation of urban floods. Rio de Janeiro, 2017. 132p. Dissertação de Mestrado - Departamento de Engenharia Civil e Ambiental, Pontifícia Universidade Católica do Rio de Janeiro.

New techniques of urban drainage have emerged in order to mitigate the negative effects of urbanization. Initially, in the United States in 1970 denominated Best Management Practices (BMPs) and then in United Kingdom in 1980 as Sustainable Urban Drainage Systems (SUDS). The goal of these techniques is to reproduce the natural hydrological cycle, mitigating flood peaks and reducing diffuse pollution through infiltration, retention and transport devices such as green roofs, percolation trenches and pervious pavements. (Canholi, 2014).

Unlike traditional pavements, pervious pavements allow the infiltration of rainwater on the surface. The infiltrated water is stored temporarily before use, infiltration into the soil, or downstream controlled discharge.

According to Field et al (1982) and Mullaney \& Lucke (2013), all types of pervious pavement share the same objectives, which are: to allow the infiltration of water on its surface; reduce the increase in the rate and volume of runoff; and improve degradation of water quality resulting from urbanization and land use change. Depending on the soil permeability, they still have the advantage of allowing the recharge of the aquifers.

There are several types of permeable pavements, such as plastic reinforcement grid pavers with grass, concrete blocks, pervious concrete and porous asphalt. In this work will be approached the pervious concrete pavement.

The pervious concrete is made of coarse aggregate, cement and water with little or no fine aggregate. The function of the aggregate is to form the concrete structure. The cement paste joins the aggregates. There are many voids that have diameters above $1 \mathrm{~mm}$ in the pervious concrete. In this way, this type of concrete contains more empty spaces than the conventional one, allowing the infiltration of the water, however the resistance of this concrete is low due to the voids. (Lian et al, 2011, Yang, Jiang, 2002).

According to Sonebi et al (2016), the combination of good quality aggregate with adequate cement paste coverage results in the formation of interconnected and 
disconnected pores; such a balanced relationship allows the formation of voids, and consequently, water infiltration and reasonable strength. as shown in Figure A.

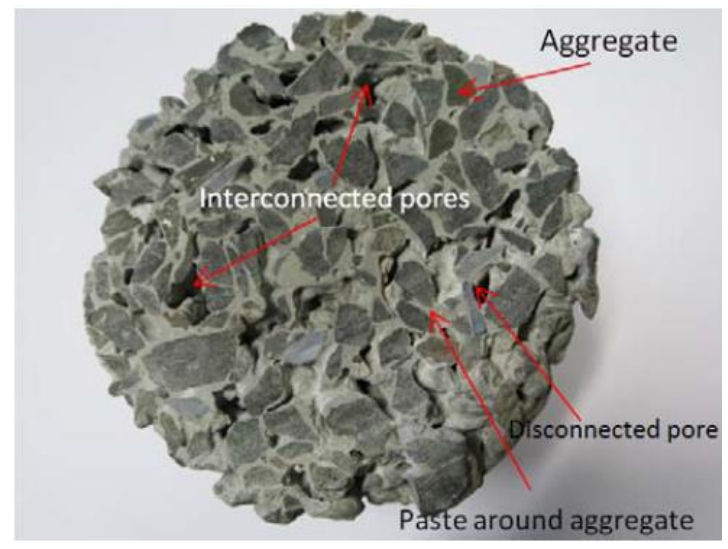

Figure A -Pervious concrete section Sonebi et al (2016)

Because of its low strength, pervious concrete pavements can only be used in low traffic areas such as parking lots, bike paths, sidewalks, trails and parks. (Ferguson, 2005).

The main objective of this work was to analyze the pervious concrete, aiming at its application as a surface of pervious pavements on the sidewalks for urban flood mitigation by an experimental study; hydraulic and hydrological model using Storm Water Management Model software, developed by the US Environmental Protection Agency (U.S. EPA); and a direct cost analyze of the proposed solution.

Additionally, this study aims to disseminate the technical knowledge about pervious concrete pavements in Brazil. According to Chandrappa \& Biligiri (2016), pervious pavement is being studied and applied in several parts of the world, but its application has not yet advanced in developing countries due to the lack of technical specifications.

With the intention of studying the pervious concrete pavement as a solution, tests were performed on pervious concrete samples at the Materials and Structure Laboratory (Laboratório de Estruturas e Materiais -LEM) and the Geotechnique and Environment Laboratory (Laboratório de Geotecnia e Meio Ambiente LGMA), both located at PUC-RIO. Additionally, to quantify the attenuation of urban runoff, the Macacos River watershed which experience flooding issues was analyzed.

The Macacos river watershed is composed of the sub basins of Cabeça river, Algodão river and Macacos river, which is the main tributary, and has a surface 
area of $9.4 \mathrm{~km}^{2}$. This watershed located in the city of Rio de Janeiro has a consolidated urban area, predominantly of residential use, it is surrounded by the Tijuca mountain range and has the Rodrigo de Freitas Lagoon as the basin outlet.

Aiming at identifying the mechanical and hydraulic characteristics of the pervious concrete in order to choose the most suitable mixture for the application on sidewalks, 7 different concrete mix designs were prepared, varying mainly the water-to-cement ratio, aggregate-to-cementitious ratio (by mass), the aggregate size and cementitious materials, as can be seen in Table A.

Table A- Pervious Concrete Materials Proportions

\begin{tabular}{|c|c|c|c|c|c|c|c|}
\hline \multirow{3}{*}{$\begin{array}{l}\text { Design } \\
\text { Mix }\end{array}$} & \multirow{2}{*}{$\begin{array}{c}\text { Cementitious } \\
\text { materials }\end{array}$} & \multirow{2}{*}{$\begin{array}{c}\text { Coarse } \\
\text { aggregate }\end{array}$} & \multirow{2}{*}{$\begin{array}{l}\text { Water- } \\
\text { to- } \\
\text { cement } \\
\text { ratio }\end{array}$} & \multirow{2}{*}{$\begin{array}{c}\text { Aggregate- } \\
\text { to- } \\
\text { cementitiou } \\
\text { s ratio }\end{array}$} & \multicolumn{3}{|c|}{ Gradation of aggregate } \\
\hline & & & & & $\begin{array}{c}9,5 \mathrm{a} \\
6,3 \\
\mathrm{~mm}\end{array}$ & $\begin{array}{c}6,3 \mathrm{a} \\
4,8 \mathrm{~mm}\end{array}$ & $\begin{array}{c}4,8 \mathrm{a} \\
2,4 \\
\mathrm{~mm}\end{array}$ \\
\hline & $\mathrm{kg} / \mathrm{m}^{3}$ & $\mathrm{~kg} / \mathrm{m}^{3}$ & & & $\%$ & $\%$ & $\%$ \\
\hline $\mathrm{T} 1$ & 180,00 & 1575,00 & 0,25 & $8,75: 1$ & 0 & 40 & 60 \\
\hline $\mathrm{T} 2$ & 225,00 & 1518,75 & 0,25 & $6,75: 1$ & 0 & 40 & 60 \\
\hline $\mathrm{T} 3$ & 270,00 & 1462,50 & 0,25 & $5,42: 1$ & 0 & 40 & 60 \\
\hline $\mathrm{T} 4$ & 315,00 & 1406,25 & 0,25 & $4,46: 1$ & 0 & 40 & 60 \\
\hline T5 & 315,00 & 1390,50 & 0,30 & $4,41: 1$ & 0 & 40 & 60 \\
\hline T6 & 315,00 & 1390,50 & 0,30 & $4,41: 1$ & 100 & 0 & 0 \\
\hline $\mathrm{T} 7$ & 315,00 & 1381,05 & 0,33 & $4,38: 1$ & 100 & 0 & 0 \\
\hline
\end{tabular}

The following materials were used for preparing samples of pervious concrete: Portland cement CP II-E-32 ${ }^{1}$, water and aggregate.

The open-cell structure of pervious concrete makes it more vulnerable to sulfate attack and less strength, for this reason the Portland cement CP II-E-32 was chosen, which among other properties, when compared to the Portland cement type I, improves the corrosion resistance by chlorides and sulfates and the final strength. The strength class of $32 \mathrm{MPa}$ was established to ensure the minimum required strength by standard ABNT NBR 16416: 2005 for application in sidewalks.

\footnotetext{
${ }^{1}$ Portland cement CP II-E-32 is compound cement produced from calcium silicate, aluminum, iron, calcium, sulfate, carbonate filler and low addition of blast furnace slag, ensuring that the product has higher initial resistance and is suitable for general construction, exposed to attack of moderate sulphate. Its compressive strength in 28 days period is $32 \mathrm{MPa}$. (CSN, 2016)
} 
Five types of tests were performed for determination of the hydraulic and mechanical characteristics of pervious concrete, as the following: unit weight, void ratio, permeability constant head, compressive strength and flexural tensile strength. Table B gives a summary of the tests results.

\begin{tabular}{c|c|c|c|c|c}
\multicolumn{7}{c}{ Table B - Summary of the tests results. } \\
\cline { 2 - 6 } Mixture & $\begin{array}{c}\text { Unit } \\
\text { weight }\end{array}$ & $\begin{array}{c}\text { Void } \\
\text { Ratio }\end{array}$ & $\begin{array}{c}\text { Permeability } \\
\text { coefficient }\end{array}$ & $\begin{array}{c}\text { Compressive } \\
\text { strength }(28 \\
\text { days })\end{array}$ & $\begin{array}{c}\text { Flexural } \\
\text { tensile } \\
\text { strength }(28 \\
\text { days) }\end{array}$ \\
\cline { 2 - 6 } & $\mathrm{kg} / \mathrm{m}^{3}$ & $\%$ & $\mathrm{~cm} / \mathrm{s}$ & $\mathrm{MPa}$ & $\mathrm{MPa}$ \\
\hline $\mathrm{T} 1 *$ & - & - & - & - & - \\
\hline $\mathrm{T} 2$ & $\mathbf{1 6 1 0 , 1 3}$ & $\mathbf{7 , 8}$ & $\mathbf{0 , 0 1}$ & $\mathbf{2 , 3 2}$ & $\mathbf{1 , 2 3}$ \\
\hline $\mathrm{T} 3$ & $\mathbf{1 6 6 3 , 7 0}$ & $\mathbf{9 , 3 \%}$ & $\mathbf{0 , 0 5}$ & $\mathbf{3 , 0 9}$ & $\mathbf{1 , 4 8}$ \\
\hline $\mathrm{T} 4$ & $\mathbf{1 7 1 8 , 4 5}$ & $\mathbf{9 , 8 \%}$ & $\mathbf{0 , 0 5}$ & $\mathbf{4 , 0 9}$ & $\mathbf{1 , 5 1}$ \\
\hline $\mathrm{T} 5$ & $\mathbf{1 8 0 7 , 1 5}$ & $\mathbf{1 3 , 0 \%}$ & $\mathbf{0 , 0 7}$ & $\mathbf{6 , 0 2}$ & $\mathbf{2 , 2 5}$ \\
\hline $\mathrm{T} 6$ & $\mathbf{1 8 2 2 , 8 4}$ & $\mathbf{2 1 , 8 \%}$ & $\mathbf{0 , 2 4}$ & $\mathbf{5 , 9 6}$ & $\mathbf{2 , 1 1}$ \\
\hline $\mathrm{T} 7$ & $\mathbf{1 7 1 2 , 5 0}$ & $\mathbf{2 7 , 5 \%}$ & $\mathbf{0 , 3 2}$ & $\mathbf{5 , 2 8}$ & $\mathbf{1 , 6 8}$ \\
\hline
\end{tabular}

Based on the results of the experimental study and the intended application on sidewalks, the mixture $\mathrm{T} 7$ was chosen because it presents better permeability coefficient $-0.32 \mathrm{~cm} / \mathrm{s}$, and mechanical strength compliant with the proposed use.

The standard ABNT NBR 16416: 2015 requires that the permeability coefficient be greater than $0,10 \mathrm{~cm} / \mathrm{s}$ and the flexural tensile strength greater than 1 MPa for application on sidewalks. The mixture T7 meets these requirements, which flexural strength is $1.68 \mathrm{MPa}$ at 28-days and the permeability coefficient is 0.32 $\mathrm{cm} / \mathrm{s}$, as shown in Table B.

According to the characteristics of the basin and the technical requirements, the areas for application on sidewalks were selected, approximately $69,000 \mathrm{~m}^{2}$, and the pervious concrete pavement was designed.

The Macacos river basin was represented in the Storm Water Management Model by examining and defining its physical characteristics, hydrologic processes, land use and existing drainage system. Vegetation areas were segregated from urban areas, due to different rainfall and infiltration regimes, as shown in Figure B. 


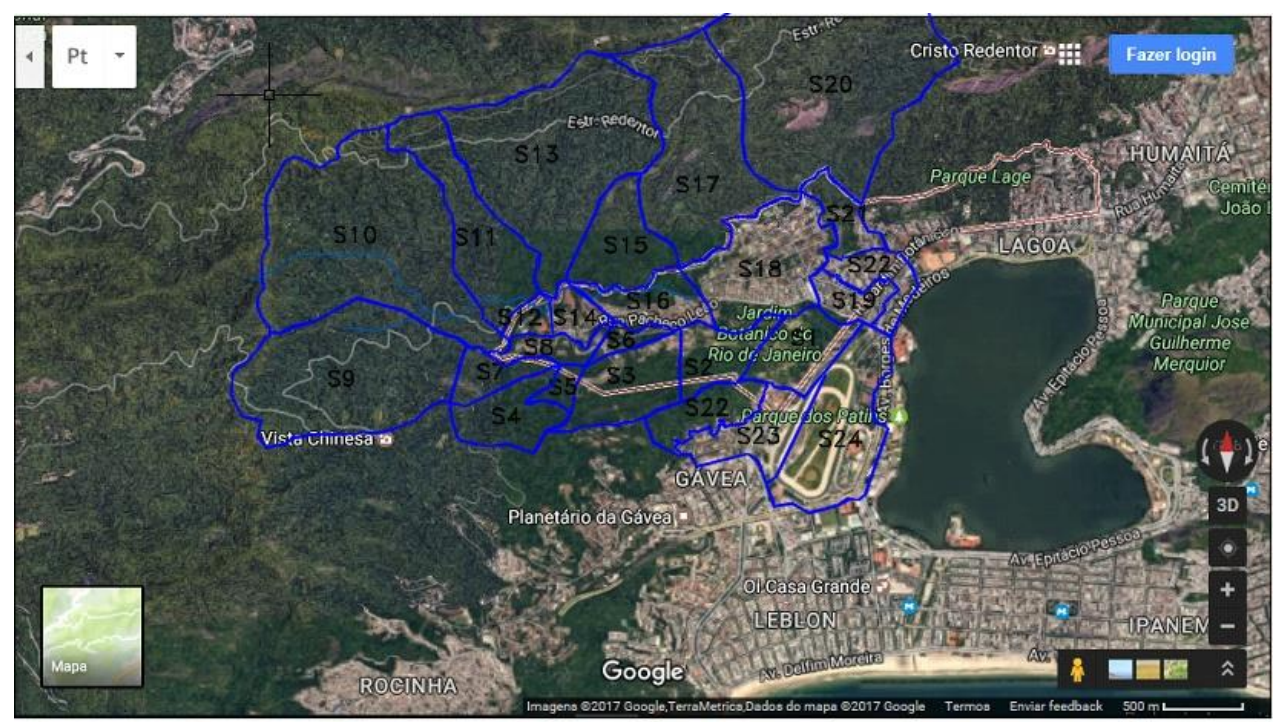

Figure B - Macacos river watershed discretization Adapted from Google Earth (2017)

For the present study, a 25-year return period and 70- minute time of concentration were used, which was defined by the George Ribeiro formula recommended by the Fundação Instituto Rio Águas for the storm water drainage system design in the city of Rio de Janeiro.

The Soil Conservation Service (SCS) Curve Number (CN) method was used for computing the runoff volume, according to guidelines from Instruções Técnicas para Elaboração de Estudos Hidrológicos e Dimensionamento Hidráulico de Sistemas de Drenagem Urbana published by Fundação Instituto Rio Águas in 2010.

The watershed studied was modeled for the scenarios before and after the application of pervious concrete pavements. By analyzing the hydrographs for both scenarios, illustrated in Graph A, it can be inferred that:

- The first peak discharge was attenuated by $37 \%$, going from 25,478 $1 / \mathrm{s}$ to $15,9471 / \mathrm{s}$.

- The volume of runoff was reduced by approximately $4 \%$, going from 169,300 to $161,857 \mathrm{~m}^{3}$.

- The discharge was attenuated up to 46 minutes after the rainy event start. After 46 minutes, the hydrographs showed a similar behavior, but the discharge of the hydrograph of the scenario after the application of pervious concrete pavements were little higher. 


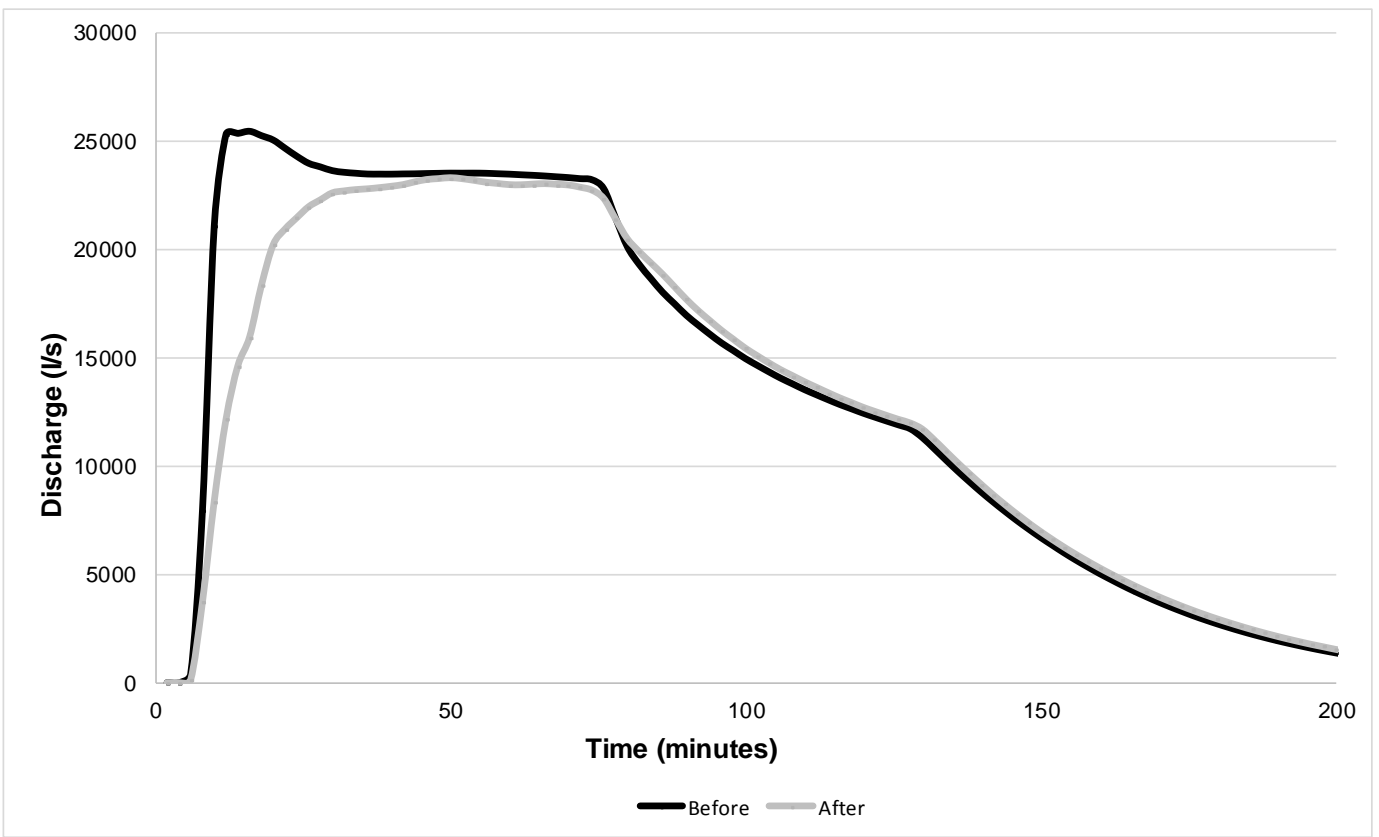

Graph A: Hydrograph of Macacos River Basin

The preliminary estimate resulted in a direct cost of $\mathrm{R} \$ 62.29$ per square meter, totaling a cost of $\mathrm{R} \$ 4,293,355.00$ for the execution of the proposed pavements.

\section{Keywords}

Urban drainage; permeable concrete pavement; attenuation of urban floods; Rio dos Macacos Basin; SWMM. 


\section{Sumário}

1 Introdução 20

$\begin{array}{lll}1.1 & \text { Considerações iniciais } & 20\end{array}$

1.2 Objetivos 23

$\begin{array}{ll}1.3 \text { Metodologia } & 25\end{array}$

1.4 Estrutura do Trabalho $\quad 26$

2 Pavimento Permeável de Concreto 28

$\begin{array}{lll}2.1 & \text { Classificação } & 30\end{array}$

$\begin{array}{lll}2.1 .1 & \text { Revestimento } & 30\end{array}$

$\begin{array}{ll}2.1 .2 & \text { Infiltração no solo } \\ \end{array}$

2.2 Estrutura dos pavimentos permeáveis de concreto 34

2.2.1 Revestimento de concreto permeável 34

2.2.2 Camada de Assentamento 44

2.2.3 Camada de Base (Reservatório) 45

$\begin{array}{lll}2.2 .4 & \text { Subleito } & 45\end{array}$

2.2.5 Camadas de filtro 46

$\begin{array}{lll}\text { 2.2.6 Camada impermeável e drenos } & 47\end{array}$

2.3 Dimensionamento do pavimento permeável 47

$\begin{array}{lll}\text { 2.3.1 Dimensionamento hidráulico } & 48\end{array}$

2.3.2 Dimensionamento mecânico 52

3 Estudo Experimental do Concreto Permeável 56

3.1 Materiais 56

3.1.1 Cimento 56

3.1.2 Agregados $\quad 58$

3.2 Proporções $\quad 59$

3.3 Preparo das Amostras $\quad 60$

$\begin{array}{lll}\text { 3.3.1 Traços T1 a T5 } & 61\end{array}$

3.3.2 Traços T6 e T7 62

3.4 Ensaios 63

3.4.1 Massa Específica e Índice de Vazios 63

3.4.2 Permeabilidade à Carga Constante 65 
3.4.3 Resistência à Compressão 68

$\begin{array}{lll}3.4 .4 & \text { Resistência à Tração na Flexão } & 70\end{array}$

4 Resultados do Estudo Experimental $\quad 72$

4.1 Massa Específica e Índice de vazios 73

$\begin{array}{lll}4.2 & \text { Permeabilidade } & 74\end{array}$

$\begin{array}{lll}4.3 & \text { Resistência à Compressão } & 74\end{array}$

$\begin{array}{lll}4.4 & \text { Resistência à Tração na Flexão } & 76\end{array}$

$\begin{array}{lll}4.5 & \text { Relação entre parâmetros } & 78\end{array}$

4.5.1 Massa Específica e Índice de Vazios 78

4.5.2 Resistências à Compressão e Resistência à Tração na Flexão 81

4.5.3 Permeabilidade 82

5 Estudo de Caso $\quad 85$

5.1 Área de estudo $\quad 85$

5.2 Modelagem Hidráulica e Hidrológica 90

5.2.1 Discretização da bacia 92

$\begin{array}{ll}5.2 .2 \text { Condutos } & 97\end{array}$

5.2.3 Dados Pluviométricos 98

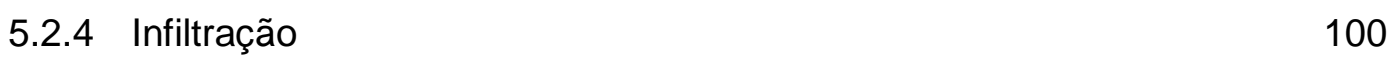

$\begin{array}{ll}\text { 5.2.5 Pavimento permeável } & 102\end{array}$

6 Resultados do Estudo de Caso 110

6.1 Atenuação do Escoamento Superficial 110

6.2 Análise de custo 122

7 Conclusões 125

8 Referências Bibliográficas $\quad 127$ 


\section{Lista de Tabelas}

Tabela 1 - Classificação quanto à forma de infiltração no solo 33

Tabela 2 - Diversos traços estudados do concreto permeável 37

Tabela 3 - Materiais para a base e as suas porosidades 45

Tabela 4 - Valores de coeficiente de permeabilidade do solo 46

Tabela 5 - Valores típicos de CBR 53

Tabela 6 - Tipologia do revestimento, resistência e espessura mínima 54

Tabela 7 - Espessura da base para atender esforços em solos de CBR $\geq 5 \% \quad 55$

Tabela 8 - Teores de componentes do CP II-E 57

Tabela 9 - Exigências físicas e mecânicas para resistência $32 \mathrm{MPa} \quad 58$

Tabela 10 - Características dos traços estudados 59

Tabela 11 - Resultados do ensaio de massa específica 73

Tabela 12 - Resultados do ensaio de índice de vazios 73

Tabela 13 - Resultados do ensaio de permeabilidade à carga constante $\quad 74$

Tabela 14 - Resultados do ensaio de resistência à compressão 75

Tabela 15 - Resultados da resistência à compressão aos 28 dias 76

Tabela 16 - Resultados do ensaio de resistência à tração na flexão 77

Tabela 17 - Resultados da resistência à tração na flexão aos 28 dias 77

Tabela 18 - Resumo dos resultados dos ensaios. 78

Tabela 19 - Cálculo da largura das sub-bacias 94

Tabela 20 - Coeficiente $\mathrm{n}$ de Manning 95

Tabela 21 - Profundidade de armazenamento em depressões 95

Tabela 22 - Dados de entrada de condutos 98

$\begin{array}{ll}\text { Tabela } 23 \text { - Valores do parâmetro CN } & 101\end{array}$

Tabela 24 - Dimensionamento do reservatório 103

Tabela 25 - S1: Área de calçadas permeáveis 105

Tabela 26 - S14: Área de calçadas permeáveis 105

Tabela 27 - S16: Área de calçadas permeáveis 106

Tabela 28 - S18: Área de calçadas permeáveis 107

Tabela 29 - S19: Área de calçadas permeáveis $\quad 108$

Tabela 30 - S21: Área de calçadas permeáveis 109

Tabela 31 - S23: Área de calçadas permeáveis $\quad 109$ 
Tabela 32 - Custo do metro quadrado do pavimento de concreto permeável 123

Tabela 33 - Custo direto total da solução proposta 


\section{Lista de Gráficos}

Gráfico 1 - Fator A/C versus resistência à compressão 43

Gráfico 2 - Relação entre porosidade e resistência à compressão. 43

Gráfico 3 - Teor de agregado versus massa específica 79

Gráfico 4 - Massa específica versus índice de vazios dos traços T2 a T7 79

Gráfico 5 - Resistência à compressão versus consumo de cimento -T2 a T4 81

Gráfico 6 - Relação entre a permeabilidade o índice de vazios 82

Gráfico 7 - Relação entre as resistências mecânicas e permeabilidade 83

Gráfico 8 - Hietograma do pluviômetro Jardim Botânico $\operatorname{Tr}=25$ anos 99

Gráfico 9 - Hietograma do pluviômetro Capela Mayrink $\mathrm{Tr}=25$ anos 99

Gráfico 10 - Hidrograma da Sub-bacia S1 114

Gráfico 11 - Hidrograma da Sub-bacia S14 115

Gráfico 12 - Hidrograma da Sub-bacia S16 116

Gráfico 13 - Hidrograma da Sub-bacia S18 117

Gráfico 14 - Hidrograma da Sub-bacia S19 118

Gráfico 15 - Hidrograma da Sub-bacia S21 119

Gráfico 16 - Hidrograma da Sub-bacia S23 120

Gráfico 17 - Hidrograma do exutório da Bacia do Rio dos Macacos 121 


\section{Lista de Figuras}

Figura 1 - Diagrama esquemático 22

Figura 2 - Metodologia 25

Figura 3 - Tipos de revestimento 30

Figura 4 - Sistema de infiltração total ou tipo A 31

Figura 5 - Sistema de infiltração parcial ou tipo B 32

Figura 6 - Sistema sem infiltração 32

Figura 7 - Reaproveitamento de água pluvial 33

Figura 8 - Estrutura típica de um pavimento permeável 34

Figura 9 - Estacionamento revestido com pavimento permeável 35

Figura 10 - Acesso em concreto permeável 35

Figura 11 - Seção transversal de uma amostra de concreto permeável 36

Figura 12 - Pouca água (a), quantidade ideal (b) e excessiva (c) 38

Figura 13 - Possíveis locais para aplicação dos filtros $\quad 46$

Figura 14 - Membrana Impermeável $\quad 47$

Figura 15 - Pavimentos permeáveis em terrenos inclinados 49

Figura 16 - Armazenamento da chuva nos pavimentos permeáveis 49

Figura 17 - Pequenas barragens em terrenos inclinados 50

Figura 18 - Exemplo de obtenção do parâmetro R 51

Figura 19 - Peneirador elétrico $\quad 59$

Figura 20 - Misturador elétrico do tipo batedeira planetária 60

Figura 21 - Concreto permeável no estado fresco (traço T4) 60

Figura 22 - Amostras do ensaio de resistência à compressão para T1 a T5 61

Figura 23 - Amostras do ensaio de flexão para T1 a T5 62

Figura 24 - Amostras do ensaio de permeabilidade para T1 a T5 62

Figura 25 - Amostras do ensaio de resistência à compressão para T6 e T7 63

Figura 26 - Amostras do ensaio de resistência à compressão para T6 e T7 63

Figura 27 - Aferição da massa da amostra na condição saturada e seca 64

Figura 28 - Permeâmetro de carga constante 65

Figura 29 - Planificadora para nivelamento das amostras 66

Figura 30 - Pedra porosa e papel filtro na base e no topo 66

Figura 31 - Vedação das laterais com manta impermeável 67 
$\begin{array}{ll}\text { Figura } 32 \text { - Permeâmetro com câmara tampada } & 67\end{array}$

Figura 33 - Ensaio de resistência à compressão 69

Figura 34 - Ensaio de resistência à tração na flexão em 3 pontos 70

Figura 35 - Comparação entre as amostras T1 e T5 72

Figura 36 - Rompimento da amostra no ensaio de resistência à compressão 75

Figura 37 - Rompimento da amostra no ensaio de resistência à tração 77

Figura 38 - Comparação entre as amostras T2, T3, T4 e T5, respectivamente 80 Figura 39 - Comparação entre as seções transversais das amostras T2 e T7 81

Figura 40 - Bacia do Rio dos Macacos e seus principais afluentes 85

Figura 41 - Enchente na Rua Jardim Botânico em 1988

Figura 42 - Enchente na Rua Jardim Botânico em $2010 \quad 86$

Figura 43 - Enchente na Rua Jardim Botânico em $2017 \quad 86$

Figura 44 - Ruas que alagam na Bacia do Rio dos Macacos 87

Figura 45 - Mapa semidetalhado de solos da Bacia do Rio dos Macacos 89

Figura 46 - Divisão de sub-bacias 93

Figura 47 - Discretização da Bacia do Rio dos Macacos 96

Figura 48 - Perfil do Rio dos Macacos $\quad 97$

Figura 49 - Estrutura do pavimento permeável. Dimensões em cm. 104 


\section{Lista de abreviaturas e siglas}

ABNT - Associação Brasileira de Normas Técnicas

DNIT - Departamento nacional de Infraestrutura de Transportes

EMBRAPA - Empresa Brasileira de Pesquisa Agropecuária

EPA - Environment Protect Agent

IBGE - Instituto Brasileiro de Geografia e Estatística

LEM - Laboratório de Estruturas e Materiais da PUC RIO

LGMA - Laboratório de Geotecnia e Meio Ambiente

NBR - Normas Brasileiras

SWMM - Storm Water Management Model 


\section{1 \\ Introdução}

\section{1}

\section{Considerações iniciais}

A revolução industrial iniciou o processo de urbanização. Na maioria das cidades do Brasil, esse processo ocorreu de maneira acelerada e sem planejamento urbano e ambiental adequado. Segundo IBGE (2011), aproximadamente 84\% da população brasileira vive em áreas urbanas, convivendo com os problemas gerados pela infraestrutura precária.

Entre 1940 e 1980, dá-se a verdadeira inversão quanto ao lugar de residência da população brasileira. Há meio século atrás (1940), a taxa de urbanização era de 26,35\%, em 1980 alcança 68,86\%. Nesses quarenta anos, triplica a população total do Brasil, ao passo que a população urbana se multiplica por sete vezes e meia. (Santos, 2005, p.31)

Segundo Goudie (1990), podem ser observados diversos impactos durante o processo de urbanização: nos primeiros estágios, o desmatamento reduz a evaporação e a interceptação vegetal e aumenta a sedimentação dos corpos d'água; posteriormente, quando começam a construção de casas, ruas e galerias, os impactos incluem a redução da infiltração, rebaixamento do lençol freático, aumento do escoamento superficial e redução do escoamento de base durante os períodos de seca; após a conclusão do desenvolvimento de prédios, o aumento da impermeabilização irá reduzir o tempo de concentração da bacia, desta forma os picos de vazão serão maiores e os tempos de pico serão menores após o início da precipitação.

A impermeabilização das superfícies impede o abastecimento de água no solo, dificultando o crescimento das plantas e a troca de calor e umidade com o ar; além disso, os materiais utilizados nas superfícies urbanas têm alta capacidade de absorção de calor, elevando a temperatura. Isso faz com que a temperatura e umidade das grandes cidades não seja ajustada, provocando o fenômeno climático conhecido como ilhas de calor o qual aumenta a probabilidade de ocorrência de chuvas intensas. (Yang, Jiang, 2002) 
Todo resíduo gerado pela limpeza urbana ineficiente, falta de conscientização da população e circulação de carros são carreados pela chuva e fluem para os corpos hídricos. A maior velocidade de escoamento devido à impermeabilização das superfícies aumenta a capacidade de arraste de cargas poluidoras, gerando a poluição da água pluvial. No Brasil, a poluição hídrica é agravada pelas ligações clandestinas das redes de esgoto nas de drenagem, gerando transbordamento de esgoto sanitário em dias de chuva.

A inundação gera riscos à vida humana e prejuízos econômicos. A pesquisa publicada pelo IBGE (2013) sobre desastres naturais nos municípios brasileiros entre 2008 e 2012 apresentou que em 27,7\% dos municípios ocorreram enchentes, $28,3 \%$ sofreram enxurradas e $16,1 \%$, deslizamentos. A pesquisa também demonstrou que aproximadamente $97 \%$ das cidades brasileiras mais urbanizadas sofreram desastres naturais ocasionados pelas chuvas intensas, o que demonstra a forte relação entre a urbanização e desastres naturais.

No âmbito da engenharia hidráulica, por muito tempo as medidas estruturais sanitário-higienistas foram consideradas como as melhores técnicas as quais tinham como fundamento o escoamento rápido das águas pluviais para fora da cidade por uma rede de condutos, evitando assim a proliferação de doenças e transtornos à população.

Nos dias atuais, grande parte dos sistemas de drenagem urbana existentes está inadequado, uma vez que foram concebidos considerando as condições de projeto no momento de sua elaboração as quais já não refletem as atuais, hajam vistas as alterações dos usos do solo e clima urbanos ocasionados pelo processo de urbanização. A falta de manutenção do sistema agrava esse cenário, uma vez que a obstrução de partes constituintes da rede, tais como bueiros e bocas de lobo, impedem o escoamento da água superficial, contribuindo para os alagamentos. Essas medidas estruturais como obras para substituição do sistema de drenagem existente por condutos de maior seção podem causar grandes transtornos à cidade, além de terem um alto custo e não serem ambientalmente adequadas, já que não respeitam a dinâmica natural do ciclo hidrológico.

Com intuito de mitigar os efeitos negativos ocasionados pela urbanização, surgiram novas técnicas de drenagem urbana. Inicialmente, nos Estados Unidos em 1970 denominadas como Best Management Practices (BMPs) e, posteriormente, no Reino Unido em 1980 como Sustainable Urban Drainage Systems (SUDS). O 
objetivo dessas técnicas é reproduzir o ciclo hidrológico natural, mitigando picos de cheia e reduzindo a poluição difusa através de dispositivos de infiltração, retenção e transporte, tais como telhados verdes, trincheiras de percolação e pavimentos permeáveis. (Canholi, 2014).

Conforme Field et al (1982) e Mullaney \& Lucke (2013), todos os tipos de pavimento permeável compartilham os mesmos objetivos, que são: permitir a infiltração da água na sua superfície; reduzir o aumento da taxa e do volume de escoamento superficial; e melhorar a degradação da qualidade da água resultante da urbanização e alteração do uso do solo. Dependendo da permeabilidade do solo, ainda apresentam a vantagem de permitir a recarga dos aquíferos.

A Figura 1 apresenta um diagrama esquemático que demonstra brevemente o problema hidrológico das cidades provocado pela urbanização.

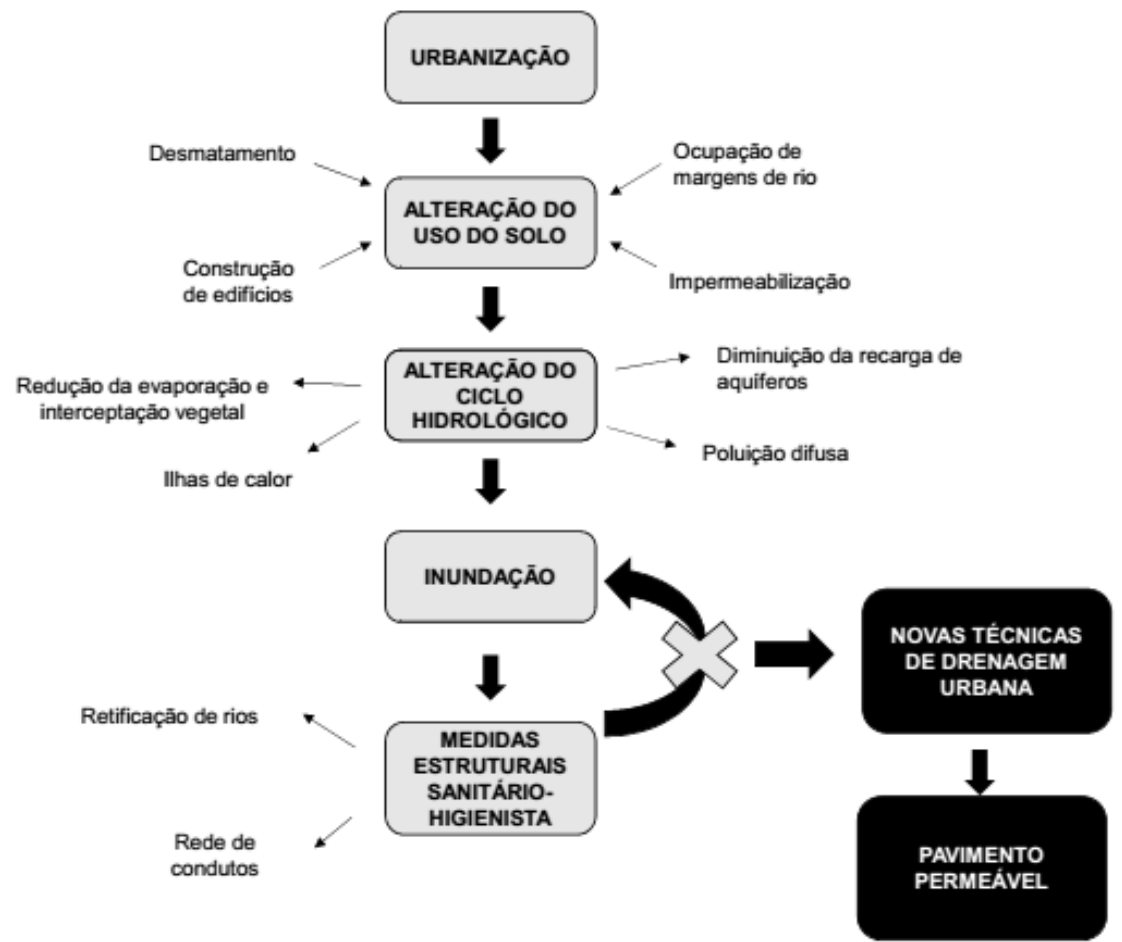

Figura 1 - Diagrama esquemático

Os pavimentos permeáveis também podem ser denominados de pavimentos porosos. Existem diversos tipos de revestimento, tais como grama reforçada, blocos de concreto, concreto permeável (ou poroso) e asfalto poroso. Nesse trabalho será abordado o pavimento permeável de concreto. 
Os pavimentos de revestimento poroso, tais como os de concreto poroso e asfalto poroso, apresentam limitada ou ausência de finos os quais criam vazios que são capazes de armazenar água pluvial dentro deles, e ainda os poros são capazes de reduzir o efeito das ilhas de calor. (Chandrappa, Biligiri, 2016)

No entanto, a aplicação desses pavimentos apresenta as seguintes desvantagens: baixa resistência - permitindo sua aplicação apenas em locais de baixo tráfego, tais como calçadas e estacionamentos; possibilidade de colmatação ao longo de tempo em caso de dimensionamento e manutenção inadequados. (Field et al, 1982; UDFCD, 2010).

\section{2}

\section{Objetivos}

O objetivo principal deste trabalho foi analisar o material concreto permeável, objetivando a sua aplicação como revestimento de pavimentos permeáveis em calçadas para a atenuação de cheias urbanas, através de ensaios de resistências mecânicas e permeabilidade; da elaboração de modelo hidráulico e hidrológico, utilizando-se como ferramenta de análise o software Storm Water Management Model, desenvolvido pela US EPA - Agência de Proteção Ambiental dos Estados Unidos da América (U.S. Environmental Protection Agency); e de uma estimativa de custos diretos da solução proposta.

O presente estudo pretende ainda contribuir para disseminar o conhecimento técnico sobre os pavimentos permeáveis de concreto no Brasil. Segundo Chandrappa \& Biligiri (2016), o pavimento permeável está sendo estudado e aplicado em várias partes do mundo, porém sua aplicação ainda não avançou em países em desenvolvimento devido à falta de especificações técnicas nesses países.

No Brasil, apenas em 2015 foi publicada a norma ABNT NBR 16416:2015 - Pavimentos Permeáveis de Concreto - Requisitos e procedimentos, elaborada pelo Comitê Brasileiro de Cimento, Concreto e Agregados (ABNT/CB-18), a qual aborda os critérios mínimos do projeto, especificação, execução e manutenção de pavimentos permeáveis de concreto, construídos com blocos de concreto, placas de concreto ou moldado no local.

Para estudar o pavimento permeável de concreto como solução, foram realizados ensaios em amostras de concreto permeável no Laboratório de Estruturas e Materiais (LEM) e no Laboratório de Geotecnia e Meio Ambiente (LGMA), 
ambos localizados na PUC- RIO, e foi selecionada uma bacia hidrográfica que apresenta eventos recorrentes de inundação - a bacia hidrográfica do Rio dos Macacos, localizada na cidade do Rio de Janeiro, principal contribuinte da Lagoa Rodrigo de Freitas.

Para isso, foi necessário atingir os seguintes objetivos intermediários:

- Identificar o referencial teórico sobre os pavimentos permeáveis de concreto a partir de pesquisa bibliográfica;

- Realizar os ensaios de massa específica, índice de vazios, permeabilidade à carga constante, resistência à compressão e resistência à tração na flexão, em amostras de diferentes traços de concreto permeável, a fim de definir a capacidade de suporte mecânico e infiltração do revestimento do pavimento;

- Levantar dados da bacia hidrográfica estudada através de informações obtidas em órgãos públicos competentes, documentos publicados, tais como: planta geral da bacia contribuinte, mapa planialtimétrico, tipo de ocupação da área, uso do solo, cadastro das redes de drenagem existentes e dados hidrológicos;

- Dimensionar o pavimento permeável de concreto, considerando os dados locais, os parâmetros do concreto permeável obtidos dos ensaios e a sua utilização em calçadas;

- Representar a bacia hidrográfica Rio dos Macacos no modelo computacional Storm Water Management Model, através da análise e determinação de suas características físicas, dados pluviométricos, uso do solo e sistema de drenagem existente;

- Avaliar as respostas hidrológicas da bacia estudada através da comparação de hidrogramas de cheia dos cenários antes e após a aplicação dos pavimentos permeáveis de concreto em calçadas, utilizando-se como ferramenta de análise o software SWMM;

- Estimar os custos diretos da aplicação dos pavimentos permeáveis de concreto na bacia em estudo. 


\section{3 Metodologia}

Esta dissertação se propõe a estudar as respostas hidrológicas de uma bacia hidrográfica à solução técnica dos pavimentos permeáveis de concreto em calçadas, utilizando-se ensaios experimentais e um modelo hidráulico e hidrológico.

A primeira etapa desta dissertação foi a elaboração de revisão bibliográfica sobre os pavimentos permeáveis de concreto, objetivando sólido embasamento teórico.

Posteriormente, iniciou-se a coleta de dados de entrada para o modelo hidráulico e hidrológico o que abrangeu informações a respeito da bacia hidrográfica, como também dados do pavimento permeável de concreto proposto.

A partir de uma análise da área em estudo, foram escolhidos os locais apropriados para o emprego do pavimento, considerando-se as características do revestimento de concreto permeável, as condições locais, o uso pretendido em calçadas e os critérios de dimensionamento. Desta maneira, os pavimentos foram dimensionados.

Com base nos dados reunidos, foi elaborado o modelo hidráulico e hidrológico, utilizando-se o software SWMM, cujos resultados de saída quantificaram a redução do escoamento superficial, demonstrando a performance hidráulica e hidrológica dos pavimentos permeáveis de concreto. Assim, foi realizada uma análise de custo da solução técnica proposta.

A Figura 2 demonstra graficamente um resumo da metodologia descrita.

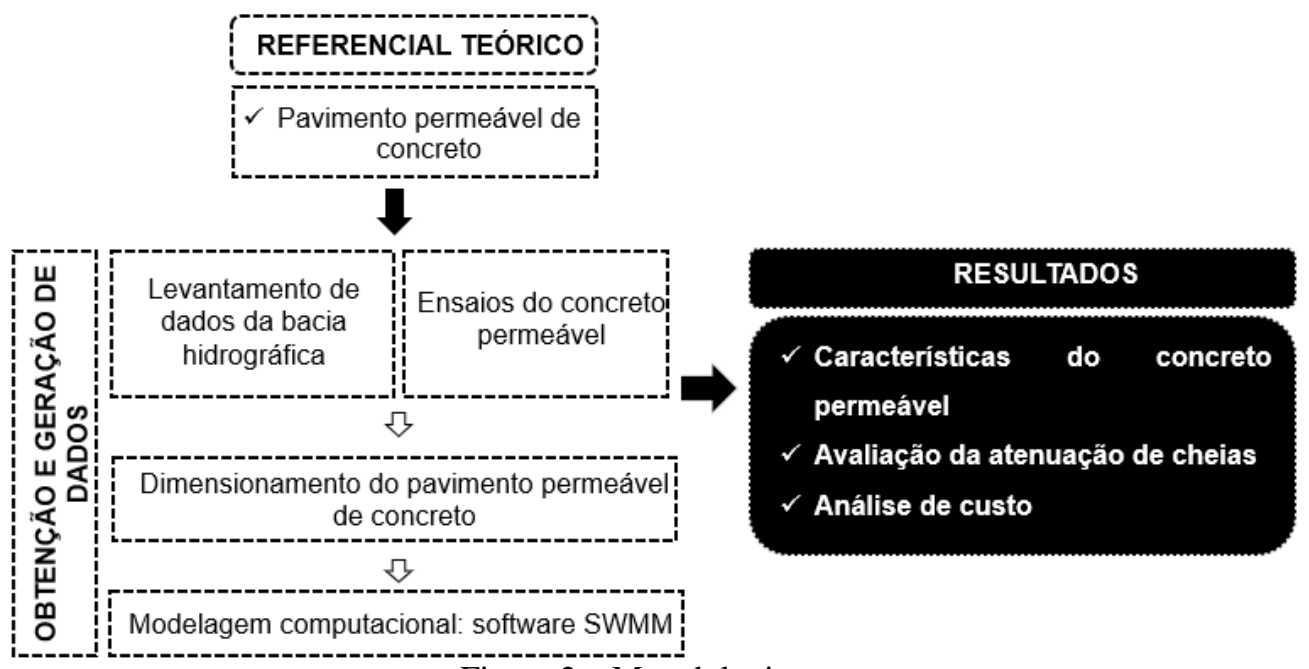

Figura 2 - Metodologia 


\section{4 \\ Estrutura do Trabalho}

O trabalho está organizado em 8 capítulos, conforme descrito a seguir:

O Capítulo 1 contém a introdução, em que é apresentado o tema da dissertação, as principais motivações para o desenvolvimento da pesquisa, assim como a metodologia adotada, os objetivos e a organização do trabalho

O Capítulo 2 apresenta uma revisão bibliográfica sobre os pavimentos permeáveis de concreto para embasamento teórico, abordando os principais aspectos, sendo estes: os tipos de classificação, as camadas que formam sua estrutura, as propriedades físicas e mecânicas do concreto permeável e seu dimensionamento hidráulico e mecânico.

No Capítulo 3 são abordados os materiais e métodos utilizados para o estudo experimental do concreto permeável. São descritas as características das 7 misturas estudadas, bem como os ensaios realizados para obtenção dos parâmetros hidráulicos e mecânicos do concreto permeável, sendo estes: massa específica, índice de vazios, permeabilidade à carga constante, resistência à compressão e resistência à tração na flexão.

O Capítulo 4 apresenta os resultados do estudo experimental do concreto permeável descrito no Capítulo 3, sendo estes: massa específica, índice de vazios, coeficiente de permeabilidade à carga constante, resistência à compressão e resistência à tração na flexão. Também são apresentados os resultados das relações entre os principais parâmetros obtidos.

O Capítulo 5 trata da área do estudo de caso, a Bacia do Rio dos Macacos que está localizada no Rio de Janeiro, abordando suas principais características e seu histórico. A partir da revisão bibliográfica sobre os pavimentos permeáveis de concreto apresentada no Capítulo 3, nos resultados do concreto permeável expostos no Capítulo 4 e nas características físicas e hidrológicas da bacia, são definidas as áreas de calçadas para aplicação e dimensionamento dos pavimentos permeáveis de concreto. Adicionalmente, são descritos todos os dados de entrada necessários para elaboração do modelo hidráulico e hidrológico, utilizando-se como ferramenta o Storm Water Management Model

O Capítulo 6 aborda os resultados do modelo hidráulico e hidrológico em que são comparados os hidrogramas de cheia na condição antes e após a aplicação 
dos pavimentos permeáveis. E ainda, é realizada uma estimativa preliminar de custos diretos da solução proposta.

No Capítulo 7 são apresentadas a conclusão da dissertação e as sugestões para trabalhos futuros.

O Capítulo 8 apresenta as referências bibliográficas. 


\section{2 \\ Pavimento Permeável de Concreto}

Nos últimos anos, o uso do concreto permeável como material de revestimento para aplicação em pavimentos de baixo tráfego e de pedestres tem ganhado importância devido às suas vantagens ambientais.

Diferentemente dos pavimentos tradicionais, os pavimentos permeáveis permitem a infiltração da água pluvial na sua superfície. A água infiltrada é armazenada temporariamente antes da sua utilização, infiltração no solo, ou descarga controlada à jusante.

Segundo Ferguson (2005), a utilização, especificamente por razões ambientais, do pavimento permeável de concreto, iniciou em 1970 na Flórida, onde exigências restritas a respeito da retenção de águas pluviais foram estabelecidas. Ainda de acordo com Ferguson (2005), a capacidade de armazenamento hidráulico e as características de solos arenosos e permeáveis da Flórida tornaram o pavimento de concreto poroso economicamente atrativo, reduzindo a necessidade de reservatórios de manejo de águas pluviais.

O principal objetivo do pavimento permeável de concreto, assim como os dos demais tipos de revestimento de pavimentos permeáveis, é controlar o escoamento superficial e a degradação da qualidade da água. Os pavimentos permeáveis são um meio eficiente de gerenciar o escoamento superficial, sendo uma medida de gerenciamento de controle na fonte, possibilitando a interceptação, redução da frequência e volume do escoamento superficial; e o tratamento preliminar da água pluvial. O processo de tratamento da água pluvial, que ocorre nas diversas camadas da estrutura do pavimento permeável, inclui as etapas de filtração, adsorção, biodegradação e sedimentação. (UDFCD, 2010)

De acordo com diversos autores Field et al (1982) e UDFCD (2010), as principais vantagens desse tipo de pavimento são:

- Atenuação da lâmina e do volume do escoamento superficial;

- Aumento da recarga do lençol freático, nos casos de pavimentos permeáveis que permitem a infiltração no solo; 
- Beneficiam as árvores, fornecendo ar e água para as raízes próximas;

- Redução de custo, já que em áreas planas e/ou em áreas que apresentam solo rochoso ou solo raso, o custo de instalação de redes de drenagem é muito alto devido aos altos diâmetros, grandes volumes de terra e dificuldades de escavação. O uso dos pavimentos permeáveis nessas áreas reduz os diâmetros e a profundidade de escavação;

- Redução ou eliminação do incômodo para pedestres e motoristas de poças e armazenamento temporário em depressões na superfície em estacionamentos, calçadas e ruas;

- Maior segurança das estradas devido ao maior coeficiente de atrito da superfície do pavimento, redução do efeito da aquaplanagem e consequentemente, melhoria da visibilidade e da segurança;

- Redução do ruído do trânsito, pois os pavimentos permeáveis de revestimentos porosos, tais como concreto poroso e asfalto poroso, são capazes de absorver ruídos;

- Mitigação do fenômeno das ilhas de calor, pois os pavimentos de revestimento poroso apresentam vazios que podem acumular calor;

- Podem ser utilizados para conseguir certificações de construções sustentáveis.

As principais desvantagens dos pavimentos permeáveis são:

- A alta susceptibilidade à colmatação;

- Baixa resistência mecânica;

- A necessidade de mão-de-obra mais especializada do que para a construção do pavimento convencional.

Apesar das inúmeras vantagens e poucas desvantagens, o concreto permeável é um material pouco utilizado. Segundo os autores Bonicelli et al (2016) e Chandrappa \& Biligiri (2016), o uso escasso desse material pode ser explicado pelo número insuficiente de padrões e especificações para fabricação e construção deste material. 


\section{1 Classificação}

Os pavimentos permeáveis podem ser classificados quanto ao revestimento e quanto à infiltração no solo. (Ballard et al, 2015; Hunt \& Collins, 2008; Interpave, 2010; UDFCD, 2010)

\subsection{1}

\section{Revestimento}

Existem diversos tipos de revestimento de pavimentos permeáveis, tais como, concreto poroso, asfalto poroso, blocos de concreto vazados preenchidos com vegetação ou areia, grama reforçada (também denominado de segmentos de plástico preenchidos com grama) (Ballard et al., 2015; Hunt \& Collins, 2008), apresentado na Figura 3.

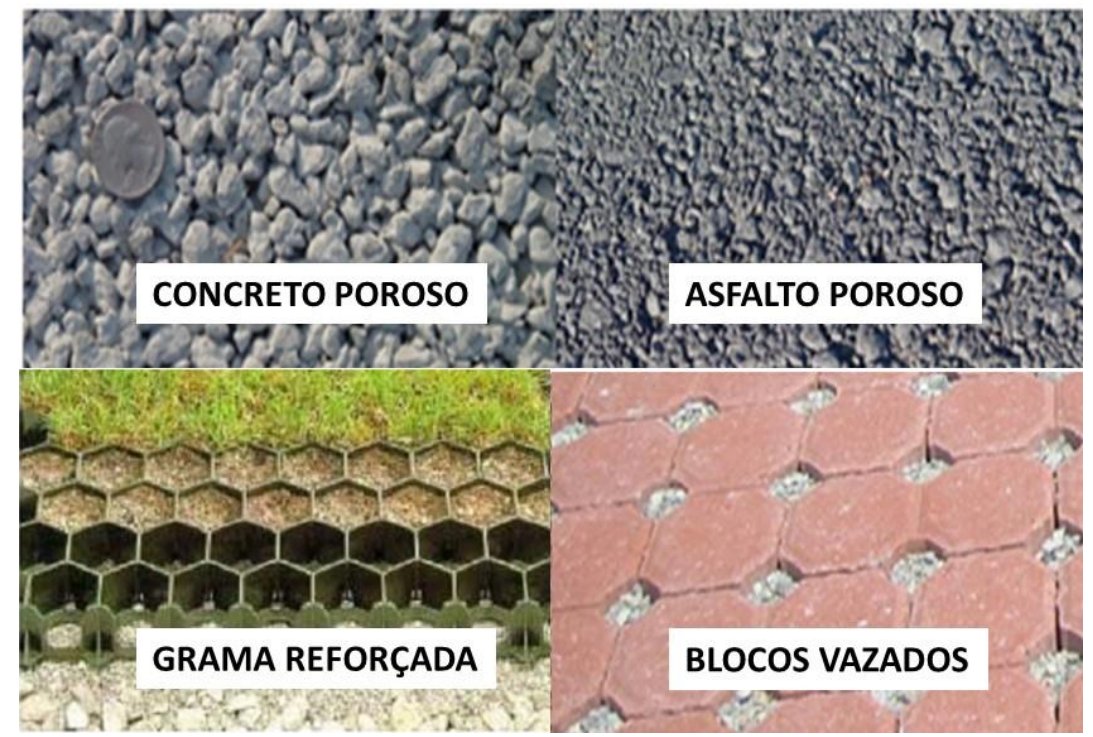

Fonte: Modificado de Collins \& Hunt (2008)

Figura 3 - Tipos de revestimento

\subsection{2}

\section{Infiltração no solo}

De acordo com Ballard et al (2015), Interpave (2010) e UDFCD (2010), os pavimentos permeáveis também podem ser classificados quanto à forma de infiltração no solo em: infiltração total, infiltração parcial e sem infiltração: 


\section{Infiltração total (ou tipo A)}

O sistema de infiltração total é o sistema em que toda água pluvial infiltra no solo subjacente, conforme apresentado na Figura 4. Esse sistema também pode ser denonimado de tipo A.

Nesse sistema a água pluvial infiltra através das camadas superficiais (camada revestimento e filtro), é armazenada temporariamente na base e posteriormente, ocorre a infiltração da água no solo.

Normalmente, não haverá vazão de descarga do sistema para um corpo hídrico ou rede de drenagem. Todavia, pode ser necessário um extravasamento de emergência para atender os eventos que excedem a chuva de projeto ou para permitir que o sistema torne-se menos eficiente durante a sua vida útil quando há diminuição das taxas de infiltração através da estrutura do pavimento.(Ballard et al, 2015; Interpave, 2010; UFCD, 2010)

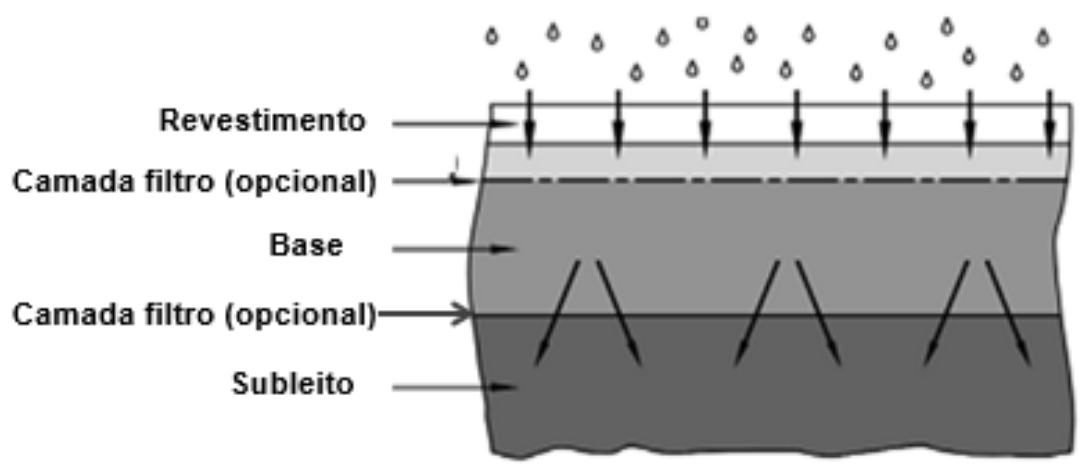

Fonte: Modificado de Ballard et al (2007) Figura 4 - Sistema de infiltração total ou tipo A

\section{Infiltração parcial (ou tipo B)}

Já no sistema de infitração parcial também chamado de tipo B, a água pluvial infiltra parcialmente, pois a intensidade pluvial excede a capacidade de infiltração do solo, conforme pode ser visto na Figura 5.

O excesso de chuva é drenado através de tubos perfurados localizados dentro ou abaixo da base. Uma manta geotêxtil ou geocomposto drenante também pode ser utilizada para recolher e distribuir a água por baixo da camada da base, impedindo o acúmulo de água acima do subleito e desta maneira, reduzindo os riscos de instabilidade do solo. (Ballard et al, 2015; Interpave, 2010) 


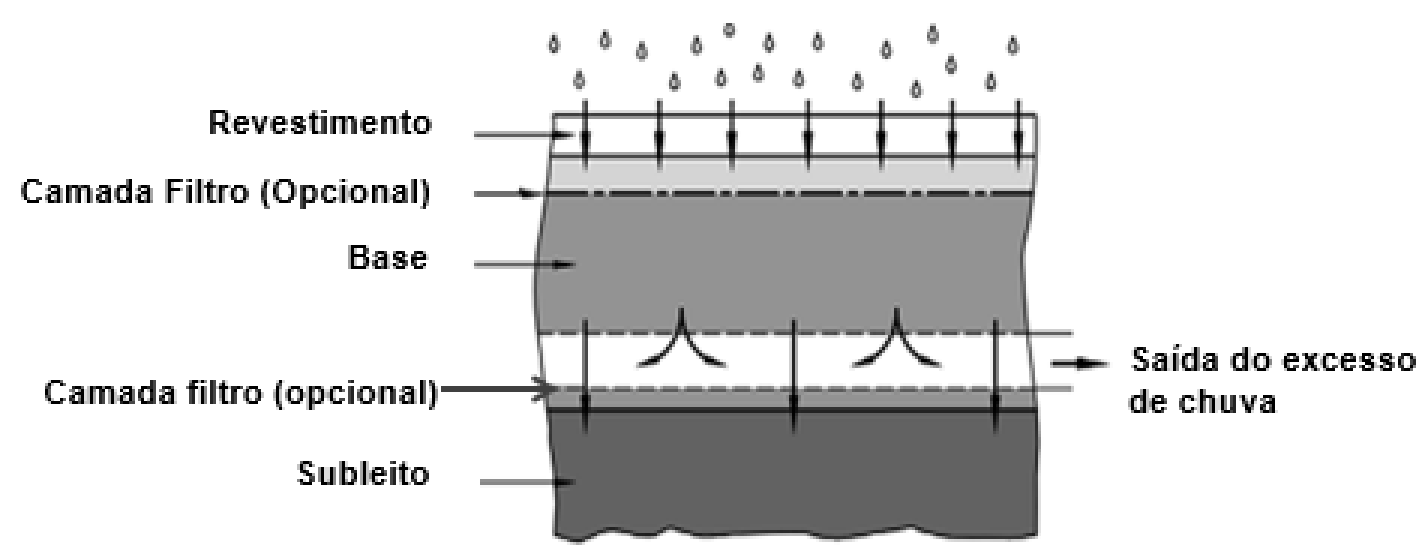

Fonte: Modificado de Ballard et al (2007)

Figura 5 - Sistema de infiltração parcial ou tipo B

\section{Sem Infiltração parcial (ou tipo C)}

A chuva não infiltra no solo no sistema sem infiltração, como pode ser visualizado na Figura 6.

A água infiltrada através da base é conduzida através de drenos, podendo ter três possíveis destinos - a rede de drenagem existente, o corpo hídrico receptor ou reaproveitamento. (Ballard et al, 2015; Interpave, 2010). Nesse sistema, a última camada do pavimento é coberta por uma geomembrana, impermeável e flexível, colocada acima da camada do solo.

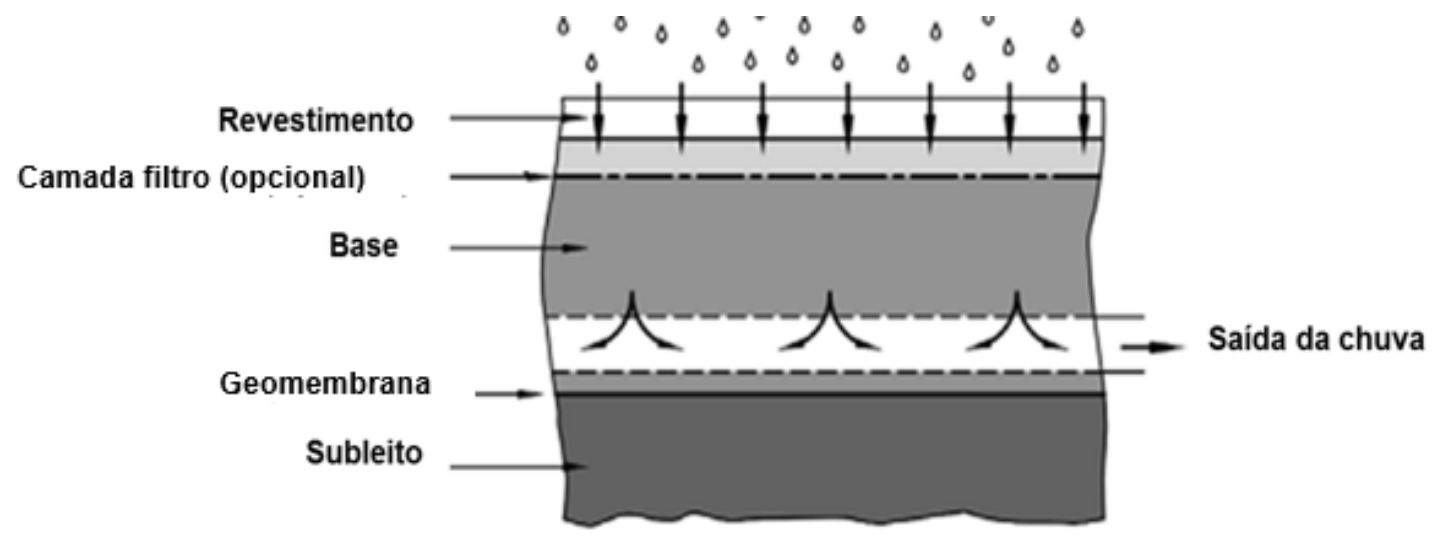

Fonte: Modificado de Ballard et al (2007)

Figura 6 - Sistema sem infiltração

A Figura 7 apresenta um exemplo de reuso de água a partir do reservatório de um pavimento permeável do tipo sem infiltração: a água da chuva é armazenada no pavimento permeável e bombeada para um reservatório de reaproveitamento de água pluvial, podendo ser utilizada para fins não potáveis. 


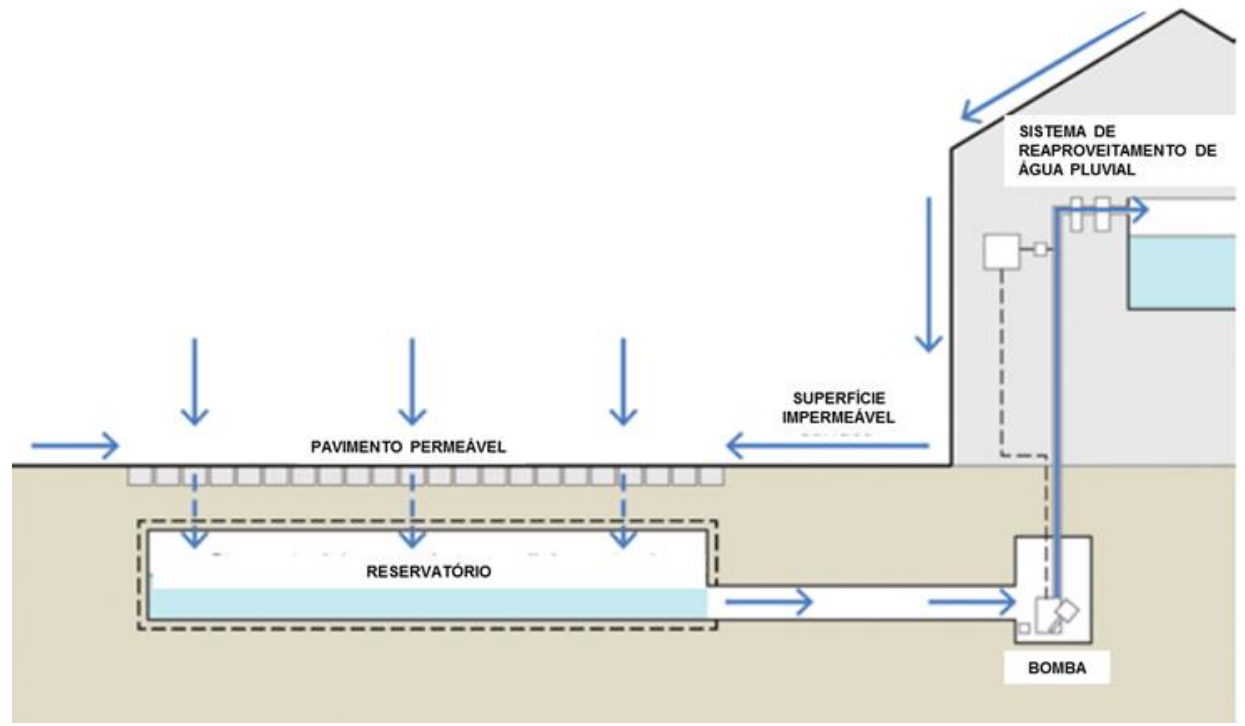

Fonte: Modificado de Interpave (2010)

Figura 7 - Reaproveitamento de água pluvial

O sistema sem infiltração é recomendado nos seguintes casos: em solos pouco permeáveis ou de baixa resistência; para aproveitamento da água da chuva para fins não potáveis; para proteção da água subterrânea; quando o nível do lençol freático for alto; em áreas contaminadas; e em locais onde os riscos de contaminação do solo e da água subterrânea devem ser mitigados. (Ballard et al, 2015; Interpave, 2010)

A Tabela 1 apresenta um resumo da classificação dos pavimentos quanto à forma de infiltração em função da permeabilidade do solo, nível do lençol freático e presença de contaminantes no solo.

\begin{tabular}{|c|c|c|c|c|}
\hline \multicolumn{2}{|c|}{ Condiçõos locais } & Infiltração & Infiltração & \\
\hline \multirow{3}{*}{$\begin{array}{c}\text { Permeabilidade } \\
\text { do subleito } \\
\text { definida pelo } \\
\text { coeficiente de } \\
\text { pemeabilidadek } \\
(\mathrm{cm} / \mathrm{s})\end{array}$} & $1 \times 10^{-6}$ a $1 \times 10^{-3}$ & $\checkmark$ & $\checkmark$ & $\checkmark$ \\
\hline & $1 \times 10^{-8}$ a $1 \times 10^{-6}$ & $x$ & $\checkmark$ & $\checkmark$ \\
\hline & $1 \times 10^{-10}$ a $1 \times 10^{-8}$ & $x$ & $x$ & $\checkmark$ \\
\hline \multicolumn{2}{|c|}{$\begin{array}{l}\text { Máximo registro do lençol freático a uma } \\
\text { distância máxima de } 1 \text { metro da camada } \\
\text { inferior da base }\end{array}$} & $x$ & $x$ & $\checkmark$ \\
\hline \multicolumn{2}{|c|}{ Presença de contaminantes no subleito } & $x$ & $x$ & $\checkmark$ \\
\hline \multicolumn{2}{|c|}{$\begin{array}{l}\text { Condições do solo em que a presença da } \\
\text { água não é recomendada }\end{array}$} & $x$ & $x$ & $\checkmark$ \\
\hline
\end{tabular}




\section{2 \\ Estrutura dos pavimentos permeáveis de concreto}

A estrutura típica dos pavimentos permeáveis de concreto é formada principalmente pelas seguintes camadas: revestimento, base (reservatório) e subleito. Podem ainda compor a estrutura dos pavimentos as camadas: camada filtro, geomembrana, camada de assentamento e drenos. A Figura 8 apresenta as camadas da estrutura do pavimento permeável de concreto.

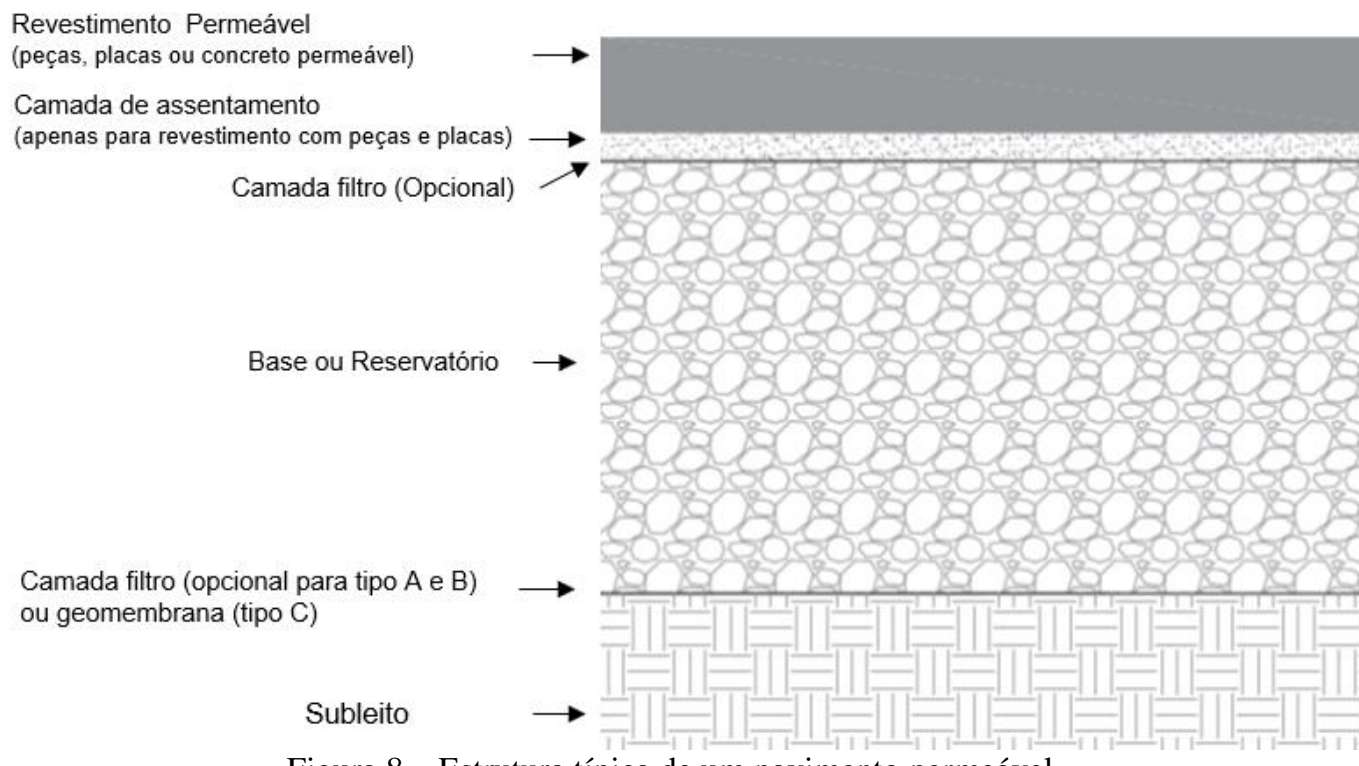

Figura 8 - Estrutura típica de um pavimento permeável

\subsection{1}

\section{Revestimento de concreto permeável}

O revestimento é a camada superior do pavimento a qual deve permitir a infiltração da água, além de resistir aos esforços mecânicos.

Segundo ABNT NBR 16416/2015 a tipologia do pavimento permeável de concreto pode ser em peças e placas pré-moldadas ou moldado no local, conforme Figura 9 e Figura 10. A presente dissertação aborda apenas a aplicação do tipo de revestimento concreto permeável moldado no local. 


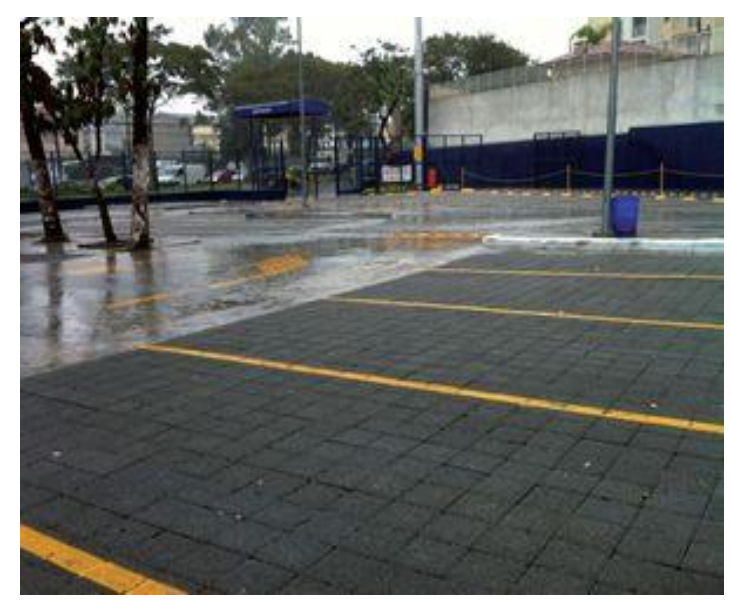

Fonte: Téchne Pini (2012)

Figura 9 - Estacionamento revestido com pavimento permeável

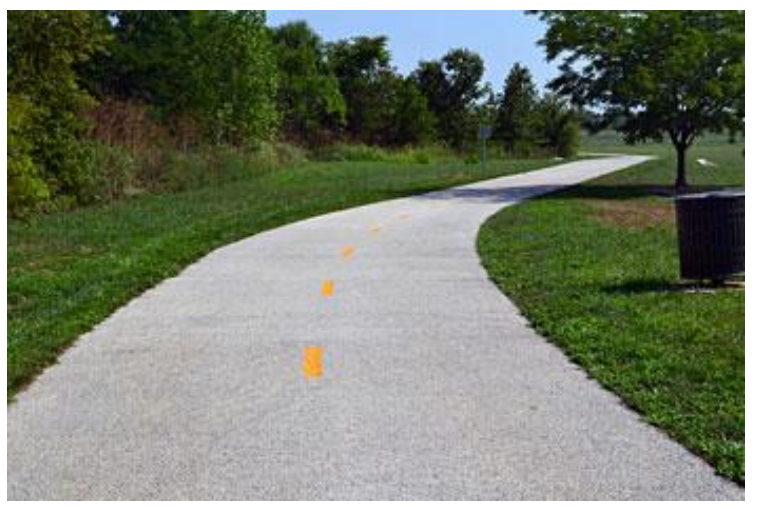

Fonte: Pervious Pavement (2017)

Figura 10 - Acesso em concreto permeável

O concreto poroso é feito de agregados graúdos graduados, cimento e água com pouco ou sem agregados finos. Quando os agregados finos são totalmente excluídos do traço, pode-se nomeá-lo de concreto sem finos. Em contraste com o concreto convencional, o concreto poroso apresenta o traço com uma baixa proporção de cimento, e essa menor quantidade é normalmente projetada para ser apenas a suficiente para ligar os agregados. (Yang, Jiang, 2002)

A função do agregado é formar a estrutura do concreto. A pasta de cimento ou argamassa une os agregados. Existem muitos vazios que apresentam diâmetros acima de $1 \mathrm{~mm}$ no concreto poroso. Desta maneira, esse tipo de concreto contém mais espaços vazios do que o convencional, permitindo a infiltração da água, porém sua resistência é baixa devido aos vazios. (Lian et al, 2011; Yang, Jiang, 2002).

De acordo com Sonebi et al (2016), a combinação entre agregado de boa qualidade com a cobertura adequada de pasta de cimento resulta na formação de poros interconectados e desconectados; tal relação quando balanceada permite a 
formação de vazios, e por consequência, a infiltração da água e razoável resistência, conforme Figura 11.

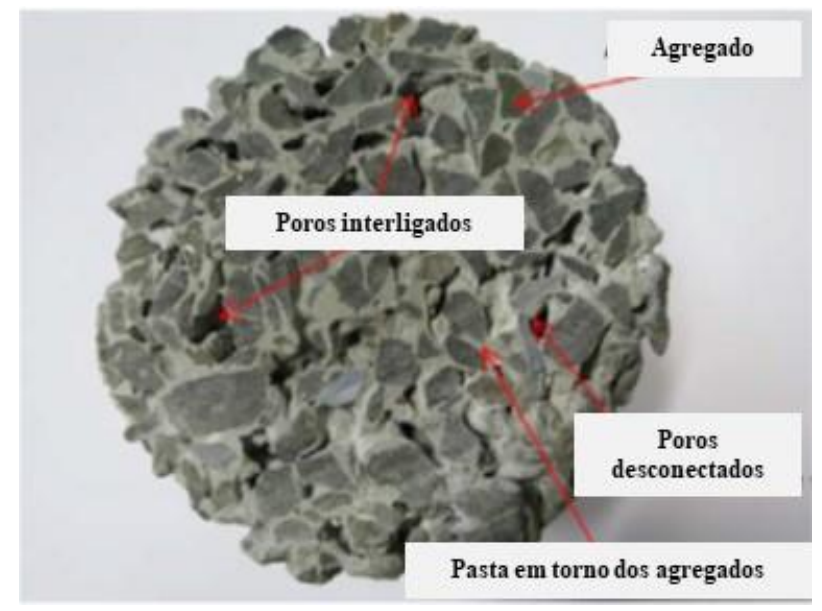

Fonte: Adaptado de Sonebi et al (2016)

Figura 11 - Seção transversal de uma amostra de concreto permeável

Devido à sua baixa resistência, o pavimento de concreto poroso apenas pode ser utilizado em áreas de baixo tráfego, tais como estacionamentos, ciclovias, calçadas, trilhas e parques. (Ferguson, 2005)

Nos subitens seguintes serão descritos os materiais utilizados para preparo do concreto permeável, suas principais propriedades no estado fresco e no estado endurecido:

\subsubsection{1 \\ Materiais e proporções}

De acordo com Bonicelli et al (2016), o traço do concreto permeável está relacionado com seu uso final, tipo de solicitação (ex.: tráfego leve, médio, pesado e o de pedestres), e as necessidades ambientais do local.

Diversos pesquisadores ao redor do mundo têm estudado materiais, suas especificações e proporções ideais para melhoria da resistência e da permeabilidade do concreto permeável, conforme apresentado na Tabela 2.

Todavia, segundo Chindaprasirt et al (2008), a condição ótima para produzir um bom concreto permeável ainda não está consolidada. O método de mistura e compactação para produzir o concreto poroso com alta resistência e durabilidade para um dado índice de vazios projetado ainda precisa ser melhor estudado. Esse fato pode ser justificado devido à peculiaridade do concreto poroso o qual deve 
apresentar vazios, para garantia da permeabilidade e, simultaneamente, boa resistência mecânica.

Tabela 2 - Diversos traços estudados do concreto permeável

\begin{tabular}{|c|c|c|c|c|c|c|c|}
\hline $\begin{array}{c}\text { Consumo } \\
\text { de cimento } \\
\left(\mathrm{kg} / \mathrm{m}^{3}\right)\end{array}$ & $\begin{array}{l}\text { Consumo } \\
\text { de } \\
\text { agregado } \\
\left(\mathrm{kg} / \mathrm{m}^{3}\right)\end{array}$ & $\begin{array}{l}\text { Dimensão } \\
\text { do } \\
\text { agregado } \\
(\mathrm{mm})\end{array}$ & $\begin{array}{c}\text { Consumo } \\
\text { de água } \\
\left(\mathrm{kg} / \mathrm{m}^{3}\right)\end{array}$ & $\begin{array}{c}\text { Fator } \\
\mathrm{A} / \mathrm{C}\end{array}$ & $\begin{array}{l}\text { Teor de } \\
\text { agregados } \\
\text { em } \\
\text { relação ao } \\
\text { cimento }\end{array}$ & $\begin{array}{c}\text { Teor de } \\
\text { finos em } \\
\text { relação ao } \\
\text { agregado }\end{array}$ & Autores \\
\hline 244-311 & $1827-2029$ & 9,5 & 93 & 0,30 & $6,5: 1$ & 0 & $\underset{(2016)}{\text { Kim et al }}$ \\
\hline $\begin{array}{c}\text { Não } \\
\text { informado }\end{array}$ & $\begin{array}{c}\text { Não } \\
\text { informado }\end{array}$ & $\begin{array}{c}6,0-3,0 \\
10,0-6,0\end{array}$ & $\begin{array}{c}\text { Não } \\
\text { informado }\end{array}$ & $\begin{array}{l}0,27- \\
0,35\end{array}$ & $5: 1$ & $\begin{array}{c}0,05: 1 \\
0,1: 1\end{array}$ & $\begin{array}{c}\text { Bonicelli } \\
\text { et al } \\
(2016)\end{array}$ \\
\hline 374 & 1660 & $\begin{array}{c}6,3 \\
6,3-4,8 \\
9,5-4,8\end{array}$ & $\begin{array}{c}\text { Não } \\
\text { informado }\end{array}$ & 0,30 & $4,4: 1$ & 0 & $\begin{array}{c}\text { Batezini } \\
(2013)\end{array}$ \\
\hline $335-458$ & $1737-2128$ & $\begin{array}{l}10,0 \\
14,0\end{array}$ & $90,5-150,8$ & 0,27 & $\begin{array}{c}5: 1 \\
2,5: 1\end{array}$ & $0,11: 1$ & $\begin{array}{c}\text { Khattab } \\
\text { et al } \\
(2013)\end{array}$ \\
\hline $\begin{array}{c}\text { Não } \\
\text { informado }\end{array}$ & $\begin{array}{c}\text { Não } \\
\text { informado }\end{array}$ & $\begin{array}{c}16,0-12,5 \\
12,5-10,0 \\
10,0-6,3\end{array}$ & $\begin{array}{c}\text { Não } \\
\text { informado }\end{array}$ & $\begin{array}{c}0,30- \\
0,45\end{array}$ & $4: 1$ & 0 & $\begin{array}{c}\text { Jain \& } \\
\text { Chouhan } \\
(2011)\end{array}$ \\
\hline $\begin{array}{c}\text { Não } \\
\text { informado }\end{array}$ & $2650-2740$ & $\begin{array}{c}13,2-4,8 \\
9,5-6,3 \\
9,5-4.8\end{array}$ & $\begin{array}{c}\text { Não } \\
\text { informado }\end{array}$ & $\begin{array}{c}0,30- \\
0,38\end{array}$ & $\begin{array}{c}4: 1- \\
4,55: 1\end{array}$ & 0 & $\begin{array}{c}\text { Lian et al } \\
\quad(2011)\end{array}$ \\
\hline $260-509$ & 1550 & $5,0-13,0$ & $68-142$ & $\begin{array}{c}0,20- \\
0,36\end{array}$ & $\begin{array}{l}3,7: 1- \\
2,15-1\end{array}$ & 0 & $\begin{array}{c}\text { Chindapas } \\
\text {-irt } \text { et al } \\
(2008) \\
\end{array}$ \\
\hline $270-415$ & $1190-1480$ & $19,0-1,2$ & $\begin{array}{c}\text { Não } \\
\text { informado }\end{array}$ & $\begin{array}{c}0,27- \\
0,34\end{array}$ & $4-4,5: 1$ & 0 & $\begin{array}{l}\text { Tennis et } \\
\text { al (2004) }\end{array}$ \\
\hline $\begin{array}{c}\text { Não } \\
\text { informado }\end{array}$ & $\begin{array}{c}\text { Não } \\
\text { informado }\end{array}$ & $\begin{array}{l}30,0-15,0 \\
20,0-15,0 \\
10,0-20,0\end{array}$ & $\begin{array}{c}\text { Não } \\
\text { informado }\end{array}$ & $\begin{array}{c}0,20- \\
0,35\end{array}$ & $\begin{array}{c}\text { Não } \\
\text { informad } \\
\text { o }\end{array}$ & $\begin{array}{l}0,15: 1 \\
0,20: 1\end{array}$ & $\begin{array}{c}\text { Yang \& } \\
\text { Jiang } \\
(2002)\end{array}$ \\
\hline
\end{tabular}

\section{Cimento}

Para o concreto permeável é geralmente utilizado o cimento Portland, como nos concretos convencionais. De acordo com Chandrappa \& Biligiri (2016), o cimento tem como função principal proporcionar suficiente cobertura ao redor do agregado a fim de aumentar a durabilidade do concreto permeável. A espessura da pasta de cimento em torno dos agregados é um fator extremamente importante na performance hidrológica e estrutural do concreto permeável, pois o acréscimo da 
espessura pode acarretar em aumento da resistência e redução da sua permeabilidade. O consumo de cimento varia entre 244 a $509 \mathrm{~kg} / \mathrm{m}^{3}$, conforme apresentado na Tabela 2.

\section{Água}

Conforme apresentado na Tabela 2, o fator água cimento (A/C) varia entre 0,20 a 0,45 e o consumo de água, de 90,5 a $150,8 \mathrm{~kg} / \mathrm{m}^{3}$.

A água e sua aplicação no concreto permeável são extremamente críticas. Uma vez que há pouca quantidade ou ausência de finos, a resistência do concreto permeável apenas depende da ligação da pasta de cimento e sua interface com o agregado. A quantidade correta de água maximiza a resistência sem comprometer a permeabilidade. (Mulligan, 2003)

Durante o preparo do concreto permeável, pode-se determinar a quantidade de água visualmente, uma vez que a quantidade ideal proporciona certo brilho na mistura, sem provocar escoamento excessivo da pasta. E ainda, durante o preparo, ao pegar uma pequena amostra do concreto poroso com a mão e fazer uma bola, a mesma não se desintegra ou perde a sua estrutura, conforme ilustrado na Figura 12. (Tennis et al, 2004).

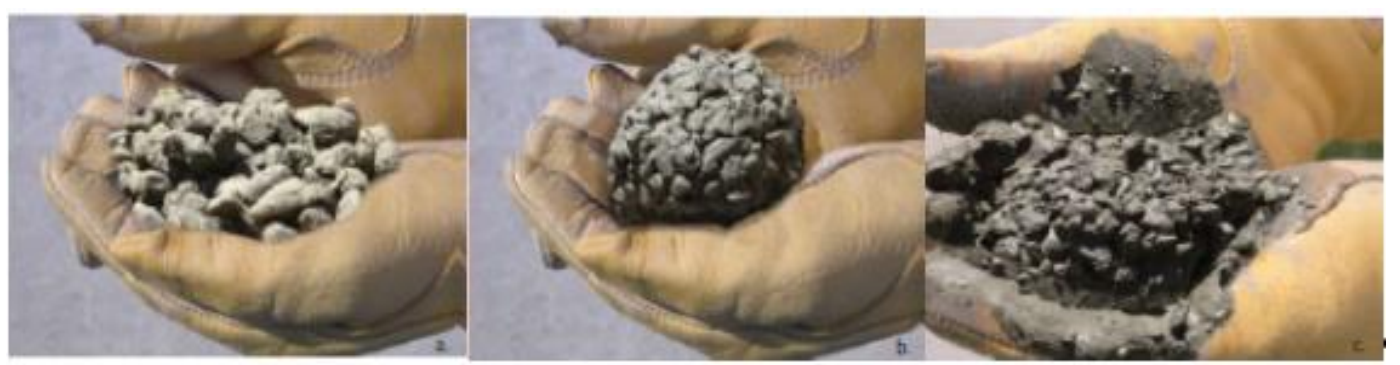

Fonte: Tennis et al (2004)

Figura 12 - Pouca água (a), quantidade ideal (b) e excessiva (c)

\section{Agregados}

Com base nas informações apresentadas na Tabela 2, normalmente existem quatro grandezas referentes aos agregados no traço do concreto permeável:

- Tamanho dos grãos - varia entre 1,2 e 30 mm;

- Consumo de agregado graúdo - varia entre 1190 a $2740 \mathrm{~kg} / \mathrm{m}^{3}$;

- Teor de finos em relação ao agregado graúdo - varia de 0 a 1:1;

- Teor de agregado em relação ao cimento - varia ente 2,15:1 a 6,5:1.

A ruptura em amostras de concreto permeável no ensaio de resistência à compressão usualmente ocorre na interface entre a pasta e o agregado. Isso 
demonstra que a resistência da ligação é mais fraca do que a resistência da pasta e a do agregado. Devido a isso, geralmente a resistência dos agregados não é muito considerada quando se discute a resistência do concreto. (Mulligan, 2003)

Todavia a influência dos agregados nas propriedades do concreto permeável tem sido estudada e, segundo diversos autores (Lian \& Zhuge, 2011; Jain \& Chouhan, 2011; Yang \& Jiang, 2002), as características físicas dos agregados, tais como: tamanho, forma, tipo e curva granulométrica influenciam na permeabilidade e resistência do concreto.

\section{Aditivos}

Assim como nos concretos convencionais, os aditivos são produtos químicos capazes de melhorar as propriedades da mistura cimentícia. (Tennis et al, 2004).

Diversos autores têm testado diferentes materiais, tais como fibras, raspas de pneu, superplastificantes, finos, retardadores de evaporação e cinza volante. Essas pesquisas pretendiam o aumento da resistência, melhoria na permeabilidade e trabalhabilidade do concreto. (Bonicelli et al, 2016; Chandrappa, Biligiri, 2016; Kim et al, 2016)

Os pesquisadores Yang \& Jiang (2002) concluíram que devido ao volume de vazios no concreto permeável é difícil obter alta resistência sem utilizar aditivos e demonstraram que o uso de superplastificante e microssílica podem aumentar a resistência do concreto.

Kim et al (2016) testaram a performance do concreto permeável quando sujeito à carga intensa e instantânea, adicionando à sua composição diversos materiais de construção alternativos, tais como: fibras, raspas de pneu e cinza volante. Suas principais conclusões foram:

- O emprego da fibra aumenta a permeabilidade e a resistência à compressão do concreto permeável, porém se o referido material for utilizado demasiadamente ocorrerá a colmatação dos seus poros;

- As raspas de pneu diminuem a resistência à compressão e a permeabilidade;

- A cinza volante diminui a resistência do concreto e, dependendo da composição de outros materiais, pode apresentar redução ou aumento de permeabilidade. 
Bonicelli et al (2016) estudaram diferentes traços do concreto poroso, com adição de areia e cinco tipos de fibra, e concluíram que a adição de areia e de fibras aumentam a resistência do concreto, porém devido ao aumento do volume da pasta, os vazios da matriz do concreto são reduzidos e, portanto, há redução da permeabilidade.

\subsubsection{2}

Propriedades do concreto permeável fresco

O concreto poroso é menos plástico do que o concreto tradicional, e desta forma exige maior esforço para ser manipulado em campo. (Kevern et al, 2006; Tennis et al, 2004).

O concreto permeável geralmente apresenta slump 0 . O tempo de trabalhabilidade do concreto poroso é de aproximadamente 60 minutos entre o início da mistura até a aplicação do concreto. No entanto, esse tempo pode ser prolongado até 90 minutos, através do uso de retardadores de pega e aditivo estabilizador de hidratação, dependendo da dosagem. (Chandrappa, Biligiri, 2016; Tennis et al, 2004)

Para o controle de qualidade, é preferível utilizar medidas de peso específico ou densidade aparente porque algumas propriedades do concreto convencional fresco, como o slump, não são muito significativas para avaliar o concreto poroso. O peso específico do concreto poroso é aproximadamente $70 \%$ do concreto convencional. (Tennis et al, 2004)

\subsubsection{3}

\section{Propriedades do concreto permeável endurecido}

As principais propriedades do concreto permeável endurecido serão descritas abaixo:

\section{Massa específica}

A densidade do concreto poroso depende das propriedades e proporções dos materiais utilizados na mistura, e dos procedimentos de compactação utilizados.

A massa específica do concreto pode variar entre $1600 \mathrm{~kg} / \mathrm{m}^{3}$ e $2000 \mathrm{~kg} / \mathrm{m}^{3}$. (Tennis et al, 2004) 


\section{Permeabilidade e índice de vazios}

A permeabilidade do concreto poroso depende dos materiais constituintes da sua mistura e da sua aplicação em campo. Os coeficientes de permeabilidade típicos estão entre $0,2 \mathrm{~cm} / \mathrm{s}$ e $0,54 \mathrm{~cm} / \mathrm{s}$, e já foram medidos até $1,2 \mathrm{~cm} / \mathrm{s}$ em ensaios de laboratório. (Crouch, 2004 apud Kevern et al, 2006).

Dependendo da sua aplicação, de acordo com Mulligan (2003), o concreto poroso pode apresentar índice de vazios entre $15 \%$ a 40\%, já o índice de vazios do concreto convencional varia entre $3 \%$ e $5 \%$.

O coeficiente de permeabilidade depende diretamente da estrutura de vazios presente no concreto poroso. Segundo Kevern et al (2006), a quantidade de vazios que permite o movimento da água no interior do concreto depende do grau de compactação e de características do agregado.

Quanto maior o índice de vazios, maior é o coeficiente de permeabilidade. O uso de agregados de maiores diâmetros produz um concreto de maior índice de vazios o que aumenta a permeabilidade. (Bhutta et al, 2012; Jain, Chouhan, 2011)

Conforme já relatado, a utilização de aditivos no concreto permeável também pode influenciar na sua capacidade de permeabilidade.

\section{Resistência à compressão e à flexão}

Quando o concreto é submetido a cargas, elas são transferidas através da camada ligante da pasta de cimento entre os agregados. A resistência do agregado é alta, no entanto as resistências da pasta e da interface entre a pasta e os agregados são baixas. E ainda, a camada da pasta de cimento é fina. Logo, o concreto poroso sempre falha na região da pasta de cimento entre os agregados. Assim, para aprimorar as propriedades mecânicas do concreto poroso seriam necessárias duas medidas: aumentar a área da pasta de cimento e melhorar a resistência da pasta de cimento. (Yang, Jiang, 2002)

$\mathrm{O}$ concreto poroso apresenta resistência à compressão entre $3,5 \mathrm{MPa}$ e 28 $\mathrm{MPa}$, sendo adequado para diversas aplicações. Como qualquer concreto, suas propriedades e seus materiais constituintes, assim como as técnicas de aplicação e condições ambientais, determinam a resistência do concreto. (Tennis et al, 2004) 
A resistência à flexão no concreto poroso varia entre 1 e 3,8 $\mathrm{MPa}$. Muitos fatores influenciam na resistência à flexão, principalmente: o grau compactação, porosidade e a relação agregado/cimento. (Tennis et al, 2004)

Segundo Yang \& Jiang (2002), as propriedades mecânicas do concreto poroso podem ser melhoradas através de agregados selecionados, aditivos e polímeros orgânicos, desta maneira, a resistência à compressão pode chegar a 50 $\mathrm{MPa}$ e resistência à flexão, $6 \mathrm{MPa}$.

Os pesquisadores Yang \& Jiang (2002) e Lian \& Zhuge (2011) demonstraram que o uso de agregados de menores dimensões pode aumentar a resistência do concreto.

Jain \& Chouhan (2011) testaram misturas de concreto permeável, variando a dimensão $(6,3,10$ e 12,5 mm) e a angularidade de agregados graúdos e o fator água cimento $(0,30$ a 0,45$)$. Os resultados obtidos indicaram que a resistência e a permeabilidade do concreto poroso variam em função do fator água cimento e as características do agregado:

- A resistência à compressão é inversamente proporcional ao tamanho do grão;

- Quanto menor o tamanho do grão, menor a permeabilidade;

- Os agregados de menor angularidade apresentaram menor permeabilidade; e maior resistência para todos os tamanhos de grãos ensaiados.

A relação entre o fator $\mathrm{A} / \mathrm{C}$ e a resistência ainda não está clara para o concreto permeável, isso se dá porque, ao contrário dos concretos convencionais, o volume de pasta é menor do que o volume de vazios entre os agregados. Desta forma, uma pasta mais resistente não garante uma maior resistência do concreto. (Tennis et al, 2004)

Os pesquisadores Jain \& Chouhan (2011) testaram diversos traços e entre seus diversos resultados obtidos, concluíram que existe um fator $\mathrm{A} / \mathrm{C}$ ótimo para cada tipo de traço utilizado em termos de resistência à compressão.

No Gráfico 1 está apresentada a relação entre o fator A/C e a resistência à compressão obtido pelos autores para o concreto poroso preparado com a relação agregado cimento de 4, agregado graúdo de diâmetro $12,5 \mathrm{~mm}$ e angularidade irregular. 


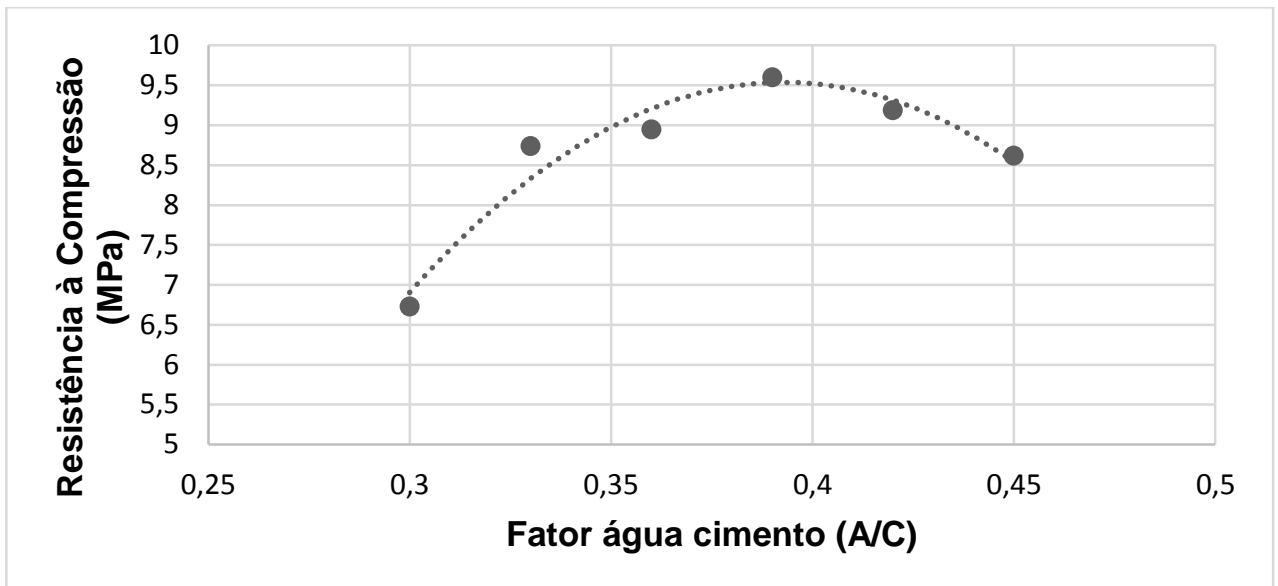

Fonte: Adaptado de Jain \& Chouhan (2011)

Gráfico 1 - Fator A/C versus resistência à compressão

A permeabilidade e a porosidade também podem ser relacionadas com a resistência a compressão. Segundo Mulligan (2003), a resistência à compressão aumenta com a presença de mais cimento na mistura, o que reduz o fator água cimento. Assim, quanto maior a proporção de cimento na mistura, menores serão os vazios ocupados pelo ar, reduzindo a permeabilidade e a porosidade do concreto, todavia aumentando a sua resistência

Lian et al (2011) estudaram a relação entre resistência à compressão e porosidade, os dados obtidos, apresentados no Gráfico 2, demonstraram que a resistência à compressão do concreto permeável decresce com o aumento da sua porosidade para um dado traço. As duas variáveis apresentaram correlação de 0,90.

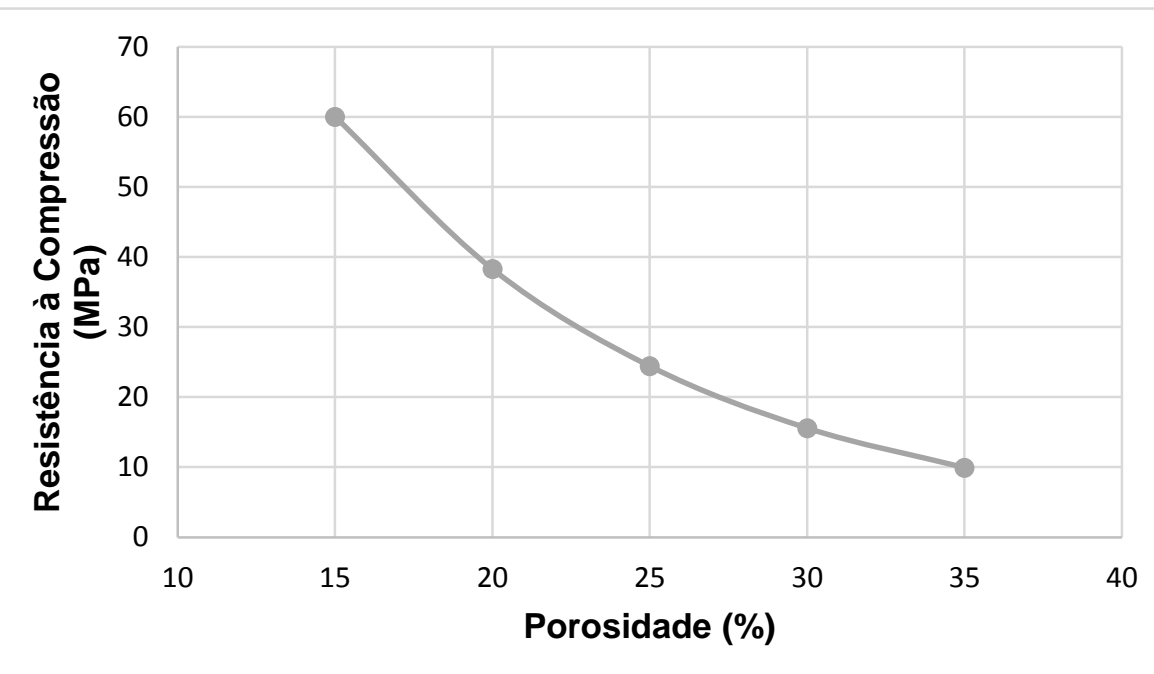

Fonte: Adaptado de Lian et al (2011)

Gráfico 2 - Relação entre porosidade e resistência à compressão. 


\section{Durabilidade}

Quanto à resistência a sulfatos, os produtos químicos agressivos em solos ou em água, como ácidos e sulfatos, são uma preocupação tanto para o concreto convencional como para o concreto permeável, e os mecanismos de ataque são semelhantes. No entanto, a estrutura aberta do concreto poroso o torna mais suscetível. A camada de base constituída por agregados, além de servir para armazenar a água da chuva, também é capaz de evitar o ataque químico, isolando o concreto permeável do solo. (Tennis et al, 2004)

Quanto à resistência à abrasão, devido à superfície rugosa e a estrutura aberta do concreto poroso, o desgaste à abrasão pode ser um problema. Essa é uma das razões que impede o concreto poroso de ser usado em rodovias de alto tráfego. A maioria dos pavimentos permeáveis de concreto apresenta perdas de agregados da sua superfície nos primeiros dias de uso, no entanto após algumas semanas a superfície se torna mais estável. (Tennis et al, 2004)

O desgaste por abrasão pode ser mitigado através das etapas construtivas de acabamento e compactação realizadas adequadamente a fim de proporcionar um pavimento durável. O acabamento apropriado do concreto poroso proporciona uma superfície nivelada e uniforme, a qual previne a desagregação dos agregados na superfície do pavimento (desgaste por abrasão), enquanto continua esteticamente agradável para o público. O concreto poroso bem-acabado proporciona uma superfície adequada para diversos fins, cadeiras de rodas, patins e atividades recreativas. (Kevern et al, 2006)

\subsection{2}

\section{Camada de Assentamento}

A camada de assentamento apenas é necessária para revestimento em placas e em blocos de concreto pré-moldado, a fim de acomodá-los e nivelá-los. O material granular deve permitir que a chuva infiltre e ao mesmo tempo deve impedir a entrada de partículas na estrutura do pavimento permeável, a fim de evitar a colmatação das camadas inferiores. Geralmente, essa camada apresenta espessura entre 25 e $50 \mathrm{~mm}$ e é constituída por material granular, cujos agregados passam na peneira de malha $6,3 \mathrm{~mm}$ e ficam retidos na malha de $3 \mathrm{~mm}$. (ABCP, 2010; Interpave, 2010; Tomaz, 2009). 


\subsection{3}

\section{Camada de Base (Reservatório)}

Assim como no pavimento convencional, a camada de base é a camada destinada a resistir e distribuir os esforços oriundos do tráfego e sobre a qual se constrói o revestimento (DNIT, 2006).

Todavia nos pavimentos permeáveis, essa camada também tem a função de armazenar temporariamente a água da chuva. A água é retida na base (também chamada de reservatório), formada pelos espaços vazios dos materiais, podendo ser composta por sistema geocelular, agregados uniformes ou graduados. A porosidade desses materiais está apresentada na Tabela 3. Em função do tipo de classificação quanto à infiltração, a água armazenada pode ser infiltrada no solo, reutilizada para fins não potáveis ou descartada. (Field et al, 1982; Ballard et al, 2007)

Os agregados são os materiais mais utilizados para construção das bases, devendo ser rígidos, duráveis, de formato angular não arredondado, para compactação adequada e manutenção da estrutura de vazios. (Tomaz, 2009)

\begin{tabular}{c|c}
\multicolumn{2}{c}{ Tabela 3 - Materiais para a base e as suas porosidades } \\
\hline Material & Porosidade, $\mathrm{n}$ \\
\hline Sistema Geocelular & $0,90-0,95$ \\
\hline Agregado Uniforme & $0,30-0,40$ \\
\hline Areia ou agregado graduado & $0,20-0,30$ \\
\hline Fonte: Ballard et al $(2007)$
\end{tabular}

\subsection{4 \\ Subleito}

O subleito é o terreno de fundação do pavimento. O subleito abaixo do pavimento permeável ficará úmido, desta forma o solo deve ser permeável, não deve ser expansivo e/ou perder a sua resistência na presença de água.

Conforme apresentado na Tabela 1, a permeabilidade do solo será importante na escolha do tipo de pavimento quanto à infiltração e dado de entrada para o seu dimensionamento mecânico e hidráulico, como será visto no item 2.3.

A Tabela 4 classifica o grau de permeabilidade do solo em alta, média, baixa, muito baixa e praticamente impermeável de acordo com os valores típicos de coeficiente de permeabilidade. 
Tabela 4 - Valores de coeficiente de permeabilidade do solo

\begin{tabular}{c|c}
\hline $\begin{array}{c}\text { Coeficiente de permeabilidade do solo, } \\
\mathrm{k}(\mathrm{cm} / \mathrm{s})\end{array}$ & Grau de permeabilidade \\
\hline$>10^{-3}$ & Alta \\
\hline $10^{-3} \mathrm{a} 10^{-5}$ & Média \\
\hline $10^{-5} \mathrm{a} 10^{-7}$ & Baixa \\
\hline $10^{-7} \mathrm{a} 10^{-9}$ & Muito baixa \\
\hline$<10^{-9}$ & Praticamente impermeável \\
\hline \multicolumn{2}{c}{ Fonte: ABNT NBR $16416: 2015$}
\end{tabular}

\subsection{5}

\section{Camadas de filtro}

As camadas de filtro são instaladas em alguns pavimentos permeáveis para separar e assim manter a integridade estrutural de cada camada. As camadas de filtro são feitas de agregado de tamanho intermediário, ou de geotêxtil permeável. As localizações potenciais das camadas de filtro estão ilustradas na Figura 13.

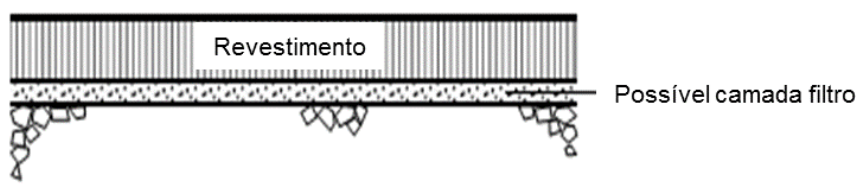

Reservatório

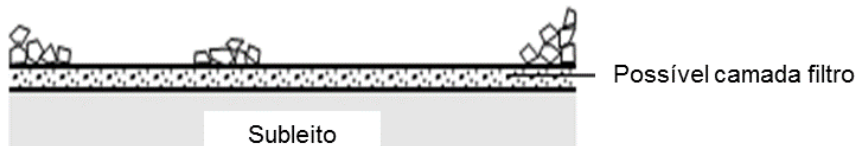

Subleito

Fonte: Adaptado de Ferguson (2005)

Figura 13 - Possíveis locais para aplicação dos filtros

A camada de filtro acima da base evita que pequenas partículas entrem nos poros da base. Enquanto que a camada abaixo da base impede que solos entrem nos vazios da camada inferior, preservando a capacidade estrutural e hidráulica da base na sua espessura de projeto original. Uma seleção apropriada de gradações de agregados para as camadas de base e de superfície pode evitar a necessidade de uma camada de filtro para separá-las. (Furgeson, 2005)

Os geotêxteis não-tecido são uma alternativa a camadas de filtros feitas por agregados. O geotêxtil deve ser capaz de resistir aos esforços, permitir a passagem da água e impedir a migração de partículas finas para a camada inferior.

A aplicação dos geotêxteis para atender a função de separação entre as camadas é mais simples, porém pode ter uma influência sobre a integridade estrutural do pavimento poroso, pois a camada geotêxtil pode formar um plano de deslizamento na construção do pavimento. (Beecham,2010) 


\subsection{6}

\section{Camada impermeável e drenos}

Para pavimentos permeáveis classificados como sem infiltração (ou tipo C), a última camada do pavimento deve ser coberta por drenos e uma geomembrana, impermeável e flexível colocados sobre a camada do solo, conforme apresentado na Figura 14. (Tomaz, 2009).

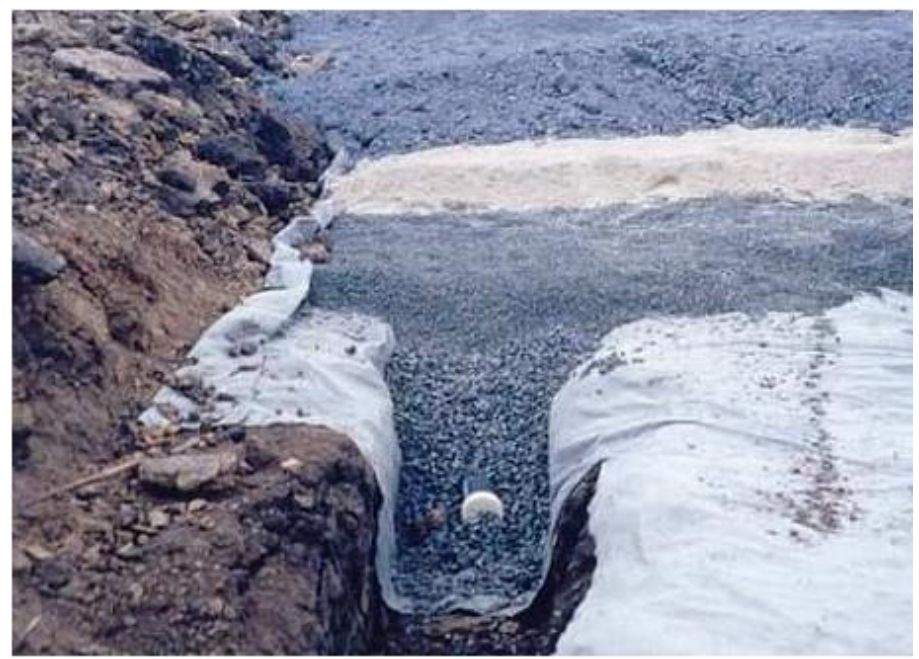

Fonte: Tomaz (2009)

Figura 14 - Membrana Impermeável

\section{3 \\ Dimensionamento do pavimento permeável}

De acordo com Ballard et al (2007), os pavimentos permeáveis têm duas funções:

- Precisam ser capazes de coletar e infiltrar na sua superfície a chuva de projeto e conduzi-la;

- Precisam ter resistência estrutural para suportar as cargas impostas de pedestres e/ou tráfego.

Desta forma, são necessários dois dimensionamentos: estrutural e hidráulico. Os projetistas devem integrar o projeto hidráulico e estrutural para alcançar um pavimento em que todos os seus componentes estão contribuindo para o seu duplo propósito. (Interpave, 2010) 


\subsection{1 \\ Dimensionamento hidráulico}

No dimensionamento hidráulico do pavimento permeável é determinada a espessura do reservatório para armazenar a chuva. Para isso, são necessários os seguintes parâmetros: a chuva de projeto, a área de contribuição, declividade e a permeabilidade do solo. A seleção da chuva de projeto deve ser em função das características climatológicas e necessidades locais. (Field et al, 1982)

As características da bacia hidrográfica, incluindo permeabilidade do solo, topografia e clima vão afetar o volume, a taxa de escoamento e os fluxos através das camadas do pavimento permeável e do solo do terreno. No entanto, a capacidade de armazenamento deve ser limitada devido às limitações física e econômica. Se a limitação for necessária, medidas de alívio (como extravasores) devem ser incorporadas no sistema para evitar inundações. (Field et al, 1982)

O dimensionamento hidráulico deve apresentar 4 etapas:

$\mathbf{1}^{\mathbf{0}}$ etapa - Definição da chuva de projeto

Escolha do local e período de retorno a fim de determinar a chuva de projeto.

$\mathbf{2}^{\mathbf{o}}$ etapa - Escolha do material de revestimento

A taxa de infiltração na superfície do pavimento deve ser significativamente maior do que a intensidade pluvial de projeto para evitar a formação excessiva de poças d'água. O cálculo da vazão de entrada deve considerar o escoamento superficial das áreas adjacentes. Geralmente, a capacidade de infiltração da superfície permeável é significativamente maior que a chuva de projeto. (Ballard et $a l, 2007)$

A norma ABNT NBR 16416:2015 estabelece que a taxa de infiltração mínima (ou coeficiente de permeabilidade) do pavimento permeável recém construído deve ser maior que $10^{-3} \mathrm{~m} / \mathrm{s}$.

$3^{\mathbf{o}}$ etapa - Selecionar o tipo de do pavimento permeável quanto à infiltração

Escolha do tipo de infiltração do pavimento permeável em função das condições locais, conforme apresentado na Tabela 1. 
$4^{\mathbf{0}}$ etapa- Determinar a espessura da camada da base (reservatório) do pavimento permeável

A capacidade necessária de armazenamento da sub-base depende da chuva de projeto, restrições de deságue, taxa de infiltração do subsolo, relação entre área de contribuição e área permeável e declividade do terreno. (Ballard et al, 2007)

De acordo com Interpave (2010), a construção de pavimentos permeáveis em terrenos inclinados pode ser ineficiente, não atingindo os resultados esperados, a água que deveria ser armazenada e infiltrada (ou apropriadamente conduzida) irá acumular nos pontos mais baixos, reduzindo a capacidade projetada de armazenamento, conforme Figura 15 e Figura 16.

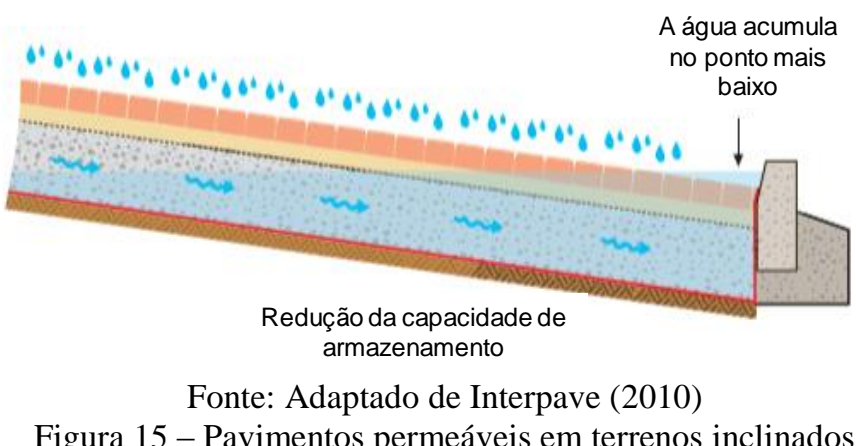

Figura 15 - Pavimentos permeáveis em terrenos inclinados

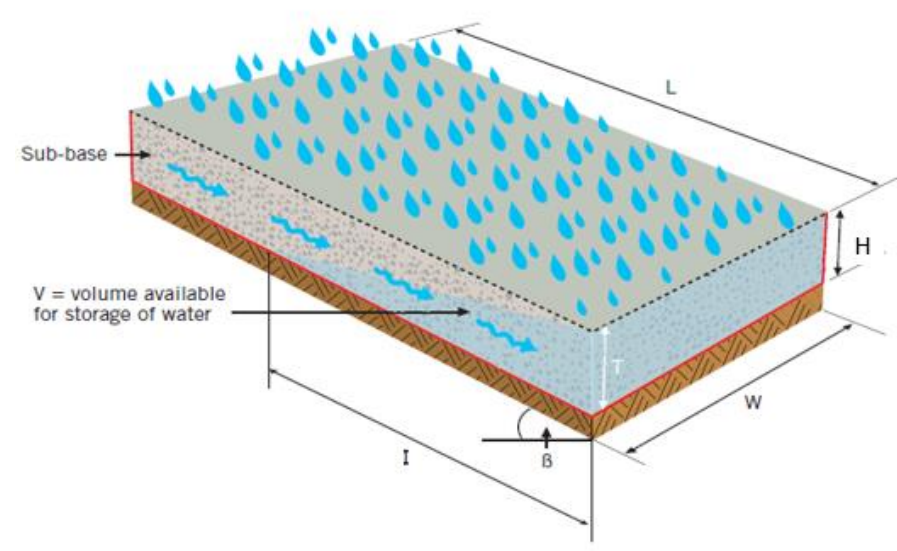

Fonte: Adaptado de Interpave (2010)

Figura 16 - Armazenamento da chuva nos pavimentos permeáveis

O volume de chuva armazenado nos pavimentos permeáveis em terrenos planos é dado por: (Interpave, 2010)

$$
V_{P}=W \times L \times H
$$

Onde,

$V_{P}$ é o volume de armazenamento na camada reservatório em terrenos planos $\left(\mathrm{m}^{3}\right)$; W é a largura do pavimento $(\mathrm{m})$; 
L é o comprimento do pavimento (m);

H é a profundidade da camada reservatório (m).

Já o volume de chuva armazenado nos pavimentos permeáveis em terrenos inclinados pode ser determinado por: (Interpave, 2010)

$$
V_{S}=0,5 \times L \times T
$$

Onde,

$\mathrm{V}_{\mathrm{s}}$ é o volume de armazenamento na camada reservatório em terrenos inclinados $\left(\mathrm{m}^{3}\right)$;

L é o comprimento do reservatório em que a água é armazenada (m). L é calculado como T dividido pela tangente de $\beta$;

$\mathrm{T}$ é a espessura da base medida verticalmente (m). Na maioria dos terrenos inclinados quando a base é rasa, $\mathrm{T}$ pode ser considerado igual a $\mathrm{H}$;

$\beta$ é o ângulo de inclinação.

A fim de impedir a perda da capacidade do reservatório e ao mesmo tempo evitar transbordamento, podem ser instaladas estruturas tipo pequenas barragens com orifícios, os quais permitem a passagem da água, como demonstrado na Figura 17. Para terrenos de declividade cima de acima de $5 \%$ não é recomendada a aplicação de pavimentos permeáveis. (Interpave, 2010)

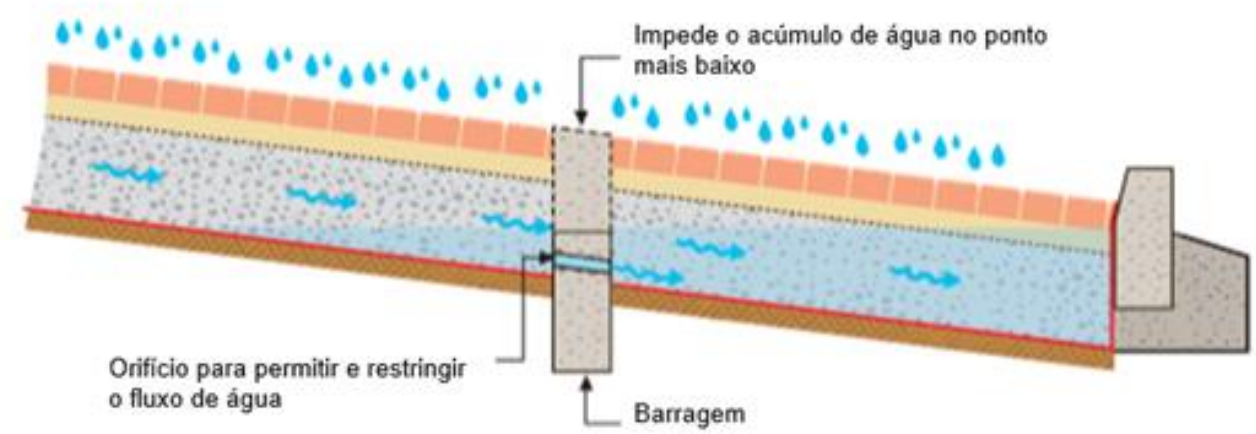

Fonte: Adaptado de Interpave (2010)

Figura 17 - Pequenas barragens em terrenos inclinados

O dimensionamento da camada reservatório depende da classificação do tipo de infiltração, conforme detalhado a seguir.

Para o pavimento permeável tipo infiltração total (ou tipo A), a espessura pode ser determinada através da equação: (Ballard et al, 2007). 


$$
H=\frac{d}{n} \times(R \times I-q)
$$

Onde,

H é a espessura total da camada do reservatório (m);

d é a duração da chuva (h);

n é o índice de vazios da camada reservatório. (adimensional)

$\mathrm{R}$ é a relação entre a área de contribuição e a área de pavimento permeável. A Figura 18 apresenta um exemplo de como determinar tal relação;

I é a intensidade da chuva $(\mathrm{m} / \mathrm{h})$;

q é a taxa de infiltração no solo $(\mathrm{m} / \mathrm{h})$.
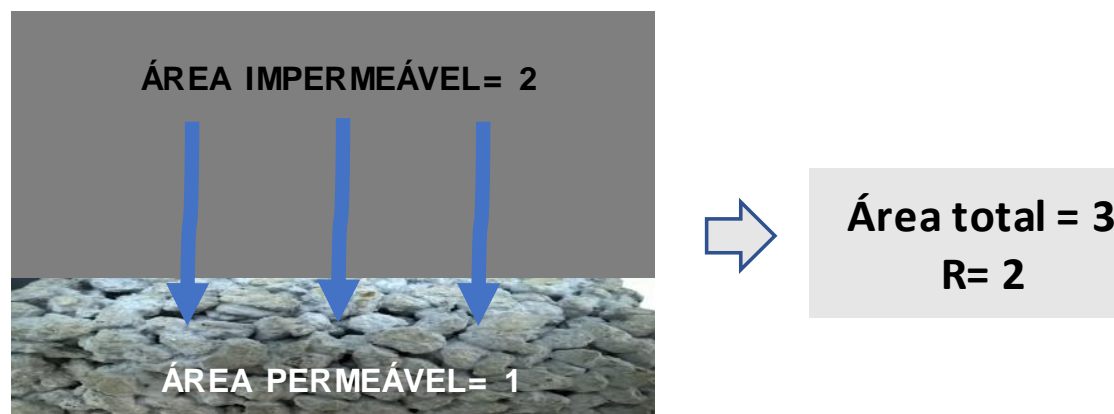

Fonte: Adaptado de Interpave (2010)

Figura 18 - Exemplo de obtenção do parâmetro R

O tempo em que a água armazenada no pavimento e demora a infiltrar no solo pode ser obtido por: (Tomaz, 2009).

$$
T_{e}=\frac{n \times H}{q}
$$

De acordo com Tomaz (2009), o dimensionamento do pavimento permeável tipo infiltração parcial (ou tipo B) é complexo, necessitando de softwares que considerem a entrada e as saídas da chuva - tanto infiltração como vazão de drenos simultaneamente, de forma a auxiliarem nos cálculos. Desta maneira, não será abordado neste trabalho.

No que tange ao dimensionamento do pavimento permeável do tipo sem infiltração (ou tipo C), utiliza-se equação similar ao tipo A, no entanto a vazão de saída do sistema é representada pela vazão dos drenos projetados, e não mais pela taxa de infiltração no solo, conforme apresentado pela equação (5): 


$$
H=\frac{d}{n} \times\left(R \times I-q_{d}\right)
$$

Onde,

H é a espessura total da camada do reservatório (m);

d é a duração da chuva (h);

n é o índice de vazios da camada reservatório (adimensional);

$\mathrm{R}$ é a relação entre a área de contribuição e a área de pavimento permeável;

I é a intensidade da chuva $(\mathrm{m} / \mathrm{h})$;

$\mathrm{q}_{\mathrm{d}}$ é a taxa de escoamento nos drenos $(\mathrm{m} / \mathrm{h})$.

O tempo em que a água armazenada no pavimento demora a escoar através dos drenos pode ser obtido por Tomaz (2009):

$$
T_{e}=\frac{n \times H}{q_{d}}
$$

A taxa de escoamento nos drenos pode ser estimada através da equação (7), de acordo com Interpave (2010):

$$
q_{d}=k \times\left(\frac{h}{b}\right)^{2}
$$

Onde,

$\mathrm{q}_{\mathrm{d}}$ é a taxa de escoamento nos drenos, em $\mathrm{m} / \mathrm{h}$;

k é o coeficiente de permeabilidade da camada reservatório $(\mathrm{m} / \mathrm{s})$;

H é a espessura da sub-base acima da área impermeável (m);

b é a metade da distância entre os drenos (m).

\subsection{2}

\section{Dimensionamento mecânico}

O princípio do projeto de qualquer pavimento é que as camadas construídas devem distribuir as cargas concentradas até um nível que o solo possa resistir sem falhas ou deformação excessiva. (Ballard et al, 2015)

Neste item será abordado o dimensionamento estrutural do pavimento permeável em 3 etapas: 
$1^{\text {o }}$ etapa - Determinação do Índice de Suporte Califórnia (ou Califórnia Bearing Ratio - CBR)

O CBR é determinado através de ensaio o qual consiste, resumidamente, em determinar a relação, em termos percentuais, entre a pressão necessária para produzir uma penetração de um pistão em um corpo-de-prova de solo, e a pressão necessária para produzir a mesma penetração em uma brita padronizada. Os corposde-prova devem ser compactados com teores crescentes de umidade, a fim de caracterizar a curva de compactação. Através dessa relação é possível determinar empiricamente a espessura de um pavimento em função do tráfego e estimar a expansão de um determinado pavimento quando saturado, assim como a perda de resistência em função da sua saturação. (DNIT, 2006)

Para os tipos de pavimento permeável de infiltração total e parcial (A e B, respectivamente), o CBR deve ser testado após saturação. (Ballard et al, 2007)

Alternativamente, o CBR pode ser estimado de acordo com o tipo do solo, conforme apresentado na Tabela 5.

Tabela 5 - Valores típicos de CBR

\begin{tabular}{c|c}
\hline Classificação do solo & Valores de CBR típicos \\
\hline Cascalho & 30 a 80 \\
\hline Areia bem graduada & 10 a 40 \\
\hline Areia mal graduada & 10 a 40 \\
\hline Areno argiloso & 5 a 20 \\
\hline Silte argiloso & 3 a 6 \\
\hline Argiloso & 2 a 5 \\
\hline Fonte: Adaptado de Interpave (2010) e ABNT NBR 16416:2015
\end{tabular}

$\mathbf{2}^{\mathbf{o}}$ etapa - Dimensionamento do revestimento

Em função do tipo de solicitação e da tipologia do revestimento de concreto, determina-se a espessura mínima e a resistência mecânica característica do revestimento, de acordo com a Tabela 6 baseada na ABNT NBR 16416:2015. 
Tabela 6 - Tipologia do revestimento, resistência e espessura mínima

\begin{tabular}{|c|c|c|c|}
\hline $\begin{array}{c}\text { Tipo de } \\
\text { Revestimento }\end{array}$ & Tipo de solicitação & $\begin{array}{l}\text { Espessura mínima } \\
(\mathrm{mm})\end{array}$ & $\begin{array}{l}\text { Resistência mecânica } \\
\text { característica (MPa) }\end{array}$ \\
\hline \multirow{2}{*}{$\begin{array}{l}\text { Peça de concreto } \\
\text { (juntas alargadas ou } \\
\text { áreas vazadas) }\end{array}$} & Tráfego de pedestres & 60 & \multirow{2}{*}{$\geq 35^{\mathrm{a}}$} \\
\hline & Tráfego leve & 80 & \\
\hline \multirow{2}{*}{$\begin{array}{l}\text { Peça de concreto } \\
\text { permeável }\end{array}$} & Tráfego de pedestres & 60 & \multirow{2}{*}{$\geq 20^{\mathrm{a}}$} \\
\hline & Tráfego leve & 80 & \\
\hline \multirow{2}{*}{$\begin{array}{l}\text { Placa de concreto } \\
\text { permeável }\end{array}$} & Tráfego de pedestres & 60 & \multirow{2}{*}{$\geq 2^{b}$} \\
\hline & Tráfego leve & 80 & \\
\hline \multirow{2}{*}{$\begin{array}{l}\text { Concreto permeável } \\
\text { moldado no local }\end{array}$} & Tráfego de pedestres & 60 & $\geq 1^{\mathrm{c}}$ \\
\hline & Tráfego leve & 100 & $\geq 2^{\mathrm{c}}$ \\
\hline \multicolumn{3}{|c|}{$\begin{array}{l}\text { Determinação da resistencia à flexão } \\
\text { c Determinação da resistência à tração na flexão }\end{array}$} & \\
\hline
\end{tabular}

Fonte: Adaptado de ABNT NBR 16416:2015

$3^{\circ}$ etapa - Dimensionamento da base

A norma ABNT NBR 16416:2015, intitulada Pavimentos Permeáveis de Concreto - Requisitos e Procedimentos não aborda o dimensionamento estrutural da camada reservatório.

Ballard et al (2015) orientam que para dimensionamento da base de pavimentos permeáveis de concreto aplicados em solos de CBR $\geq 5 \%$ sejam consideradas as dimensões mínimas expostas na Tabela 7, em função da categoria de tráfego. Para solos que apresentam valores menores de CBR, são necessárias ações construtivas específicas as quais também podem ser consultadas em Ballard et al (2015).

A espessura do projeto deve ser adotada como a maior das medidas entre o dimensionamento hidráulico e estrutural. 
Tabela 7 - Espessura da base para atender esforços em solos de CBR $\geq 5 \%$

\begin{tabular}{c|c|l|c}
\hline $\begin{array}{c}\text { Categoria } \\
\text { de tráfego }\end{array}$ & $\begin{array}{c}\text { Carga } \\
\text { máxima de } \\
\text { tráfego }\end{array}$ & \multicolumn{1}{|c}{ Exemplos de uso } & $\begin{array}{c}\text { Espessura } \\
\text { mínima da } \\
\text { base (mm) }\end{array}$ \\
\hline 5 & 8 & $\begin{array}{l}\text { Áreas de pedestres sujeitas a tráfego ocasional de } \\
\text { veículos comerciais e de manutenção e } \\
\text { estacionamentos que recebem veículos } \\
\text { comerciais ocasionalmente }\end{array}$ & 300 \\
\hline 4 & 8 & $\begin{array}{l}\text { Vias urbanas sem excesso de veículos, áreas para } \\
\text { pedestres ou estacionamentos para veículos } \\
\text { comerciais leves }\end{array}$ & 300 \\
\hline 3 & 2 & $\begin{array}{l}\text { Pequenos estacionamentos para veículos de } \\
\text { passeio, acessos para motos }\end{array}$ & 225 \\
\hline 1 & 2 & $\begin{array}{l}\text { Áreas de pedestres e ciclistas, entradas de carros } \\
\text { de passeios }\end{array}$ & 150 \\
\hline 0 & 1 & $\begin{array}{l}\text { Áreas exclusivas para pedestres, incluindo usos } \\
\text { domésticos }\end{array}$ & $\begin{array}{c}\text { Suficiente } \\
\text { para facilitar a } \\
\text { construção }\end{array}$ \\
\hline
\end{tabular}




\section{3 Estudo Experimental do Concreto Permeável}

Foram realizados cinco ensaios a fim de obter as características hidráulicas e mecânicas do concreto permeável, sendo estes: massa específica, índice de vazios, permeabilidade à carga constante, resistência à compressão e resistência à tração na flexão.

A moldagem das amostras e os ensaios de resistência foram realizados no Laboratório de Estruturas e Materiais (LEM), já os ensaios de massa específica, índice de vazios e permeabilidade foram realizados no Laboratório de Geotecnia e Meio Ambiente (LGMA), ambos localizados na Pontifícia Universidade Católica do Rio de Janeiro (PUC-Rio).

\section{1 Materiais}

Para o preparo do concreto permeável foram utilizados os materiais: cimento, água e agregado, conforme descritos abaixo.

\subsection{1 \\ Cimento}

Foi utilizado cimento Portland composto com escória de alto-forno de classe de resistência 32 MPa, CP II-E-32.

Conforme já relatado neste trabalho, a estrutura aberta do concreto poroso o torna mais vulnerável ao ataque por sulfatos e menos resistente, desta maneira foi escolhido o cimento Portland composto com escória de alto forno o qual entre outras propriedades, quando comparado ao cimento Portland comum, melhora a resistência à corrosão por cloretos e sulfatos e a resistência final. A escolha da classe de resistência de $32 \mathrm{MPa}$ se justifica para assegurar a resistência do concreto permeável requerida na ABNT NBR 16416:2005 para o tipo de utilização pretendido em calçadas (tráfego de pedestres).

A norma brasileira ABNT NBR 11578 define o cimento Portland composto como 
"aglomerante hidráulico obtido pela moagem de clínquer ao qual se adiciona, durante a operação, a quantidade necessária de uma ou mais formas de sulfato de cálcio. Durante a moagem é permitido adicionar a esta mistura os materiais pozolânicos, escória granuladas de alto-forno e/ou materiais carbonáticos"

As escórias de alto-forno são obtidas durante a fabricação do ferro gusa em unidades industriais denominadas de altos-fornos nas indústrias siderúrgicas. As escórias apresentam a propriedade de ligante hidráulico, e ao reagir na presença de água, desenvolvem características aglomerantes semelhantes ao clínquer. Isso torna possível a substituição de parte do clínquer do cimento pela escória, reduzindo a produção do clínquer, bem como a emissão de $\mathrm{CO}_{2}$ decorrente da sua produção. (ABCP, 2002; Thomaz, 2002)

Respeitadas certas proporções, ao adicionar a escória de alto-forno à moagem do clínquer com gesso, obtêm-se um cimento capaz de atender aos usos mais comuns e apresentar melhoria de algumas propriedades, como durabilidade, trabalhabilidade, prevenção da reação álcalis-agregado, resistência à corrosão por cloretos e sulfatos e resistência final. (ABCP, 2002; Thomaz, 2002)

Os cimentos Portland que apresentam na sua composição a escória de altoforno são o cimento Portland composto com escória de alto-forno - CP II-E (6 a $34 \%$ de escória) e cimento Portland de alto forno - CP III (35 a 70\% de escória).

A Tabela 8 e a Tabela 9 apresentam, respectivamente, os teores dos componentes do cimento Portland composto com escória de alto-forno e as exigências físicas e mecânicas para classe de resistência de $32 \mathrm{MPa}$.

Tabela 8 - Teores de componentes do CP II-E

\begin{tabular}{c|c|c|c|c}
\hline \multirow{2}{*}{$\begin{array}{c}\text { Classes de } \\
\text { resistência } \\
(\mathrm{MPa})\end{array}$} & $\begin{array}{c}\text { Clínquer }+ \\
\text { sulfatos de } \\
\text { cálcio (\%) }\end{array}$ & $\begin{array}{c}\text { Componentes (\% em massa) } \\
\text { granulada em } \\
\text { alto forno (\%) }\end{array}$ & $\begin{array}{c}\text { Material } \\
\text { pozolânico (\%) }\end{array}$ & $\begin{array}{c}\text { Material } \\
\text { carbonático (\%) }\end{array}$ \\
\cline { 4 - 5 } 25 & \multirow{2}{*}{$94-56$} & $6-34$ & - & $0-10$ \\
\hline 32 & & 6 & & \\
\hline 40 &
\end{tabular}

Fonte: Adaptado de NBR 11578 
Tabela 9 - Exigências físicas e mecânicas para resistência $32 \mathrm{MPa}$

\begin{tabular}{c|c|c|c}
\hline \multirow{2}{*}{ Características e propriedades } & Unidade & $\begin{array}{c}\text { Limite de classe }-32 \\
\mathrm{MPa}\end{array}$ \\
\hline \multirow{2}{*}{ Finura } & Resíduo na peneira $75 \mu \mathrm{m}$ & $\%$ & $\leq 12$ \\
\cline { 2 - 4 } & Área específica & $\mathrm{m}^{2} / \mathrm{kg}$ & $\geq 260$ \\
\hline \multicolumn{2}{c}{ Tempo de início de pega } & $\mathrm{h}$ & $\geq 1$ \\
\hline \multirow{2}{*}{$\begin{array}{c}\text { Expansibilidade a quente } \\
\text { compressão }\end{array}$} & 3 dias de idade & $\mathrm{mm}$ & $\geq 10$ \\
\cline { 2 - 4 } & 7 dias de idade & $\mathrm{MPa}$ & $\geq 20$ \\
\cline { 2 - 4 } & 28 dias de idade & $\mathrm{MPa}$ & $\geq 32$ \\
\hline
\end{tabular}

Fonte: Adaptado de NBR 11578

\subsection{2}

\section{Agregados}

Os agregados utilizados foram fornecidos pela empresa IBRATA Mineração Ltda. Foram elaboradas 5 misturas (T1 a T5) preparadas com agregados classificados como miúdos e graúdos, conforme classificação da ABNT NBR 7211/2009, de diâmetros variando entre 6,3 a 2,4 mm; e 2 misturas (T6 e T7) com agregados classificados apenas como graúdos, de diâmetro de 9,5 a 6,3 mm. No item 3.2 serão detalhados os traços das misturas T1 a T7.

Os traços T1 a T5 tiveram suas frações granulométricas determinadas pelo ensaio de peneiramento manual através das peneiras de série normal e intermediária.

Para os traços T6 e T7 foram utilizados apenas diâmetros de 9,5 a 6,3 mm. A brita recebida pela mineradora foi separada no peneirador elétrico (Figura 19) a fim de selecionar apenas os agregados retidos na peneira de abertura de malha 6,3 $\mathrm{mm}$. 


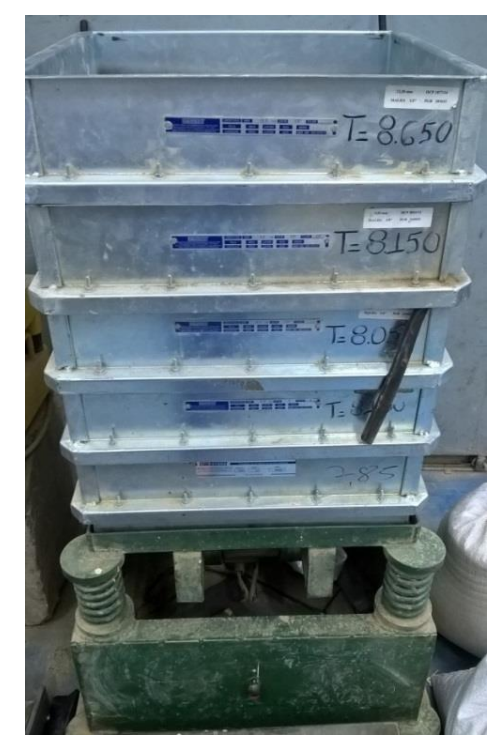

Figura 19 - Peneirador elétrico

\section{2 \\ Proporções}

Com intuito de estudar as características mecânicas e hidráulicas do concreto permeável para escolher a mais adequada para a aplicação em calçadas, foram preparadas 7 diferentes misturas, variando principalmente o fator água cimento, o diâmetro do agregado e o percentual de cimento em relação à massa total, conforme pode ser visualizado na Tabela 10 .

\begin{tabular}{|c|c|c|c|c|c|c|c|c|}
\hline \multirow{3}{*}{ Traço } & \multirow{2}{*}{$\begin{array}{c}\text { Consumo } \\
\text { de } \\
\text { cimento }\end{array}$} & \multirow{2}{*}{$\begin{array}{l}\text { Consumo } \\
\text { de } \\
\text { agregado }\end{array}$} & \multirow[b]{2}{*}{$\begin{array}{l}\text { Consumo } \\
\text { de água }\end{array}$} & \multirow{2}{*}{$\begin{array}{l}\text { Fator } \\
\text { água } \\
\text { cimen } \\
\text { to }\end{array}$} & \multirow{2}{*}{$\begin{array}{l}\text { Teor de } \\
\text { agregado } \\
\text { em } \\
\text { relação } \\
\text { ao } \\
\text { cimento }\end{array}$} & \multicolumn{3}{|c|}{$\begin{array}{l}\text { Diâmetro do agregado } \\
(\mathrm{mm})\end{array}$} \\
\hline & & & & & & $\begin{array}{c}9,5 \mathrm{a} \\
6,3\end{array}$ & $\begin{array}{c}6,3 \mathrm{a} \\
4,8\end{array}$ & $\begin{array}{c}4,8 \mathrm{a} \\
2,4\end{array}$ \\
\hline & $\mathrm{kg} / \mathrm{m}^{3}$ & $\mathrm{~kg} / \mathrm{m}^{3}$ & $\mathrm{~kg} / \mathrm{m}^{3}$ & & & $\%$ & $\%$ & $\%$ \\
\hline $\mathrm{T} 1$ & 180,00 & 1575,00 & 45,00 & 0,25 & $8,75: 1$ & 0 & 40 & 60 \\
\hline $\mathrm{T} 2$ & 225,00 & 1518,75 & 56,25 & 0,25 & $6,75: 1$ & 0 & 40 & 60 \\
\hline $\mathrm{T} 3$ & 270,00 & 1462,50 & 67,50 & 0,25 & $5,42: 1$ & 0 & 40 & 60 \\
\hline $\mathrm{T} 4$ & 315,00 & 1406,25 & 78,75 & 0,25 & $4,46: 1$ & 0 & 40 & 60 \\
\hline T5 & 315,00 & 1390,50 & 94,50 & 0,30 & $4,41: 1$ & 0 & 40 & 60 \\
\hline T6 & 315,00 & 1390,50 & 94,50 & 0,30 & $4,41: 1$ & 100 & 0 & 0 \\
\hline T7 & 315,00 & 1381,05 & 103,95 & 0,33 & $4,38: 1$ & 100 & 0 & 0 \\
\hline
\end{tabular}




\section{3}

\section{Preparo das Amostras}

Para a preparação dos traços estudados do concreto permeável foi utilizado o misturador elétrico do tipo batedeira planetária demonstrada na Figura 20, seguindo-se as seguintes etapas:

- Colocar todo o agregado no misturador;

- Colocar todo o cimento no misturador;

- Misturar manualmente o agregado e o cimento.

- Abrir a mistura em coroa circular e colocar a água lentamente;

- Ligar o misturador, por cerca de 3 minutos, até se obter uma mistura homogênea.

A Figura 21 mostra o traço T4 do concreto permeável no estado fresco, logo após a sua preparação. $\mathrm{O}$ aspecto demonstrado na referida figura é similar para todos os traços estudados.

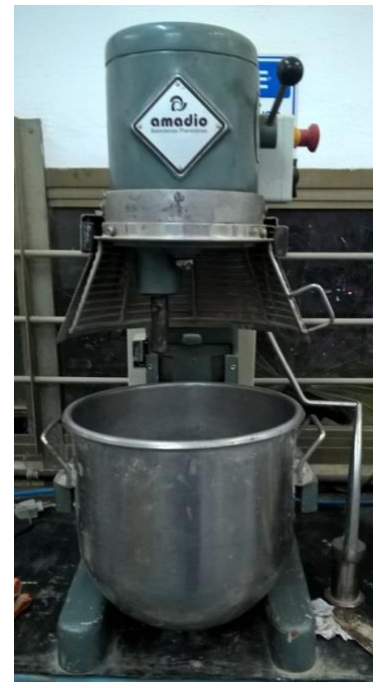

Figura 20 - Misturador elétrico do tipo batedeira planetária

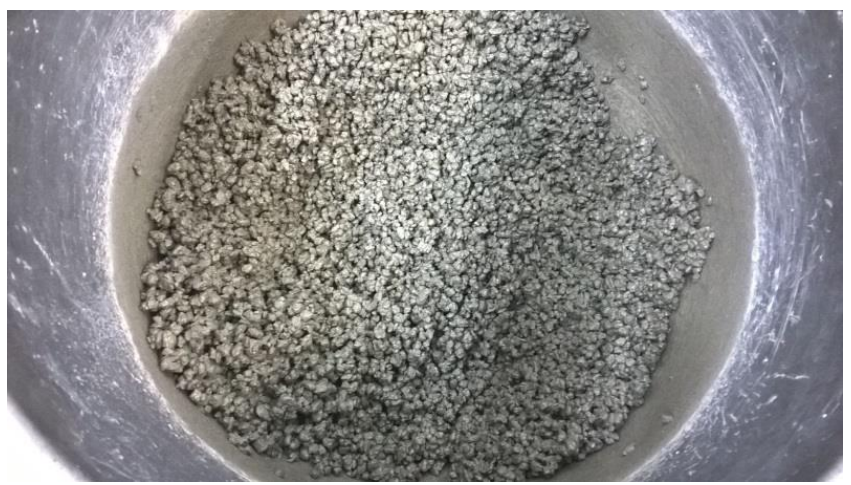

Figura 21 - Concreto permeável no estado fresco (traço T4) 
Foram moldados três corpos de prova para cada tipo de ensaio. Em função dos tamanhos de diâmetro máximo dos agregados das misturas, foram utilizados moldes de tamanhos diferentes: para as misturas T1 a T5, as quais utilizaram agregados de diâmetro máximo de $6,3 \mathrm{~mm}$, foram moldadas amostras de tamanhos menores que as misturas T6 e T7, as quais utilizaram agregados de diâmetro máximo de 9,5 mm, conforme descrito a seguir:

As amostras não foram vibradas porque a mesa vibratória do laboratório apresenta alta intensidade de vibração, podendo ocasionar compactação excessiva e diminuição da porosidade e, consequentemente, da permeabilidade do concreto poroso.

\subsection{1}

\section{Traços T1 a T5}

Para o ensaio de compressão, foram utilizadas fôrmas cilíndricas de $5 \mathrm{~cm}$ de diâmetro e $10 \mathrm{~cm}$ de altura. $\mathrm{O}$ concreto foi lançado em 3 camadas e em cada uma foram dados 5 golpes, com auxílio de um bastão metálico, a fim de obter mínima compactação possível, conforme Figura 22.

No ensaio de tração à flexão foram empregadas fôrmas prismáticas de seção transversal de $4 \times 4 \mathrm{~cm}$ e comprimento de $16 \mathrm{~cm}$, conforme Figura 23 . O concreto foi lançado em 2 camadas e em cada uma delas foram dados 15 golpes, com auxílio de um bastão metálico, a fim de obter mínima compactação possível.

Para o ensaio de permeabilidade foram utilizadas fôrmas cilíndricas de $10 \mathrm{~cm}$ de diâmetro e $20 \mathrm{~cm}$ de altura, porém preenchidas somente até a metade da altura, ou seja, $10 \mathrm{~cm}$, conforme demonstrado na Figura 24. O concreto foi lançado em 3 camadas e em cada uma delas foram dados 15 golpes com auxílio de um bastão metálico, a fim de obter mínima compactação possível.

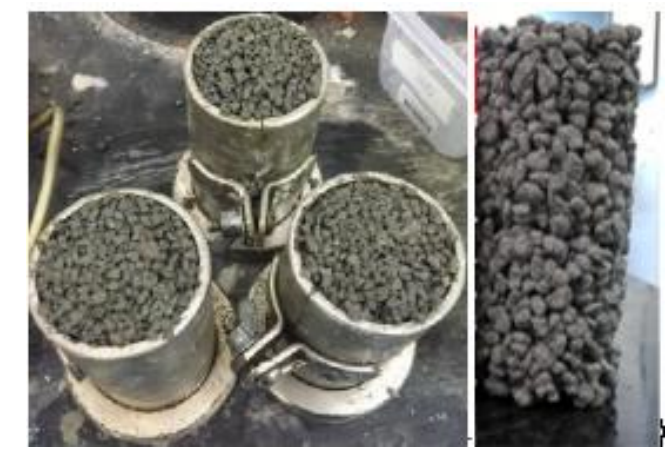

Figura 22 - Amostras do ensaio de resistência à compressão para T1 a T5 


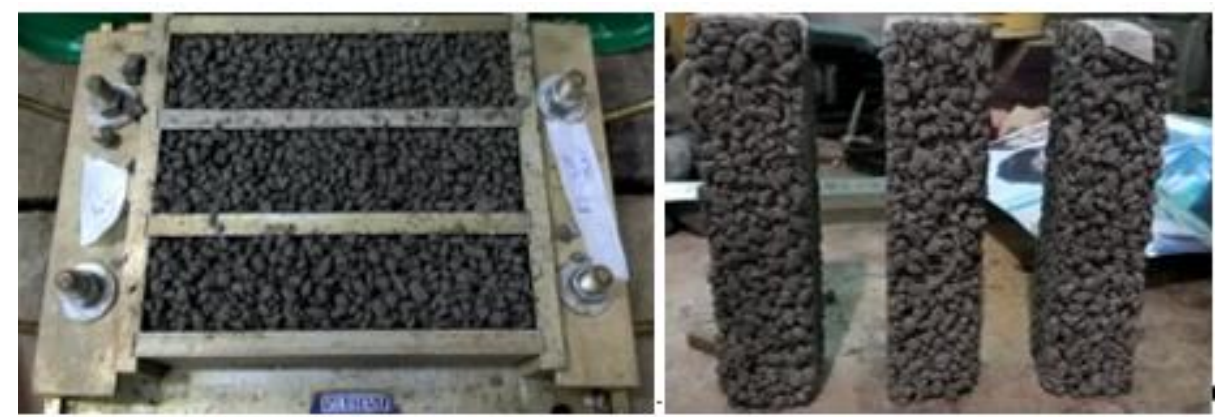

Figura 23 - Amostras do ensaio de flexão para T1 a T5

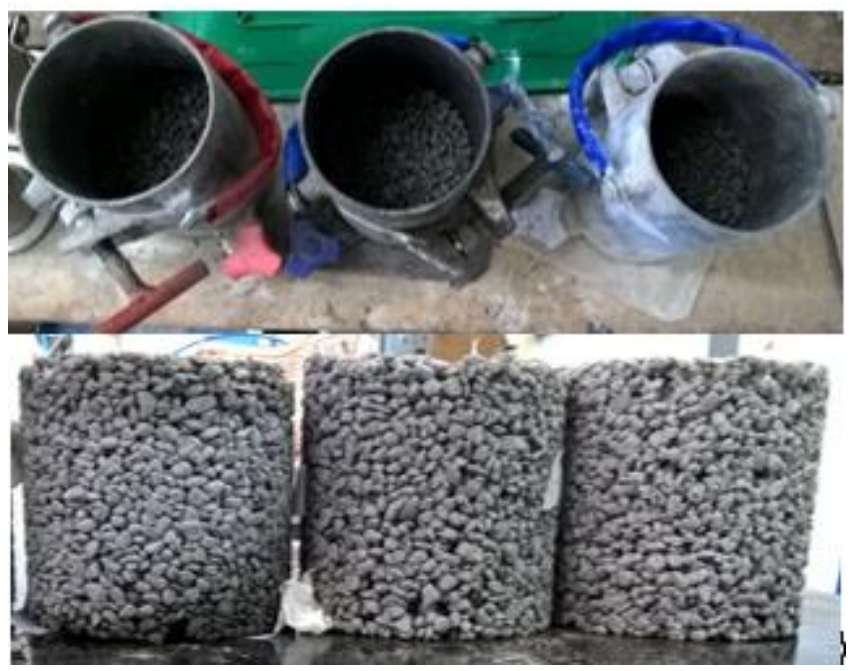

Figura 24 - Amostras do ensaio de permeabilidade para T1 a T5

Após a moldagem, todas as amostras foram curadas durante 7 dias nas próprias fôrmas de moldagem, pois, segundo Batezini (2013) e Bonicelli et al (2016), as amostras de concreto permeável não apresentam estrutura estável para serem desmoldadas após 24 horas, distinto do procedimento tradicional preconizado por norma brasileira para concretos convencionais.

\subsection{2}

\section{Traços T6 e T7}

Para o ensaio de compressão, foram utilizadas 3 fôrmas cilíndricas de $10 \mathrm{~cm}$ de diâmetro e $20 \mathrm{~cm}$ de altura para cada traço, as quais estão demonstradas na Figura 25.

O concreto foi lançado em 3 camadas e em cada uma foram dados 15 golpes com auxílio de um bastão metálico, a fim de obter mínima compactação possível. 


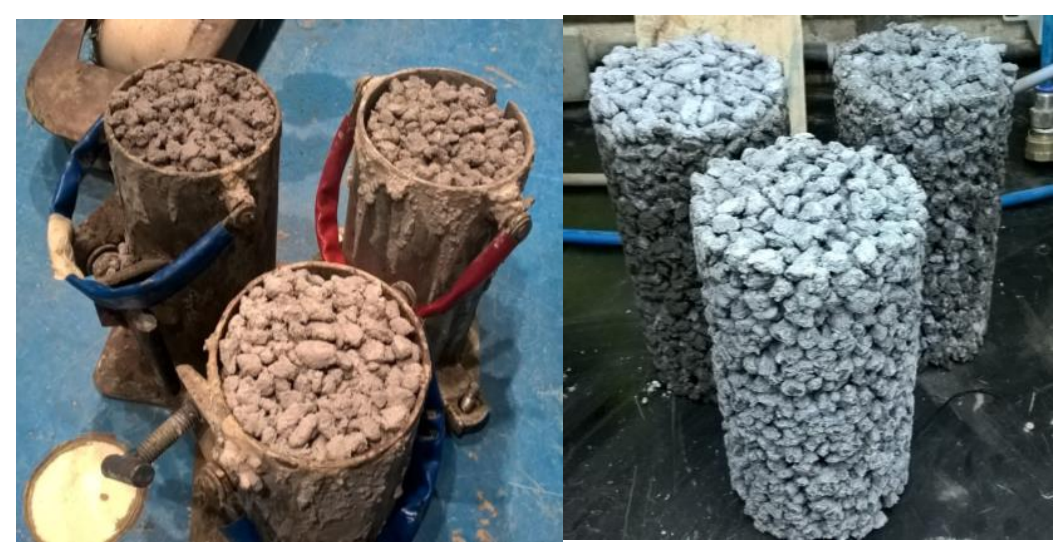

Figura 25 - Amostras do ensaio de resistência à compressão para T6 e T7

No ensaio de resistência à tração na flexão foram empregadas 3 fôrmas prismáticas de seção transversal de $10 \times 10 \mathrm{~cm}$ e comprimento de $40 \mathrm{~cm}$ para cada traço estudado, conforme Figura 26. O concreto foi lançado em 3camadas e em cada uma delas foram dados 30 golpes, utilizando-se um bastão metálico visando mínima compactação possível, a fim de assegurar a estrutura de vazios.

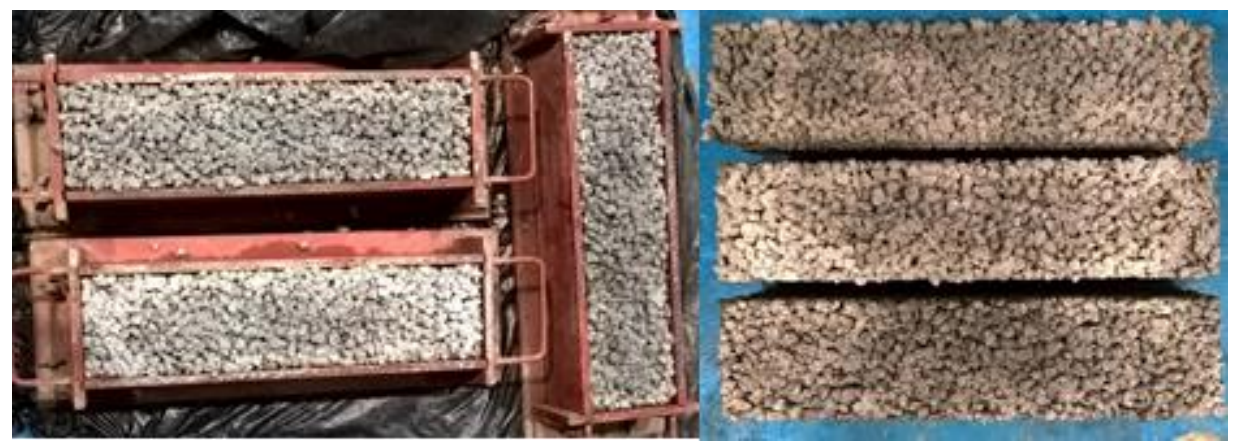

Figura 26 - Amostras do ensaio de resistência à compressão para T6 e T7

A moldagem das amostras para o ensaio de permeabilidade e os procedimentos de desmoldagem e cura foram realizados conforme relatado para as amostras dos traços T1 a T5.

\section{4}

\section{Ensaios}

A seguir serão descritos os procedimentos para a realização dos ensaios.

\subsection{1 Massa Específica e Índice de Vazios}

Para o ensaio de massa específica e índice de vazios foram aferidas as massas da amostra na condição saturada, ao final do ensaio de permeabilidade, e 
posteriormente, na condição seca, após secá-la em estufa, conforme Figura 27. O ensaio de permeabilidade será descrito no item 3.4.2.
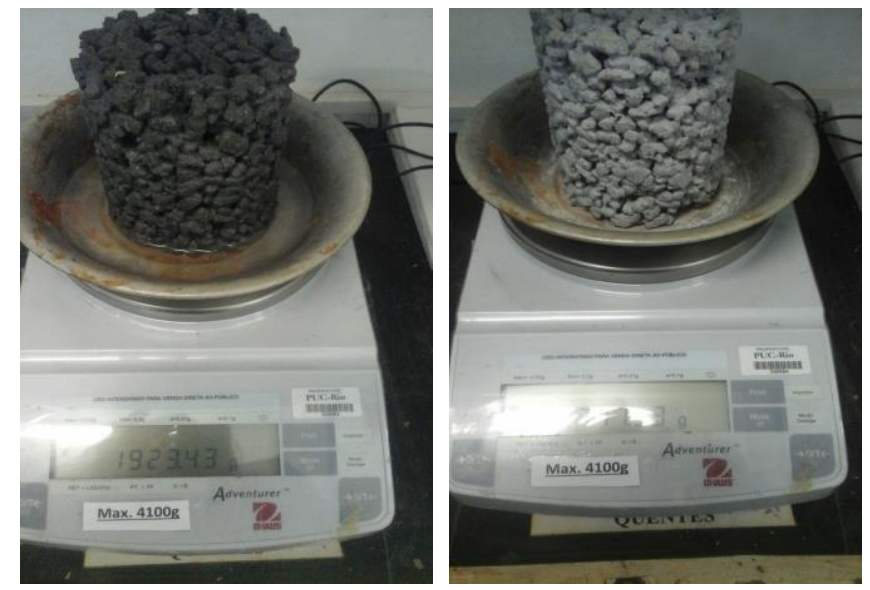

Figura 27 - Aferição da massa da amostra na condição saturada e seca

A massa específica foi obtida através da fórmula (8):

$$
M=\frac{M_{s}}{V}
$$

Onde,

M é a massa específica $\left(\mathrm{kg} / \mathrm{m}^{3}\right)$;

$\mathrm{M}_{\mathrm{s}}$ é a massa seca em estufa, em $\mathrm{kg}$.

V é o volume da amostra $\left(\mathrm{m}^{3}\right)$, o qual foi obtido através da medição com paquímetro das dimensões da amostra.

O índice de vazios foi obtido através de (9) e (10):

$$
V_{v}=\frac{M_{w}-M_{s}}{\rho_{w}}
$$

Onde,

$\mathrm{V}_{\mathrm{v}}$ é o volume de vazios $\left(\mathrm{m}^{3}\right)$;

$\mathrm{M}_{\mathrm{w}}$ é a massa saturada $(\mathrm{kg})$;

$\mathrm{M}_{\mathrm{s}}$ é a massa seca $(\mathrm{kg})$;

$\rho_{w}$ é a massa específica da água $\left(\mathrm{kg} / \mathrm{m}^{3}\right)$

$$
e=\frac{V_{v}}{V_{s}}=\frac{V_{v}}{V_{t}-V_{v}}
$$


Onde,

e é o índice de vazios (adimensional);

Vv é o volume de vazios $\left(\mathrm{m}^{3}\right)$;

$\mathrm{V}_{\mathrm{s}}$ é o volume de sólidos $\left(\mathrm{m}^{3}\right)$;

$\mathrm{V}_{\mathrm{t}}$ é o volume total da amostra $\left(\mathrm{m}^{3}\right)$;

\subsection{2}

\section{Permeabilidade à Carga Constante}

O ensaio de permeabilidade à carga constante tem como objetivo determinar o coeficiente de permeabilidade das amostras de concreto permeável. O equipamento utilizado foi permeâmetro que consiste em uma câmara, onde fica a amostra; um conjunto de válvulas para controle das pressões de topo, base e confinamento; instrumento para medição de pressão conectado a um software instalado no computador e dois pequenos reservatórios para acúmulo de água - um conectado à base e outro, ao topo. Os elementos descritos podem ser visualizados na Figura 28.

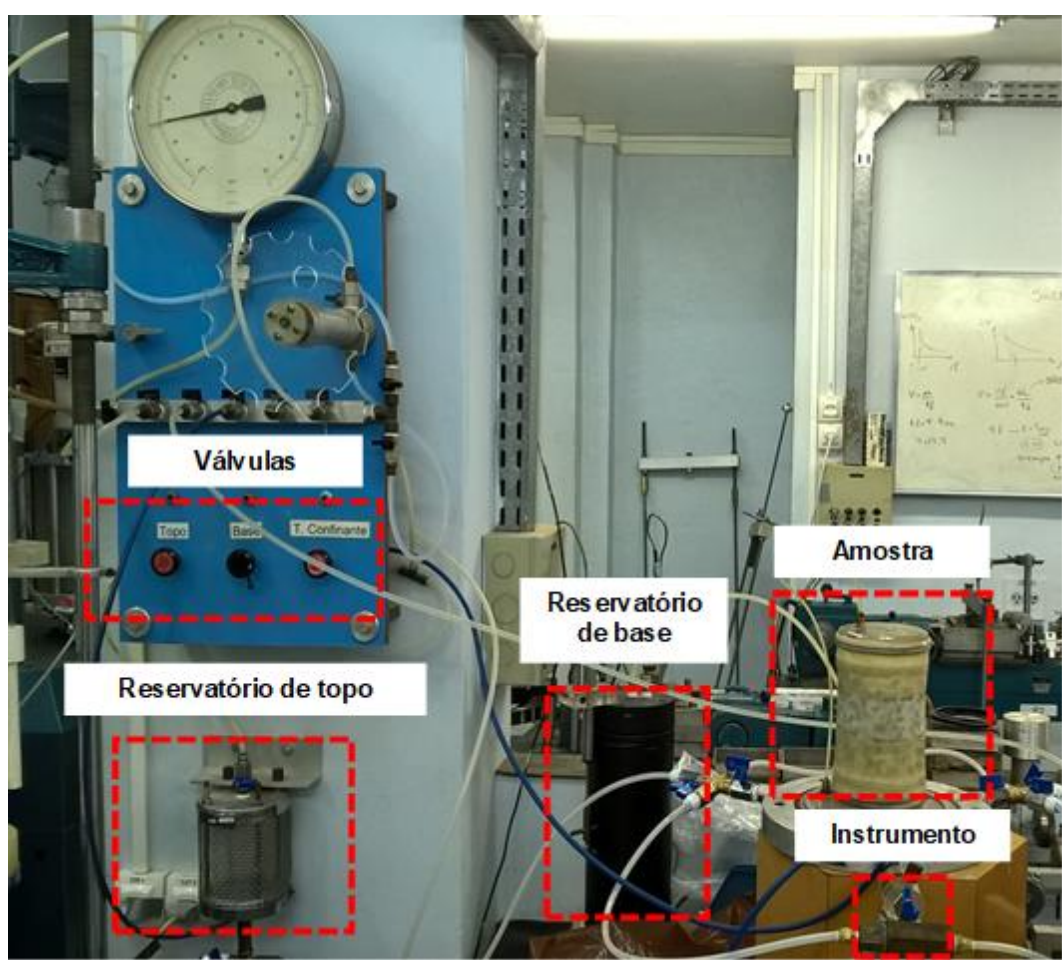

Figura 28 - Permeâmetro de carga constante 
Devido à dificuldade de nivelamento dos topos das amostras durante a moldagem, foi necessário um preparo inicial das amostras para nivelá-las, com auxílio de uma planificadora (Figura 29).

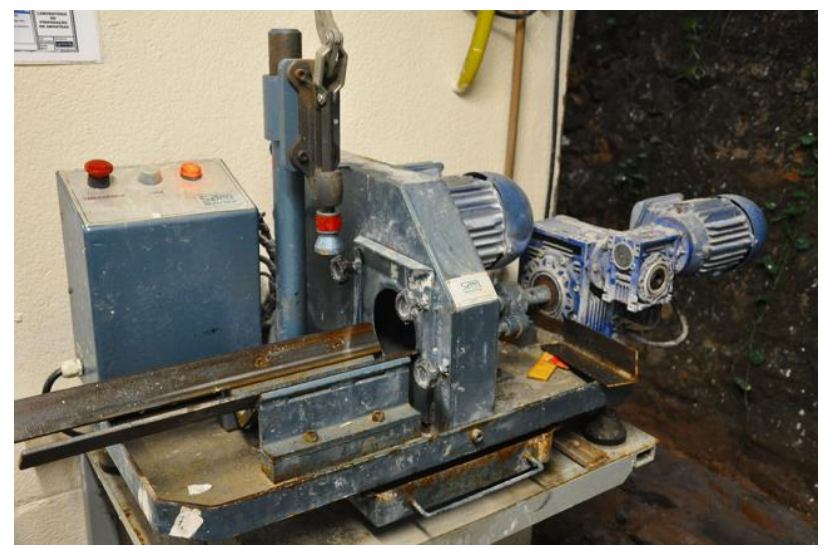

Figura 29 - Planificadora para nivelamento das amostras

As amostras tiveram suas dimensões medidas com auxílio de um paquímetro, devido às possíveis reduções das medidas ocasionadas pela planificadora e deformações existentes nas fôrmas utilizadas.

Para montagem do ensaio de permeabilidade inicialmente foram colocadas pedras porosas e papéis filtro no topo e na base do corpo de prova, conforme demonstrado na Figura 30. Esse mesmo procedimento é realizado para amostras de solos. As funções da pedra porosa são receber o fluxo de água concentrado e distribuir para amostra, já as funções do papel filtro são filtrar e impedir o transporte de finos.

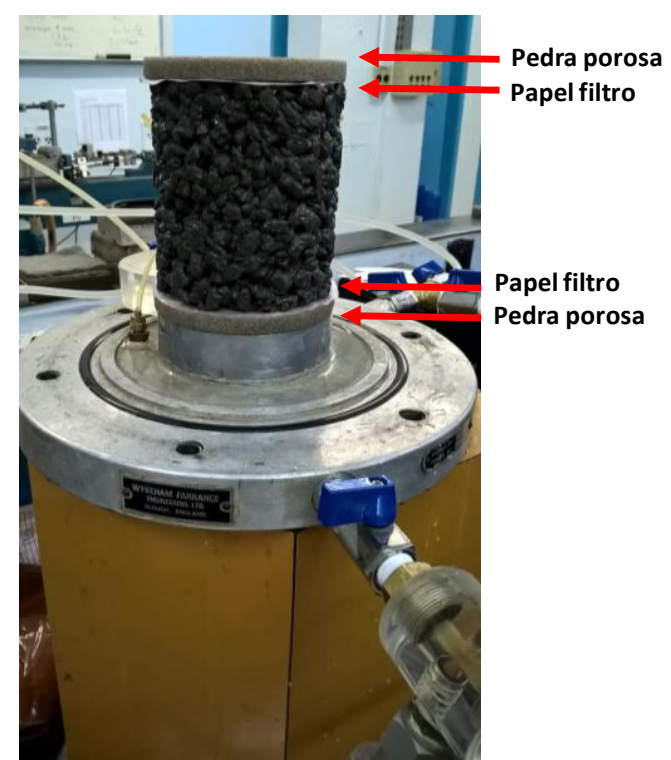

Figura 30 - Pedra porosa e papel filtro na base e no topo 
No entanto, foi observado que os resultados obtidos de coeficiente de permeabilidade foram iguais para todos os diferentes traços estudados, desta forma percebeu-se que a pedra porosa limitava a permeabilidade dos corpos de prova de concreto e os ensaios tiveram que ser refeitos sem a pedra porosa e o papel filtro.

As amostras tiveram suas laterais vedadas através da colocação de uma membrana impermeável a fim de evitar a entrada de água pelas laterais, conforme Figura 31.

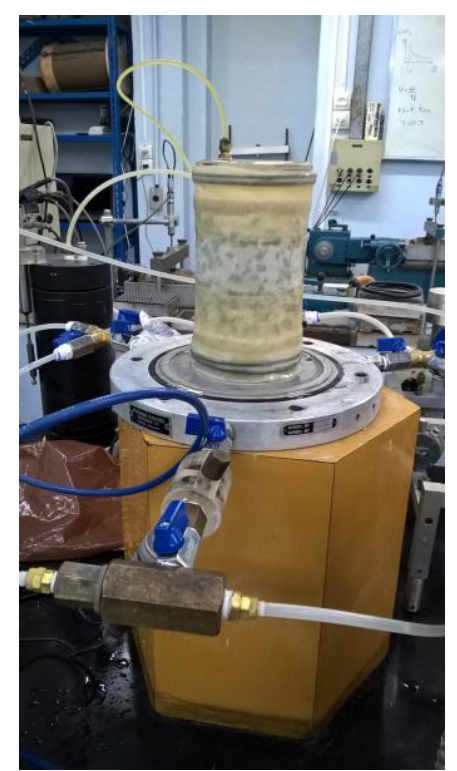

Figura 31 - Vedação das laterais com manta impermeável

A câmara foi tampada, através da colocação da sua célula, e o equipamento foi preenchido com água, conforme Figura 32.

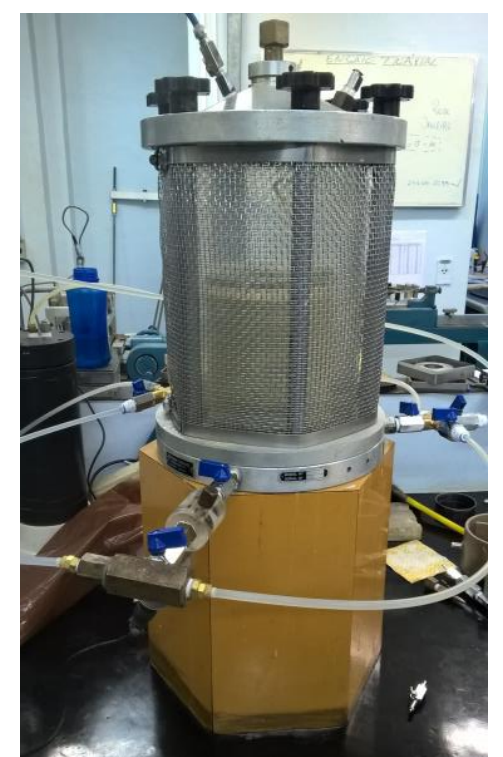

Figura 32 - Permeâmetro com câmara tampada 
O ensaio foi iniciado a partir da aplicação da tensão confinante e da leitura da poro-pressão até a amostra chegar à condição de saturação, a qual é verificada quando a variação da poro-pressão dividida pela variação da tensão confinante imposta à amostra é próxima a 1.

Já no estado de saturação, foi imposta uma pressão maior na base e uma pressão menor no topo da amostra, a fim de estabelecer um fluxo ascendente de água através da amostra.

Desta maneira, um volume conhecido de água do reservatório foi percolado na amostra em um determinado intervalo de tempo e carga hidráulica, os quais foram registrados pelo software do computador conectado ao equipamento.

A partir dos dados obtidos no ensaio, os cálculos para determinação do coeficiente de permeabilidade foram obtidos através da Lei de Darcy, conforme a equação abaixo:

$$
k=\frac{Q \times L}{A \times h}
$$

Onde,

$\mathrm{k}$ é o coeficiente de permeabilidade $(\mathrm{cm} / \mathrm{s})$;

Q é a vazão $\left(\mathrm{cm}^{3} / \mathrm{s}\right)$, a qual foi obtida pela diferença de volume inicial e final e o intervalo de tempo registrados;

Lé a altura da amostra (cm);

t é o intervalo de tempo em que determinado volume é passado na amostra, em s.

A é a área da seção transversal da amostra $\left(\mathrm{cm}^{2}\right)$;

h é a carga hidráulica $(\mathrm{cm})$, a qual foi obtida pela diferença entre as pressões aplicadas no topo e na base da amostra.

\subsection{3}

\section{Resistência à Compressão}

O ensaio de resistência à compressão uniaxial foi realizado em uma prensa hidráulica, demonstrada na Figura 33, conectada à um software para aquisição de dados. A taxa de deslocamento da célula de carga foi de $0,5 \mathrm{~mm} / \mathrm{min}$. 


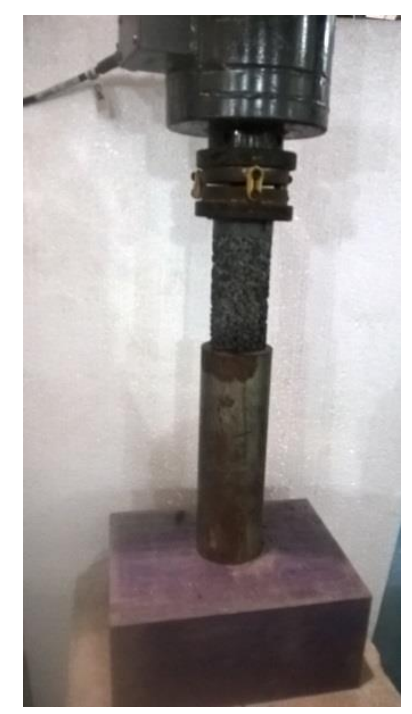

Figura 33 - Ensaio de resistência à compressão

Os resultados do ensaio foram tempo, em s; força axial, em $\mathrm{kN}$; e deslocamento axial, em mm. A partir desses dados, foram realizados os seguintes cálculos, a partir de (12) e (13) a fim de obter gráficos de tensão de compressão versus deformação longitudinal:

$$
\varepsilon=\frac{\Delta l}{L}
$$

Onde,

$\varepsilon$ é a deformação longitudinal (grandeza adimensional);

$\Delta \mathrm{L}$ é a variação do comprimento longitudinal da amostra $(\mathrm{m})$;

Lé o comprimento da amostra (m);

$$
\sigma=\frac{F}{A}
$$

Onde,

$\sigma$ é a tensão de compressão $(\mathrm{kPa})$;

F é a força axial $(\mathrm{kN})$;

A é a área da seção transversal $\left(\mathrm{m}^{2}\right)$.

Devido à dificuldade de nivelamento da superfície das amostras, antes dos ensaios, os corpos de provas foram nivelados com massa adesiva plástica cinza, a fim de evitar a concentração de tensões. 


\subsection{4 Resistência à Tração na Flexão}

Foram realizados os ensaios de resistência à tração na flexão do tipo 3 pontos em uma prensa hidráulica conectada à um software para a aquisição de dados.

O ensaio de flexão em 3 pontos consistiu em aplicar uma carga crescente no meio do vão da amostra bi apoiada, com controle de deslocamento numa taxa de $0,2 \mathrm{~mm} / \mathrm{min}$, gerando uma flecha no meio do vão, a qual foi medida através de dois transdutores de deslocamento tipo LVDT.

Devido às diferentes dimensões dos corpos de prova para as misturas T2 a T5, foi montado um sistema em que a distância entre os apoios foi de $14 \mathrm{~cm}$; e para T6 e T7, a referida distância foi de $34 \mathrm{~cm}$. Os corpos de prova tiveram que ser nivelados através de massa plástica a fim de evitar a concentração de tensões e fixar a placa metálica a qual serviu de apoio para instalação dos LVDTs, conforme ilustrado na Figura 34.

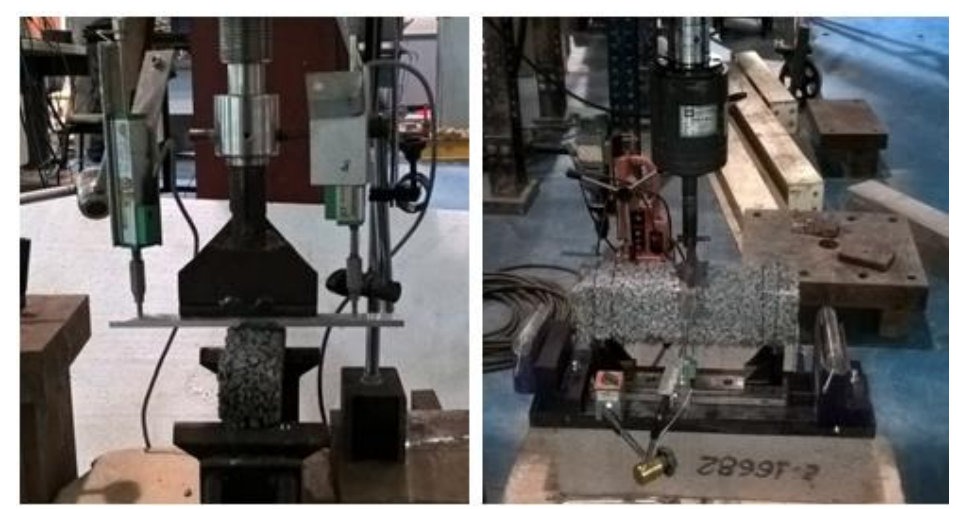

Figura 34 - Ensaio de resistência à tração na flexão em 3 pontos

Os resultados do ensaio foram: tempo, em s; força axial, em kN; deflexão medida pelo LVDT 1, em mm; e deflexão medida pelo LVDT 2, em mm. A partir desses dados, foram realizados os seguintes cálculos, a partir das equações (14) e (15), a fim de obter gráficos de tensão versus deformação.

$$
v=\frac{v_{1}+v_{2}}{2}
$$

Onde,

$v$ é a deflexão média (mm);

$v_{1}$ é a deflexão medida pelo LVDT 1 (mm);

$v_{2}$ é a deflexão medida pelo LVDT 2 (mm). 


$$
\sigma=\frac{M y}{I}
$$

Onde,

$\sigma$ é a tensão de resistência à flexão $(\mathrm{kPa})$;

M é o momento fletor, em $\mathrm{kNm}$, obtido pela força aplicada no meio do vão multiplicada pela distância entre os apoios dividida por 4 .

y é a linha neutra, obtida pela dimensão da seção transversal quadrada dividida por $2, \mathrm{em} \mathrm{m}$.

I é o momento de inércia da seção transversal quadrada, $\mathrm{em}^{4}$. Obtido pela medida do lado do quadrado elevado a 4 e dividida por 12 . 


\section{4 \\ Resultados do Estudo Experimental}

Neste capítulo serão apresentados os resultados dos ensaios de massa específica, índice de vazios, permeabilidade à carga constante, resistência à compressão e resistência à tração na flexão das amostras T2 a T7, já que as amostras moldadas com traço $\mathrm{T} 1$ foram descartadas, uma vez que houve muita perda de grãos apenas ao serem manipuladas.

Essa desintegração pode ser justificada devido ao pouco volume de pasta para promover a ligação entre os grãos, já que foram utilizados baixos teor de cimento $(10 \%)$ e fator água cimento $(0,25)$ e alto teor de agregado em relação ao cimento $(8,75: 1)$, conforme apresentado na Tabela 10.

Para fins de comparação e registro da desintegração do corpo de prova, na Figura 35 são apresentados dois corpos de prova: o da esquerda é a amostra T1 e o da direita, a T5. A perda de material da amostra T1 está assinalada em vermelho. Desta forma, a amostra T1 foi descartada antes da realização dos ensaios.

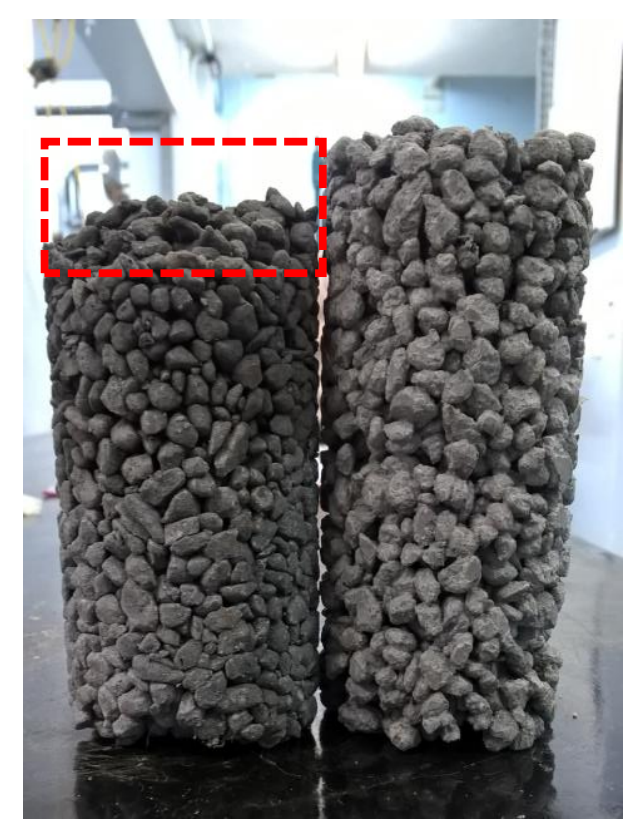

Figura 35 - Comparação entre as amostras T1 e T5 


\section{1 Massa Específica e Índice de vazios}

Os valores de massa específica encontrados variaram entre 1.610,13 a $1.822,84 \mathrm{~kg} / \mathrm{m}^{3}$. Os resultados obtidos ficaram dentro do intervalo esperado -1600 a $2000 \mathrm{~kg} / \mathrm{m}^{3}$, segundo revisão bibliográfica (descrito no item 2.2.1.3).

Os valores obtidos de índice de vazios variaram entre 0,078 a 0,275, conforme apresentado na Tabela 12.

As misturas T2 a T5 apresentaram índice de vazios abaixo do limite inferior do intervalo esperado para o concreto permeável de $15 \%$ a $40 \%$, segundo revisão bibliográfica (descrito no item 2.2.1.3). Isso ocorreu devido a faixa granulométrica dos agregados ser composta por pequenos diâmetros. Já as misturas T6 e T7 apresentaram valores de índices de vazios coerentes com os indicados na bibliografia.

Os resultados individuais das amostras, a média, o desvio padrão e o coeficiente de variação (CV) de cada traço estudado estão apresentados na Tabela 11 e na Tabela 12.

Tabela 11 - Resultados do ensaio de massa específica

\begin{tabular}{|c|c|c|c|c|c|c|}
\hline \multirow{2}{*}{ Traço } & \multicolumn{5}{|c|}{ Massa Específica $\left(\mathrm{kg} / \mathrm{m}^{3}\right)$} & \multirow{2}{*}{$\mathrm{CV}$} \\
\hline & M1 & M2 & M3 & Média & Desvio Padrão & \\
\hline $\mathrm{T} 2$ & 1584,65 & 1640,18 & 1605,57 & 1610,13 & 28,04 & $1,74 \%$ \\
\hline $\mathrm{T} 3$ & 1689,59 & 1676,86 & 1624,65 & 1663,70 & 34,41 & $2,07 \%$ \\
\hline $\mathrm{T} 4$ & 1708,69 & 1751,98 & 1694,68 & 1718,45 & 29,87 & $1,74 \%$ \\
\hline T5 & 1778,72 & 1832,19 & 1810,55 & 1807,15 & 26,90 & $1,49 \%$ \\
\hline T6 & 1838,21 & 1823,70 & 1806,62 & 1822,84 & 15,81 & $0,87 \%$ \\
\hline $\mathrm{T7}$ & 1694,50 & 1735,00 & 1708,00 & 1712,50 & 20,62 & $1,20 \%$ \\
\hline
\end{tabular}

Tabela 12 - Resultados do ensaio de índice de vazios

\begin{tabular}{|c|c|c|c|c|c|c|}
\hline \multirow{2}{*}{ Traço } & \multicolumn{5}{|c|}{ Índice de Vazios } & \multirow{2}{*}{$\mathrm{CV}$} \\
\hline & E1 & E2 & E3 & Média & Desvio Padrão & \\
\hline $\mathrm{T} 2$ & 0,075 & 0,077 & 0,081 & 0,078 & 0,003 & $3,93 \%$ \\
\hline $\mathrm{T} 3$ & 0,094 & 0,089 & 0,097 & $\mathbf{0 , 0 9 3}$ & 0,004 & $4,30 \%$ \\
\hline $\mathrm{T} 4$ & 0,094 & 0,099 & 0,101 & $\mathbf{0 , 0 9 8}$ & 0,004 & $3,91 \%$ \\
\hline T5 & 0,125 & 0,129 & 0,136 & 0,130 & 0,006 & $4,28 \%$ \\
\hline T6 & 0,223 & 0,220 & 0,212 & 0,218 & 0,006 & $2,60 \%$ \\
\hline $\mathrm{T} 7$ & 0,285 & 0,268 & 0,271 & 0,275 & 0,009 & $3,30 \%$ \\
\hline
\end{tabular}




\section{2 \\ Permeabilidade}

Os resultados dos coeficientes de permeabilidade para cada amostra ensaiada, o desvio padrão e o coeficiente de variação $(\mathrm{CV})$ de cada traço estudado estão apresentados na Tabela 13. Os valores do coeficiente de permeabilidade encontrados variaram entre $0,014 \mathrm{~cm} / \mathrm{s}$ e $0,323 \mathrm{~cm} / \mathrm{s}$.

Assim como nos resultados dos índices de vazios, as misturas T2 a T5 apresentaram coeficiente de permeabilidade abaixo do limite inferior do intervalo típico para o concreto permeável, que seria entre $0,2 \mathrm{~cm} / \mathrm{s}$ a $0,54 \mathrm{~cm} / \mathrm{s}$, segundo revisão bibliográfica (ver item 2.2.1.3). Novamente, pode-se explicar esse comportamento devido aos pequenos diâmetros da faixa granulométrica dos agregados.

Já as misturas T6 e T7, apresentaram valores de coeficiente de permeabilidade dentro do intervalo esperado.

Tabela 13 - Resultados do ensaio de permeabilidade à carga constante

\begin{tabular}{c|c|c|c|c|c|c}
\hline \multirow{2}{*}{ Traço } & \multicolumn{5}{|c|}{ Coeficiente de permeabilidade $(\mathrm{cm} / \mathrm{s})$} & \multirow{2}{*}{ CV } \\
\cline { 2 - 6 } & $\mathrm{k} 1$ & $\mathrm{k} 2$ & $\mathrm{k} 3$ & Média & Desvio Padrão & \\
\hline T2 & 0,0127 & 0,0136 & 0,0161 & $\mathbf{0 , 0 1 4}$ & 0,002 & $12,46 \%$ \\
\hline T3 & 0,038 & 0,054 & 0,047 & $\mathbf{0 , 0 4 6}$ & 0,008 & $17,31 \%$ \\
\hline T4 & 0,046 & 0,058 & 0,047 & $\mathbf{0 , 0 5 0}$ & 0,007 & $13,14 \%$ \\
\hline T5 & 0,065 & 0,068 & 0,075 & $\mathbf{0 , 0 6 9}$ & 0,005 & $7,40 \%$ \\
\hline T6 & 0,253 & 0,220 & 0,242 & $\mathbf{0 , 2 3 8}$ & 0,017 & $7,05 \%$ \\
\hline T7 & 0,313 & 0,325 & 0,330 & $\mathbf{0 , 3 2 3}$ & 0,009 & $2,71 \%$ \\
\hline
\end{tabular}

A ABNT NBR 16416:2015 exige que o revestimento de concreto permeável tenha coeficiente de permeabilidade maior que $0,10 \mathrm{~cm} / \mathrm{s}$, desta maneira, apenas os traços T6 e T7 atenderiam esse critério e poderiam ser utilizados para construção de pavimentos permeáveis de concreto.

\section{3 Resistência à Compressão}

Os resultados de resistência à compressão, a idade do concreto, a média, o desvio padrão e o coeficiente de variação $(\mathrm{CV})$ de cada traço estudado estão apresentados na Tabela 14. 
Tabela 14 - Resultados do ensaio de resistência à compressão

\begin{tabular}{|c|c|c|c|c|c|c|c|}
\hline \multirow[b]{2}{*}{ Traço } & \multirow{2}{*}{$\begin{array}{c}\text { Idade do } \\
\text { Concreto } \\
\text { (dias) }\end{array}$} & \multicolumn{5}{|c|}{ Resistência à Compressão (MPa) } & \multirow[b]{2}{*}{$\mathrm{CV}$} \\
\hline & & $\mathrm{C} 1$ & $\mathrm{C} 2$ & $\mathrm{C} 3$ & Média & $\begin{array}{l}\text { Desvio } \\
\text { Padrão }\end{array}$ & \\
\hline $\mathrm{T} 2$ & 28 & 3,04 & 1,57 & 2,35 & 2,32 & 0,74 & $31,79 \%$ \\
\hline $\mathrm{T} 3$ & 28 & 3,37 & 3,15 & 2,75 & 3,09 & 0,32 & $10,20 \%$ \\
\hline $\mathrm{T} 4$ & 7 & 2,50 & 3,75 & 3,31 & 3,19 & 0,63 & $19,83 \%$ \\
\hline T5 & 7 & 4,32 & 5,57 & 4,18 & 4,69 & 0,77 & $16,33 \%$ \\
\hline T6 & 7 & 5,84 & 4,11 & 3,97 & 4,64 & 1,04 & $22,42 \%$ \\
\hline $\mathrm{T} 7$ & 7 & 3,90 & 4,58 & 3,87 & 4,12 & 0,40 & $9,76 \%$ \\
\hline
\end{tabular}

Durante os ensaios de resistência à compressão, foi observado que o rompimento do concreto poroso se deu na região da pasta de cimento entre os agregados, conforme ilustrado na Figura 36. Este comportamento já era esperado, pois já havia sido descrito por Mulligan (2003), em que foi constatado que a resistência da ligação é mais fraca do que a resistência da pasta e a do agregado.

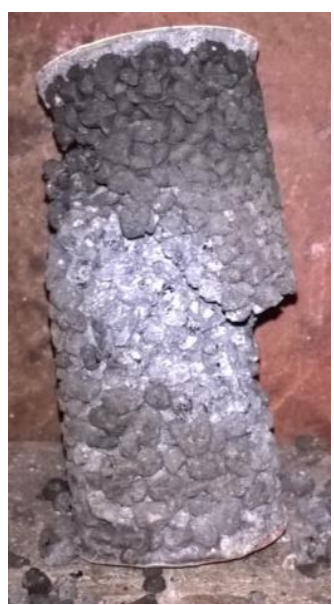

Figura 36 - Rompimento da amostra no ensaio de resistência à compressão

Os ensaios das amostras T2 e T3 foram realizados aos 28 dias de idade do concreto, já as amostras T4 a T7 foram ensaiadas aos 7 dias.

A fim de analisar os resultados utilizando a mesma base de comparação, seguindo recomendações da ABNT NBR 6118/2014, os resultados das amostras T2 a T3 ensaiadas aos 7 dias foram convertidos para 28 dias através da equação (16).

$$
\beta_{1}=e^{\left\{s\left(1-\left(\frac{28}{t}\right)^{1 / 2}\right)\right\}}
$$

Onde,

s é igual a 0,38 para concreto de cimento CPIII e IV;

s é igual a 0,25 para concreto de cimento CPI e II; 
sé igual a 0,20 para concreto de cimento CPV - ARI;

t é igual a idade do concreto (dias);

O cimento utilizado foi o cimento CPII-E, então foi adotado o valor de 0,25 para o parâmetro s. Os resultados obtidos estão apresentados na Tabela 15.

Tabela 15 - Resultados da resistência à compressão aos 28 dias

\begin{tabular}{c|c|c|c|c|c}
\hline \multirow{2}{*}{ Traço } & \multirow{2}{*}{$\begin{array}{c}\text { Idade do } \\
\text { Concreto } \\
\text { (dias) }\end{array}$} & $\mathrm{s}$ & $\beta 1$ & $\begin{array}{c}\text { Resultados } \\
\text { médios do } \\
\text { ensaio }\end{array}$ & $\begin{array}{c}\text { Resultados aos 28 } \\
\text { dias }\end{array}$ \\
\cline { 5 - 6 } & 28 & 0,25 & 1,00 & 2,32 & 2,32 \\
\hline T2 & 28 & 0,25 & 1,00 & 3,09 & 3,09 \\
\hline T3 & 7 & 0,25 & 0,78 & 3,19 & 4,09 \\
\hline T4 & 7 & 0,25 & 0,78 & 4,69 & 6,02 \\
\hline T5 & 7 & 0,25 & 0,78 & 4,64 & 5,96 \\
\hline T6 & 7 & 0,25 & 0,78 & 4,12 & 5,28 \\
\hline T7 & & & & &
\end{tabular}

Conforme relatado na revisão bibliográfica (item 2.2.1.3), de acordo com Tennis et al (2004), a resistência à compressão do concreto poroso varia entre 3,5 e $28 \mathrm{MPa}$.

As resistências à compressão dos traços estudados ficaram dentro da faixa esperada, com exceção dos resultados dos traços T2 e T3, respectivamente $34 \%$ e $12 \%$ abaixo de 3,5 MPa. Esse resultado pode ser explicado devido ao baixo consumo de cimento na mistura dos traços T2 e T3, 180 e $225 \mathrm{~kg} / \mathrm{m}^{3}$, respectivamente.

Considerando o objetivo de aplicação do concreto permeável em calçadas, não foram utilizados aditivos e nem cimento de melhor desempenho nas misturas, por consequência, esperava-se baixos valores de resistência.

\section{4}

\section{Resistência à Tração na Flexão}

A Tabela 16 apresenta os resultados de resistência à tração na flexão para cada amostra ensaiada, a idade do concreto, a média, o desvio padrão e o coeficiente de variação $(\mathrm{CV})$ de cada traço estudado. 
Tabela 16 - Resultados do ensaio de resistência à tração na flexão

\begin{tabular}{|c|c|c|c|c|c|c|c|}
\hline \multirow[b]{2}{*}{ Traço } & \multirow{2}{*}{$\begin{array}{l}\text { Idade do } \\
\text { Concreto } \\
\text { (dias) }\end{array}$} & \multicolumn{5}{|c|}{ Resistência à Tração na Flexão (MPa) } & \multirow[b]{2}{*}{$\mathrm{CV}$} \\
\hline & & $\mathrm{T} 1$ & $\mathrm{~T} 2$ & $\mathrm{~T} 3$ & Média & $\begin{array}{l}\text { Desvio } \\
\text { Padrão }\end{array}$ & \\
\hline $\mathrm{T} 2$ & 28 & 1,30 & 1,08 & 1,30 & 1,23 & 0,13 & $10,31 \%$ \\
\hline T3 & 28 & 1,53 & 1,58 & 1,32 & 1,48 & 0,14 & $9,43 \%$ \\
\hline $\mathrm{T} 4$ & 7 & 1,13 & 1,21 & 1,18 & 1,18 & 0,04 & $3,31 \%$ \\
\hline T5 & 7 & 1,85 & 1,93 & 1,46 & 1,75 & 0,25 & $14,57 \%$ \\
\hline T6 & 7 & 1,48 & 1,96 & 1,48 & 1,64 & 0,28 & $16,80 \%$ \\
\hline $\mathrm{T} 7$ & 7 & 1,32 & 1,22 & 1,39 & 1,31 & 0,09 & $6,62 \%$ \\
\hline
\end{tabular}

Idêntico ao observado nos ensaios de resistência à compressão, o rompimento do concreto poroso durante os ensaios de resistência à tração na flexão também ocorreu na região da pasta de cimento entre os agregados, de acordo com o esperado, conforme pode ser constatado na Figura 37.

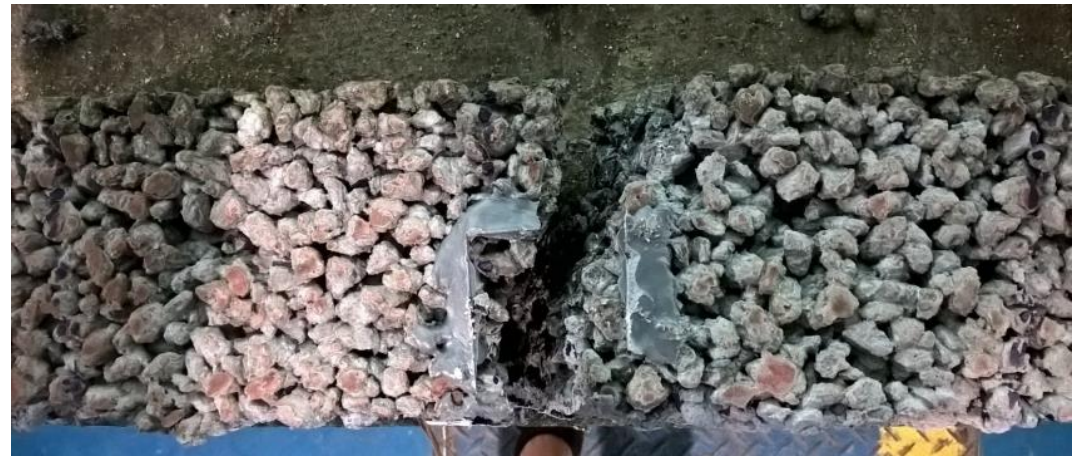

Figura 37 - Rompimento da amostra no ensaio de resistência à tração

Assim como no tratamento dos dados de resistência à compressão, os valores de resistência à tração na flexão dos ensaios aos 7 dias foram convertidos para 28 dias. Os resultados obtidos estão apresentados na Tabela 17.

Tabela 17 - Resultados da resistência à tração na flexão aos 28 dias

\begin{tabular}{c|c|c|c|c|c}
\hline & \multirow{2}{*}{ Traço } & \multirow{2}{*}{$\begin{array}{c}\text { Idade do } \\
\text { Concreto } \\
\text { (dias) }\end{array}$} & \multicolumn{3}{|c}{ Resistência à Tração na Flexão (MPa) } \\
\cline { 3 - 6 } & & $\mathrm{s}$ & $\beta 1$ & Média & $\begin{array}{c}\text { Resultados aos } \\
28 \text { dias }\end{array}$ \\
\hline T2 & 28 & 0,25 & 1,00 & 1,23 & 1,23 \\
\hline T3 & 28 & 0,25 & 1,00 & 1,48 & 1,48 \\
\hline T4 & 7 & 0,25 & 0,78 & 1,18 & $\mathbf{1 , 5 1}$ \\
\hline T5 & 7 & 0,25 & 0,78 & 1,75 & $\mathbf{2 , 2 5}$ \\
\hline T6 & 7 & 0,25 & 0,78 & 1,64 & $\mathbf{2 , 1 1}$ \\
\hline T7 & 7 & 0,25 & 0,78 & 1,31 & $\mathbf{1 , 6 8}$ \\
\hline
\end{tabular}


Segundo descrito na revisão bibliográfica (item 2.2.1.3), a resistência à flexão no concreto poroso varia entre 1 e 3,8 $\mathrm{MPa}$.

As resistências à compressão dos traços estudados ficaram dentro da faixa esperada, porém próximas ao limite inferior.

A ABNT NBR 16416:2015 orienta que a resistência à tração na flexão para o concreto permeável moldado no local para tráfego de pedestres deve ser acima de $1 \mathrm{MPa}$. Considerando somente esse critério, seria possível aplicar todos os traços estudados em calçadas.

\section{5}

\section{Relação entre parâmetros}

A Tabela 18 apresenta um resumo dos resultados dos ensaios. No presente item serão discutidas as relações entre os parâmetros obtidos e as características das misturas estudadas, as quais foram apresentadas na Tabela 10.

\begin{tabular}{c|c|c|c|c|c}
\multicolumn{2}{c}{} & Tabela 18- Resumo dos resultados dos ensaios. & & \\
Traço & $\begin{array}{c}\text { Massa } \\
\text { Específica }\end{array}$ & $\begin{array}{c}\text { Índice de } \\
\text { Vazios }\end{array}$ & $\begin{array}{c}\text { Coeficiente de } \\
\text { permeabilidade }\end{array}$ & $\begin{array}{c}\text { Resistência à } \\
\text { Compressão aos } \\
28 \text { dias }\end{array}$ & $\begin{array}{c}\text { Resistência à } \\
\text { Tração na } \\
\text { Flexão aos } 28 \\
\text { dias }\end{array}$ \\
\cline { 2 - 6 } & $\mathrm{kg} / \mathrm{m}^{3}$ & $\%$ & $\mathrm{~cm} / \mathrm{s}$ & $\mathrm{MPa}$ & $\mathrm{MPa}$ \\
\hline T1* & - & - & - & - & - \\
\hline T2 & $\mathbf{1 6 1 0 , 1 3}$ & $\mathbf{7 , 8}$ & $\mathbf{0 , 0 1}$ & $\mathbf{2 , 3 2}$ & $\mathbf{1 , 2 3}$ \\
\hline T3 & $\mathbf{1 6 6 3 , 7 0}$ & $\mathbf{9 , 3 \%}$ & $\mathbf{0 , 0 5}$ & $\mathbf{3 , 0 9}$ & $\mathbf{1 , 4 8}$ \\
\hline T4 & $\mathbf{1 7 1 8 , 4 5}$ & $\mathbf{9 , 8 \%}$ & $\mathbf{0 , 0 5}$ & $\mathbf{4 , 0 9}$ & $\mathbf{1 , 5 1}$ \\
\hline T5 & $\mathbf{1 8 0 7 , 1 5}$ & $\mathbf{1 3 , 0 \%}$ & $\mathbf{0 , 0 7}$ & $\mathbf{6 , 0 2}$ & $\mathbf{2 , 2 5}$ \\
\hline T6 & $\mathbf{1 8 2 2 , 8 4}$ & $\mathbf{2 1 , 8 \%}$ & $\mathbf{0 , 2 4}$ & $\mathbf{5 , 9 6}$ & $\mathbf{2 , 1 1}$ \\
\hline T7 & $\mathbf{1 7 1 2 , 5 0}$ & $\mathbf{2 7 , 5 \%}$ & $\mathbf{0 , 3 2}$ & $\mathbf{5 , 2 8}$ & $\mathbf{1 , 6 8}$ \\
\hline
\end{tabular}

\subsection{1}

\section{Massa Específica e Índice de Vazios}

Com base nos resultados expostos no Gráfico 3 para os traços T2 a T7, observou-se que os valores de massa específica obtidos das amostras apresentam forte correlação com os teores de agregado em relação ao cimento $\left(R^{2}>0,90\right)$. Foi observado que quanto menor o teor de agregado em relação ao cimento, maior a massa específica.

Durante o preparo das amostras, observou-se que os traços com alto teor de agregado em relação ao cimento, portanto apresentando baixo volume de pasta de 
cimento, eram de difícil manipulação, impossibilitando que os grãos fossem melhor compactados durante a etapa de moldagem, resultando em menores valores de massa específica.

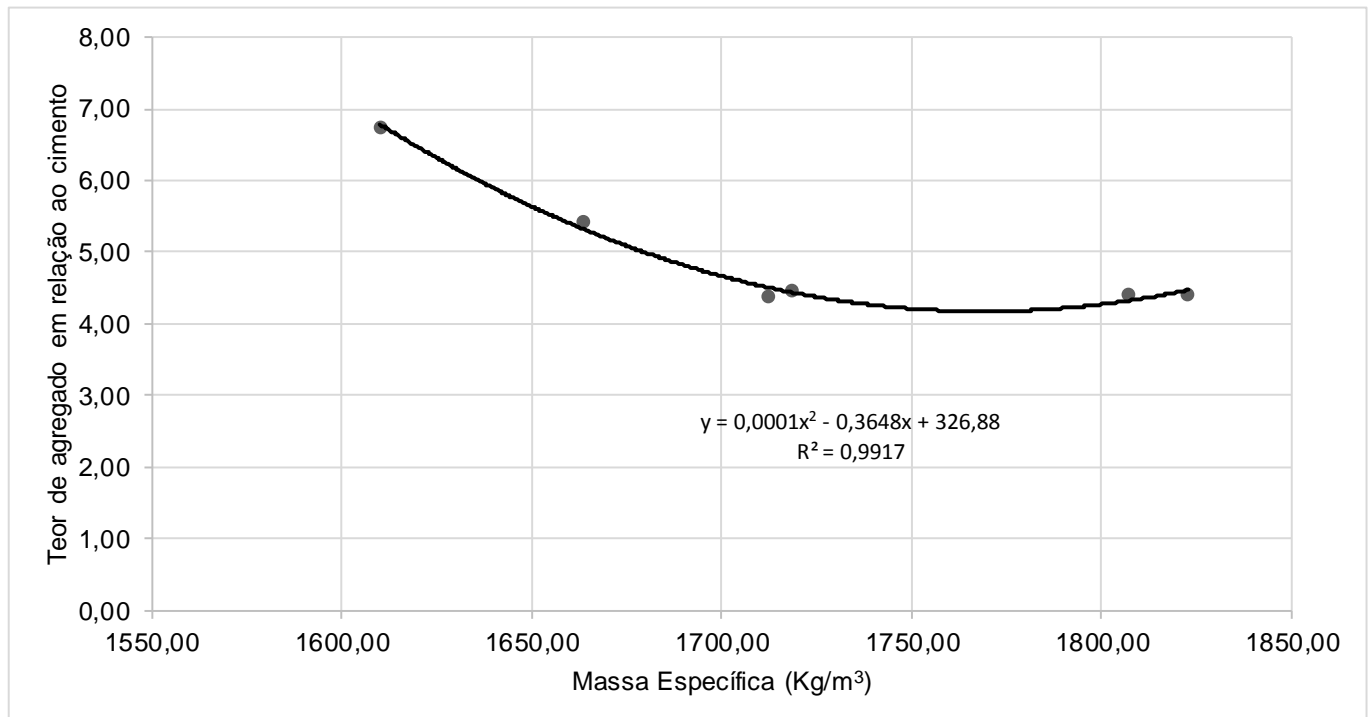

Gráfico 3 - Teor de agregado versus massa específica

O Gráfico 4 apresenta a relação entre a massa específica e o índice de vazios para os traços T2 a T7. Os dados obtidos também demonstram forte correlação $\left(\mathrm{R}^{2}>\right.$ $0,90)$ entre essas duas variáveis.

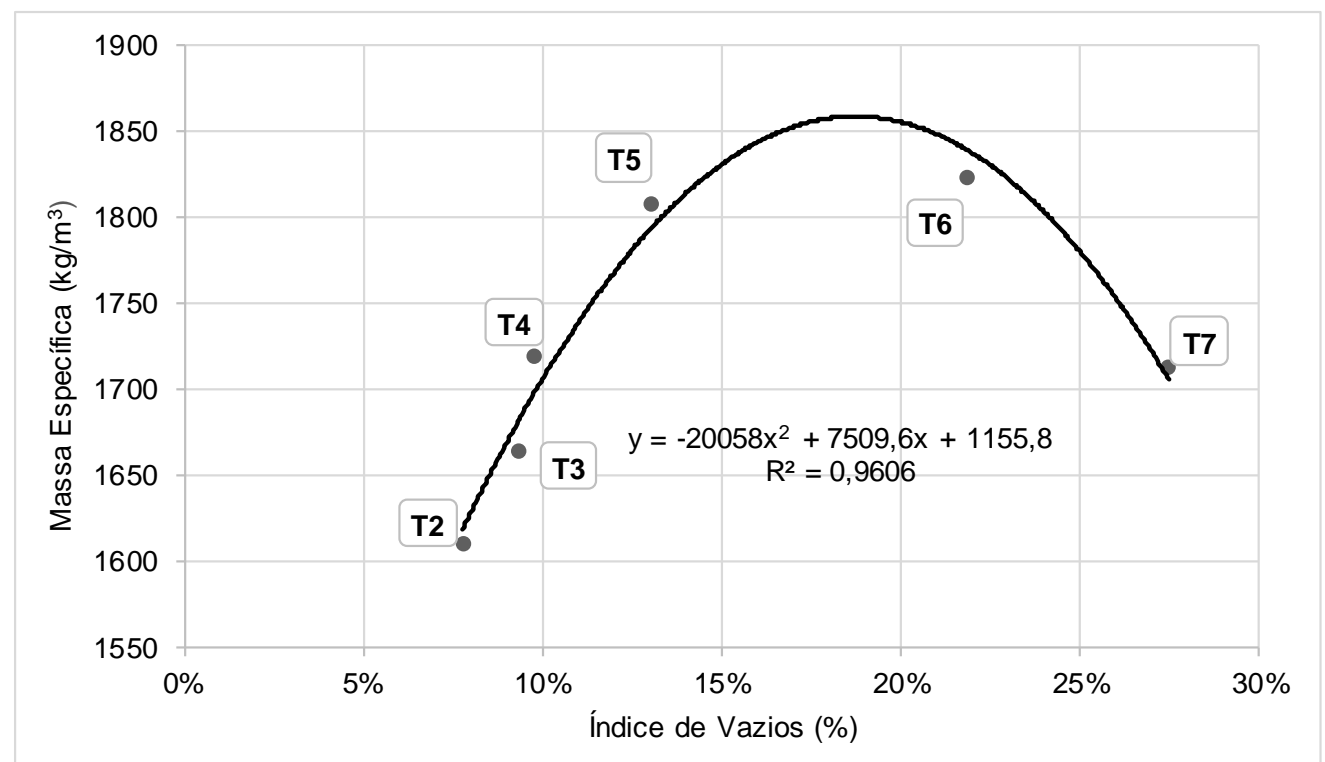

Gráfico 4 - Massa específica versus índice de vazios dos traços T2 a T7

Foi observado que o pouco volume de pasta de cimento causava atrito entre os grãos, dificultando a moldagem dos corpos de prova, desta maneira, o aumento gradual do consumo de cimento e do fator água cimento - aplicados nos traços T2 
a T5 - geraram maior volume de pasta, possibilitando uma compactação mais eficiente para o número padrão de golpes aplicado. $\mathrm{O}$ resultado foi um melhor arranjo entre os agregados e, consequentemente, uma maior massa específica e maior índice de vazios.

A Figura 38 apresenta as amostras T2 a T5. Nota-se que não há uma alteração visual muito significativa da estrutura dos grãos, no entanto o índice de vazios evoluiu de 7,8\% (T2) para 13\% (T5).

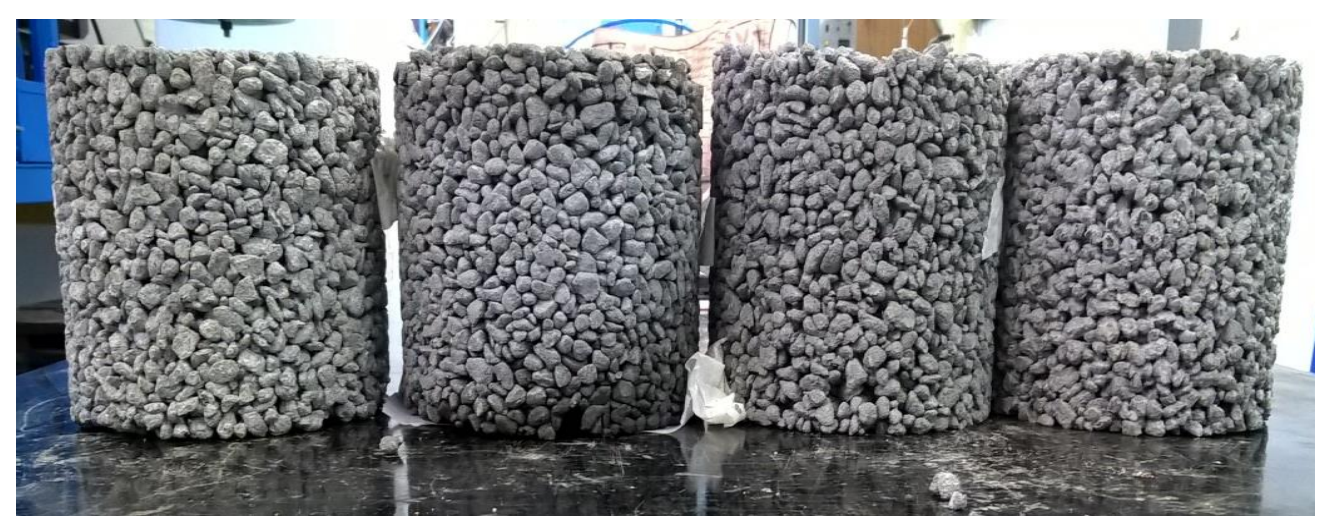

Figura 38 - Comparação entre as amostras T2, T3, T4 e T5, respectivamente

No traço T6, foram mantidas as demais características da mistura T5 e aplicados agregados de diâmetros maiores, resultando em maior índice de vazios e menor massa específica. Já para o traço T7, foram mantidas as demais características da mistura T5 e aumentado o fator água cimento de 0,30 para 0,33, resultando em maior índice de vazios e menor massa específica.

A Figura 39 apresenta as seções transversais dos traços estudados a fim de evidenciar a diferença entre as estruturas de vazios das amostras T2 a T5, nas quais foram utilizados agregados de diâmetros menores que $6,3 \mathrm{~mm}$, e nas amostras T6 e T7 de agregados de diâmetro acima de 6,3 mm. É facilmente perceptível que houve um aumento significativo dos vazios nos traços $\mathrm{T} 6$ e $\mathrm{T} 7$, em relação à $\mathrm{T} 5$. Comparando-se a diferença entre as seções transversais dos traços da seção T6 e $\mathrm{T} 7$, nota-se sutilmente que houve acréscimo dos vazios, devido ao aumento do fator água cimento. 


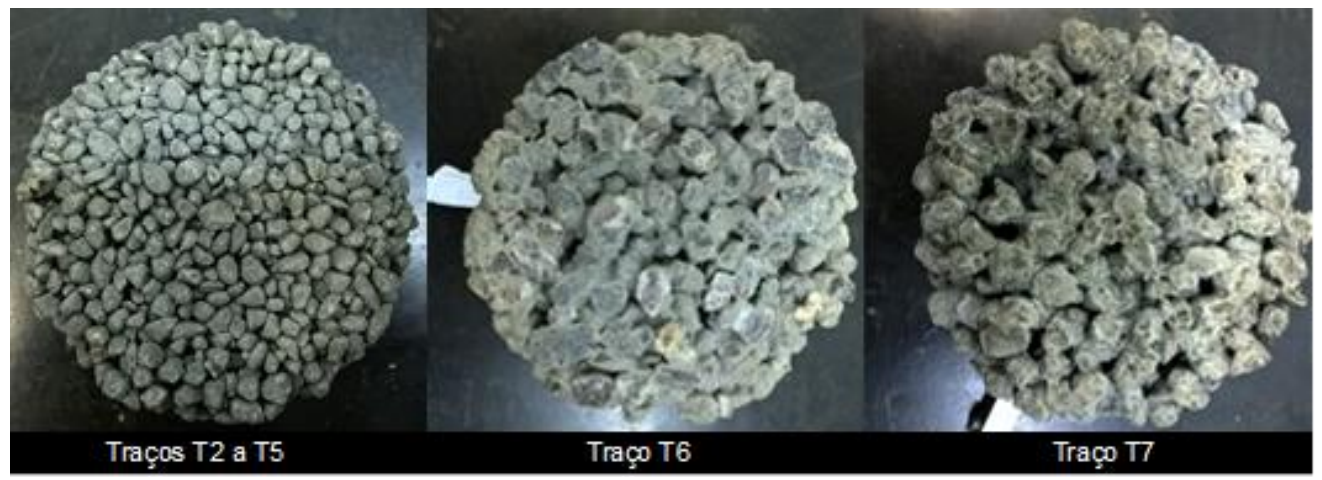

Figura 39 - Comparação entre as seções transversais das amostras T2 e T7

\subsection{2}

\section{Resistências à Compressão e Resistência à Tração na Flexão}

Conforme demonstrado na Tabela 18, o consumo de cimento foi aumentado do traço $\mathrm{T} 2$ a T4, resultando em resistências à compressão e tração na flexão maiores.

O Gráfico 5 apresenta a forte correlação $\left(R^{2}=1\right)$ entre os valores de consumo de cimento $\left(\mathrm{kg} / \mathrm{m}^{3}\right)$ e das resistências à compressão e à tração na flexão (MPa), indicando que o percentual de cimento em relação à massa aumenta as resistências mecânicas.

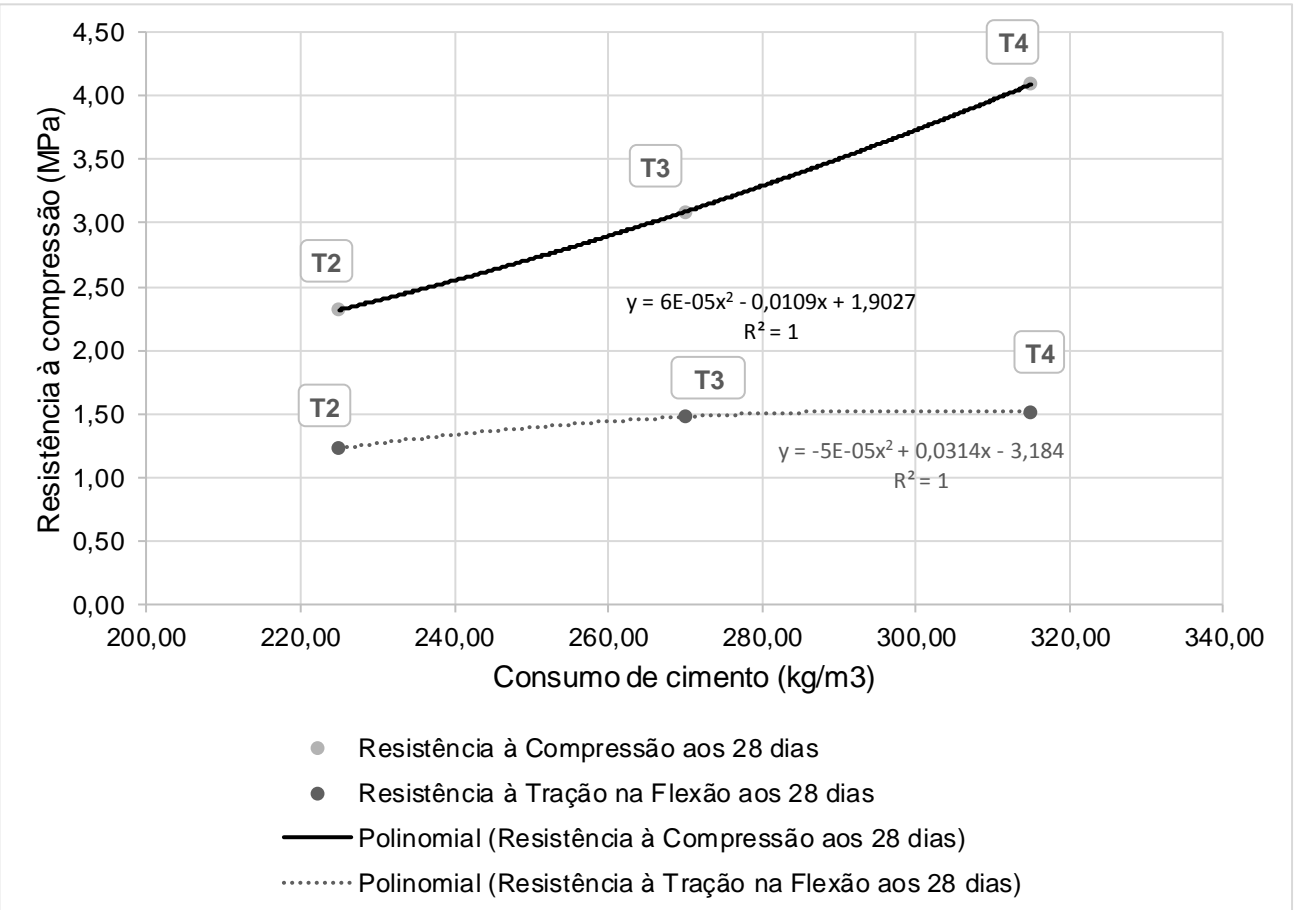

Gráfico 5 - Resistência à compressão versus consumo de cimento -T2 a T4

SegundoYang \& Jiang (2002), as propriedades mecânicas do concreto poroso podem ser aumentadas através da área da pasta de cimento. Nos traços T2 a T5, 
houve aumento do consumo de cimento (T2 a T4) e aumento do fator água cimento (T5), acarretando em maior área de pasta de cimento e, consequentemente, em resistências maiores.

Na mistura T6 apenas foram alterados os diâmetros dos agregados o que resultou em aumento do índice de vazios. Esse resultado era esperado, pois segundo Jain \& Chouhan (2011), mantidas todas as demais características constantes, a resistência varia também com o tamanho do agregado, onde quanto maior o tamanho do grão, menor a resistência. Portanto, conforme o esperado, em T6 houve perda de resistência em relação à amostra T5.

Para a mistura T7 apenas foi aumentado o fator água cimento em relação à T6, todavia dessa vez o aumento do volume de pasta de cimento diminuiu a resistência e aumentou o índice de vazios em relação à T6.

\subsection{3}

\section{Permeabilidade}

O Gráfico 6 apresenta a relação entre o índice de vazios e a permeabilidade medida pelo coeficiente de permeabilidade, onde quanto maior o índice de vazios, maior a permeabilidade. Essas duas variáveis estão fortemente correlacionadas $\left(\mathrm{R}^{2}>0,90\right)$.

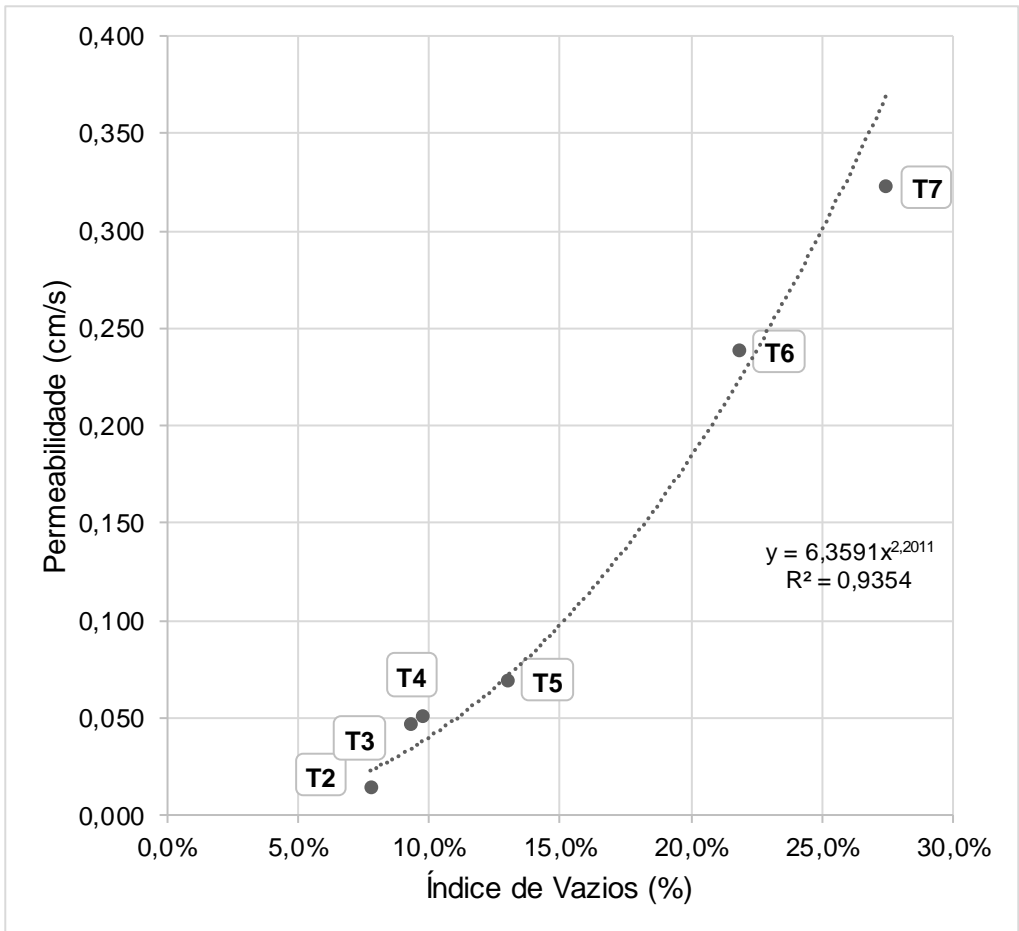

Gráfico 6 - Relação entre a permeabilidade o índice de vazios 
Tal resultado era esperado, uma vez que quanto maior o índice de vazios, maior é a capacidade do concreto de permitir o escoamento de água através dele. O tamanho do diâmetro dos agregados também influencia na permeabilidade do material, onde quanto maior o tamanho dos grãos, maior a permeabilidade. Observou-se que a alteração para agregados de maiores diâmetros resultou em um importante ganho de índice de vazios e, desta forma, em um concreto mais permeável.

O Gráfico 7 mostra o comportamento das resistências à compressão e à tração na flexão com o aumento da permeabilidade do concreto permeável.

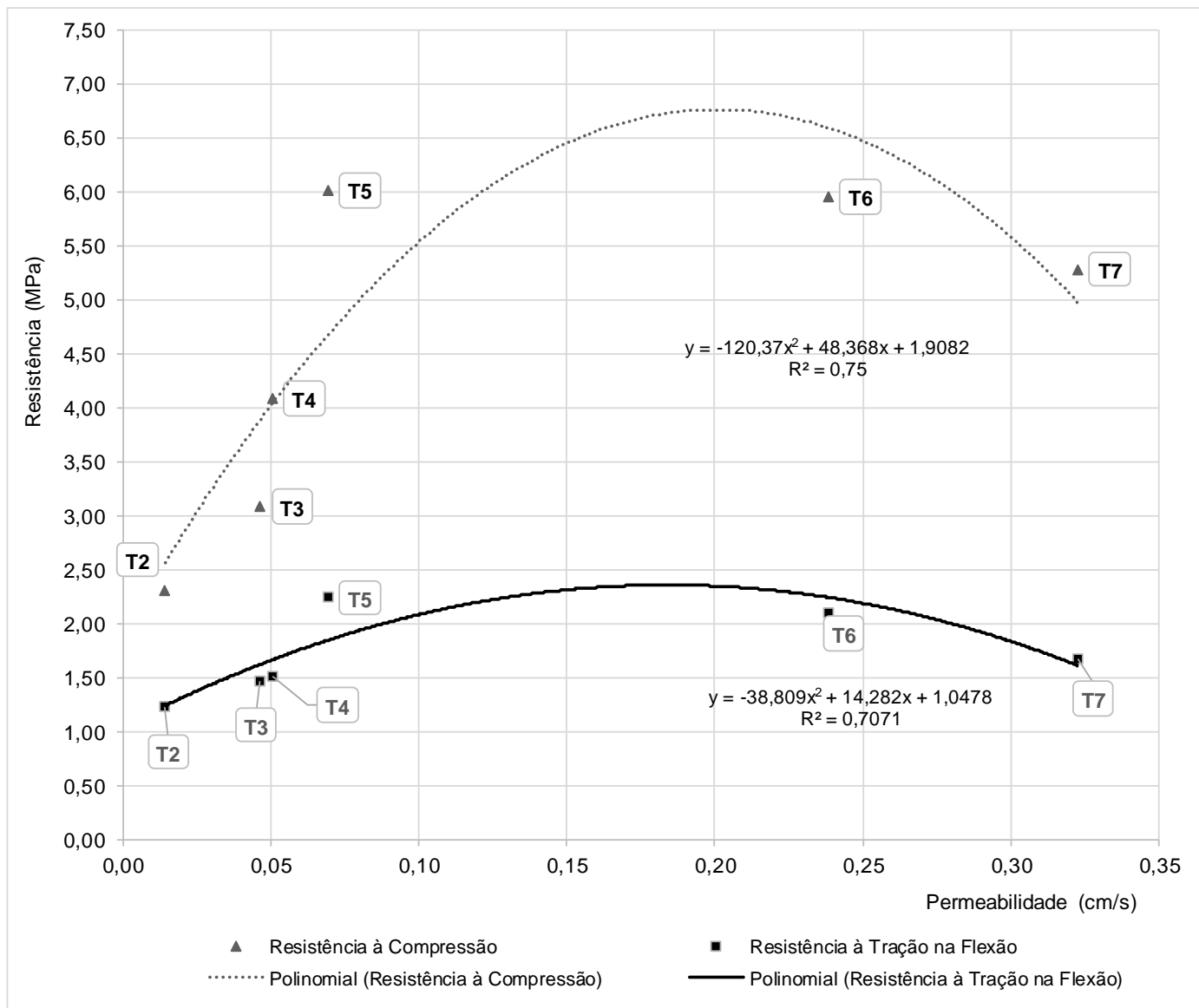

Gráfico 7 - Relação entre as resistências mecânicas e permeabilidade

Conforme já exposto, nos traços T2 a T5 houve aumento do volume da pasta de cimento o que possibilitou um melhor arranjo entre os grãos e aumento das resistências mecânicas, desta maneira houve aumento do índice de vazios e, portanto, da permeabilidade. 
Na mistura T6 foram utilizados agregados de diâmetros maiores o que resultou em uma pequena perda de resistência mecânica, porém em um ganho significativo de permeabilidade em relação ao traço T5.

Para a mistura T7 apenas foi aumentado o fator água cimento, aumentando novamente o volume de pasta, todavia desta vez houve perda significativa de resistência em relação à T6 (11\%), todavia com ganho de cerca de $35 \%$ de permeabilidade. 


\section{5 \\ Estudo de Caso}

\section{1}

\section{Área de estudo}

A bacia do Rio dos Macacos apresenta área total de 9,4 km², sendo composta principalmente pelas sub-bacias do Rio Cabeça, Rio Algodão e Rio dos Macacos, tendo como principal afluente o Rio dos Macacos.

A bacia do Rio dos Macacos, representada na Figura 40, se caracteriza por ter uma área urbana consolidada, predominantemente de uso residencial, ser circundada pelo Maciço da Tijuca e ter como exutório a Lagoa Rodrigo de Freitas.

O Rio dos Macacos e seus afluentes têm suas nascentes na Serra da Carioca, localizada no extremo oriental da Serra da Tijuca, em uma Unidade de Conservação, o Parque Nacional da Tijuca. O início do canal está localizado próximo ao Horto Florestal do Jardim Botânico e segue paralelo à Rua Pacheco Leão em direção ao sul, desaguando na Lagoa Rodrigo de Freitas.

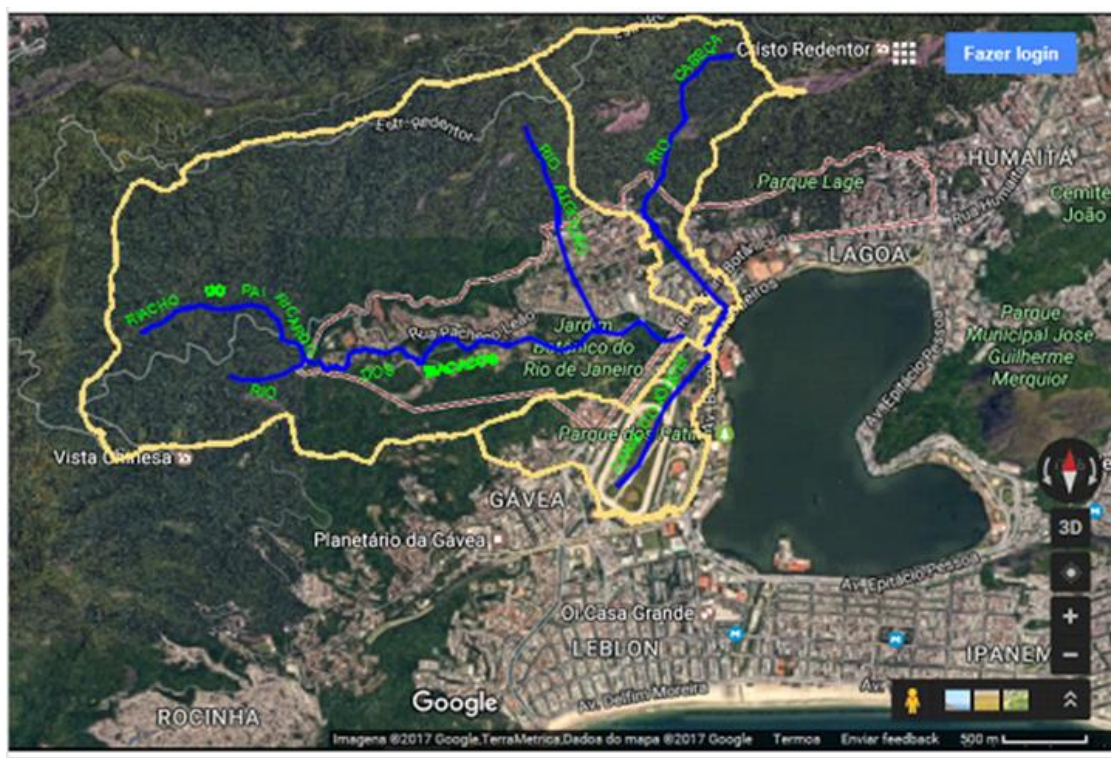

Fonte: Adaptado de Google Earth (2017)

Figura 40 - Bacia do Rio dos Macacos e seus principais afluentes 
A área sofre com eventos recorrentes de inundação, conforme demonstrado nas Figura 41, Figura 42 e Figura 43 os episódios de enchentes de 1988, 2010 e 2017 , respectivamente.

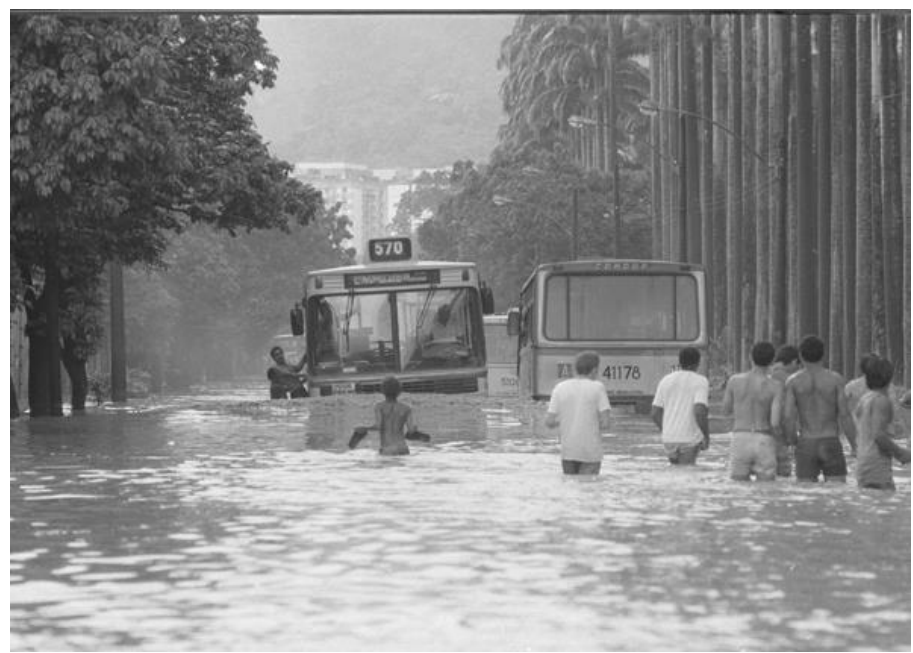

Fonte: Globo (2010)

Figura 41 - Enchente na Rua Jardim Botânico em 1988

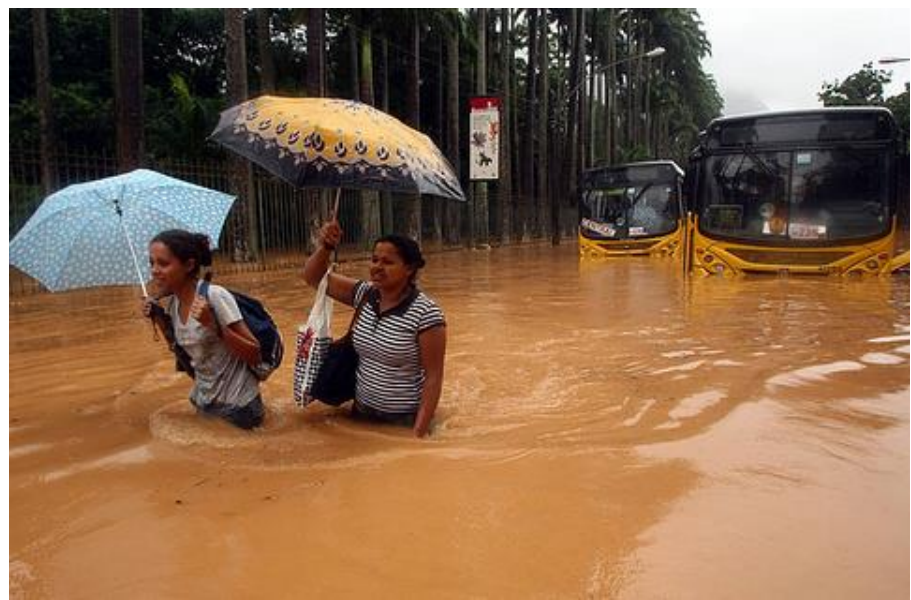

Fonte: Globo (2016)

Figura 42 - Enchente na Rua Jardim Botânico em 2010

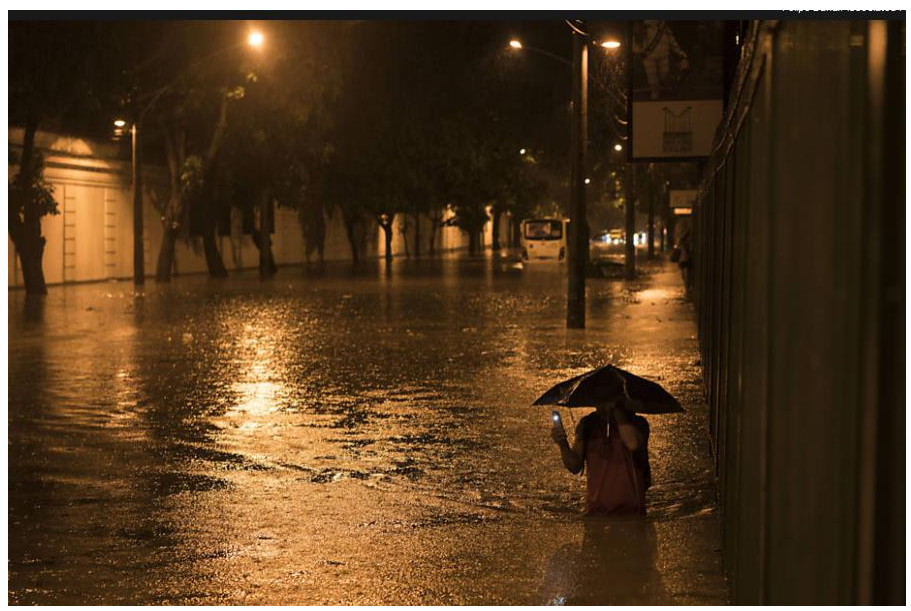

Fonte: Folha de São Paulo (2017)

Figura 43 - Enchente na Rua Jardim Botânico em 2017 
De acordo com informações publicadas pela Fundação Instituto Rio Águas (2015), os pontos mais críticos da área em estudo são:

- Rua Von Martius;

- Aproximadamente entre o número 650 da Rua Pacheco Leão e a Rua Jardim Botânico;

- Rua Visconde de Carandaí;

- Rua 86;

- Rua Jardim Botânico entre a Associação de Amigos do Jardim Botânico e a Rua Lopes Quintas;

- Rua General Garzon;

- Avenida Lineu de Paula Machado, entre a Rua General Garzón e a Rua Saturnino de Brito.

As referidas ruas estão indicadas pelas linhas azuis na Figura 44.

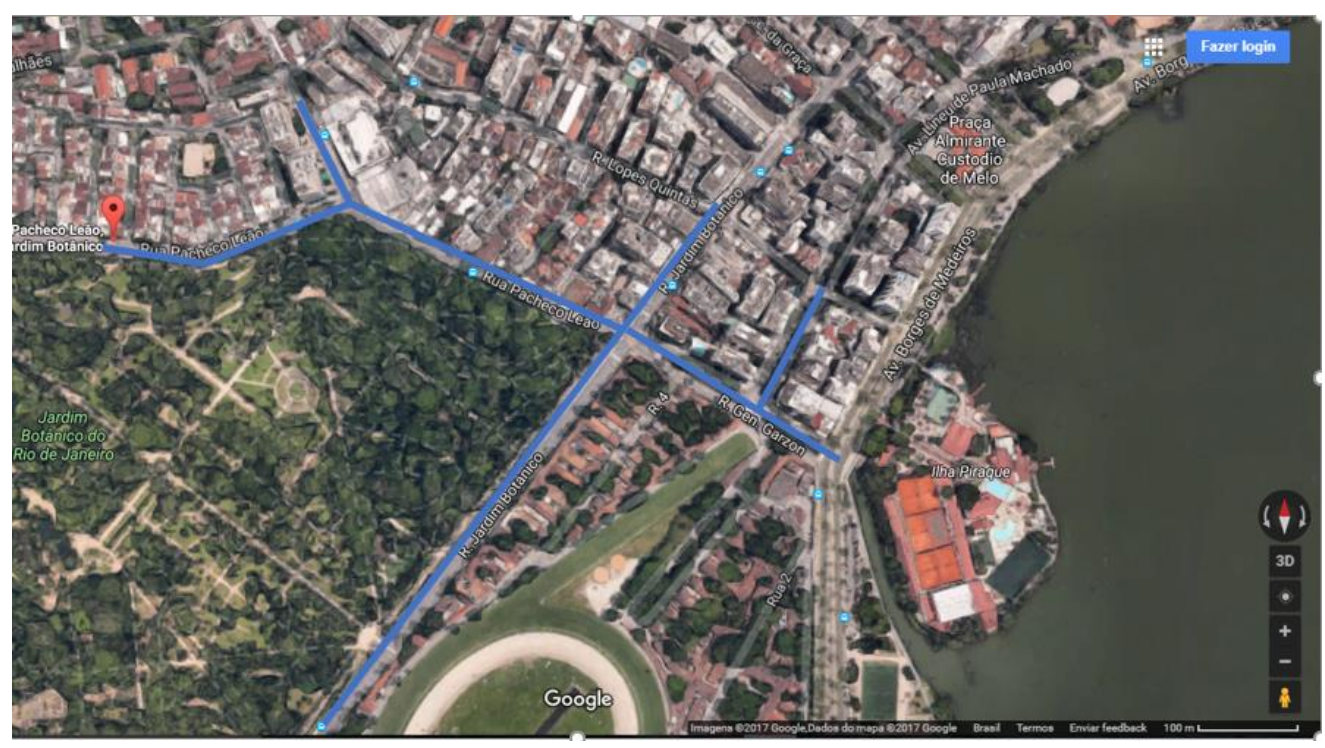

Fonte: Adaptado de Google Earth (2017)

Figura 44 - Ruas que alagam na Bacia do Rio dos Macacos

\section{Breve histórico}

A região sofreu diversas transformações urbanas ao longo do tempo. A fundação do bairro Jardim Botânico ocorreu em 1571, antes nomeado de Engenho d'El Rey pelo seu próprio fundador, o governador Cristóvão de Barros. Posteriormente, no século XVII, o bairro foi dividido em dois engenhos: o de Nossa Senhora da Cabeça e o de Nossa Senhora da Conceição da Lagoa. (SMU, 2003)

Em 1808, a Família Real adquiriu o engenho e instalou a Fábrica Real de Pólvora e um jardim para aclimatação de plantas exóticas, que posteriormente deu origem ao Real Jardim Botânico, e atualmente é conhecido como Instituto de Pesquisas Jardim Botânico do Rio de Janeiro. (SMU, 2003) 
Por diversas questões, entre elas, explosões, a falta de força motriz e um sistema de drenagem ineficiente, em 1831 a fábrica foi transferida para a Serra da Estrela, onde hoje se situam os municípios de Magé, Petrópolis e Duque de Caxias. (Moreira, 2005)

Durante 1880, intensificou-se o estabelecimento de indústrias têxteis na região, como por exemplo, a fábrica da Companhia de Fiação e Tecidos Corcovado. Próximo às indústrias eram formadas vilas operárias, principalmente localizadas nos terrenos pantanosos e insalubres das margens da lagoa Rodrigo de Freitas, assim constituía-se uma região popular entre os bairros nobres da zona sul. (SMU, 2003; Von Der Weid, 1997)

A implantação de bondes, movidos à tração animal em 1871 e, posteriormente, à eletricidade em 1902, trouxe grande valorização aos terrenos das chácaras remanescentes, fazendo com que, durante o século $\mathrm{XX}$, as terras antes ocupadas por fábricas e chácaras, fossem desmembradas em lotes. A cidade foi expandida através de importantes obras de aterramento que mudaram de forma significativa a orla da Lagoa, surgindo os primeiros núcleos residenciais. Nessa mesma época também foram realizadas obras relevantes de saneamento pelo engenheiro sanitarista Saturnino de Brito, como a regularização dos canais do Jardim de Alah e na Avenida Visconde de Albuquerque, Leblon. Os terrenos, inicialmente tomados por mansões, foram posteriormente ocupados por edifícios de alto luxo. (SMU, 2003)

\section{Solo e Cobertura vegetal}

A área da bacia ocupada pelo Maciço da Tijuca, segundo estudo da Embrapa (2004), pode ser classificada na sua parte mais baixa do relevo por unidade PVad5 e a parte mais alta, LVad4, conforme demonstrado na Figura 45.

A unidade LVad4 apresenta classe de solo do tipo latossolo vermelhoamarelo, de textura argilosa, tendo como cobertura vegetal a floresta tropical subperenifólia e relevo montanhoso (declividade entre $45 \%$ a $75 \%$ ). A floresta tropical subperenifólia está presente nas encostas mais úmidas e em maciços de alta altitude; sua vegetação se caracteriza por ser densa e de grande porte, ocorrendo em regiões de clima mesotérmico. Ainda segundo Embrapa (2004), essa área é de alta vulnerabilidade ambiental devido à alta suscetibilidade à erosão e aos altos índices pluviométricos. Em algumas áreas ocorrem afloramentos de rocha. 


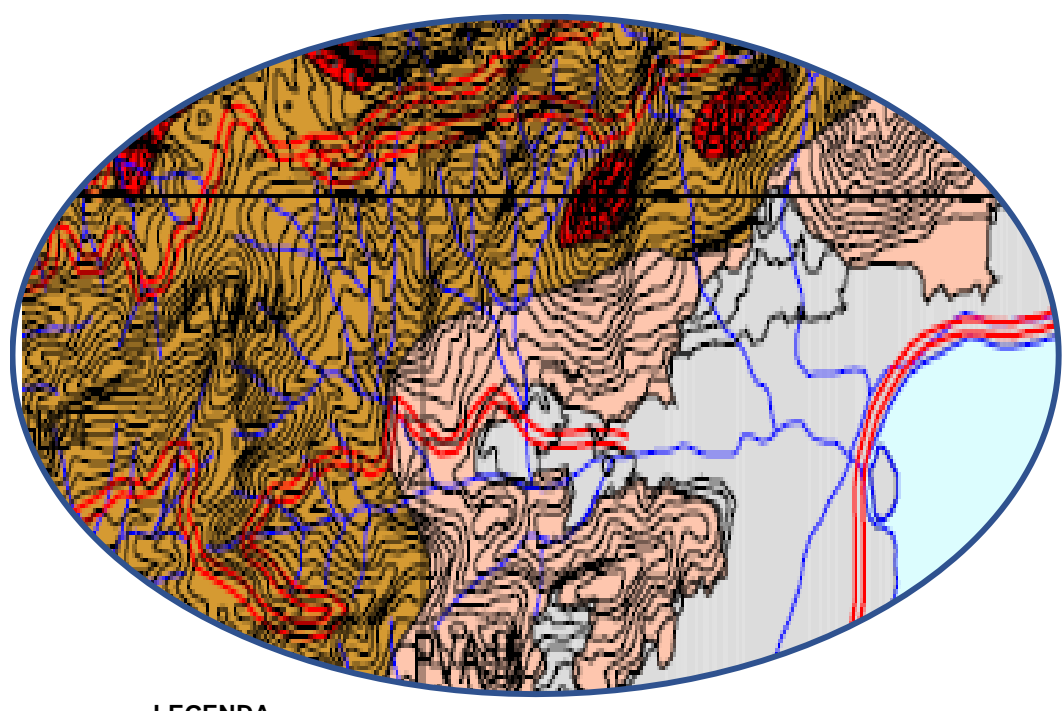

LEGENDA

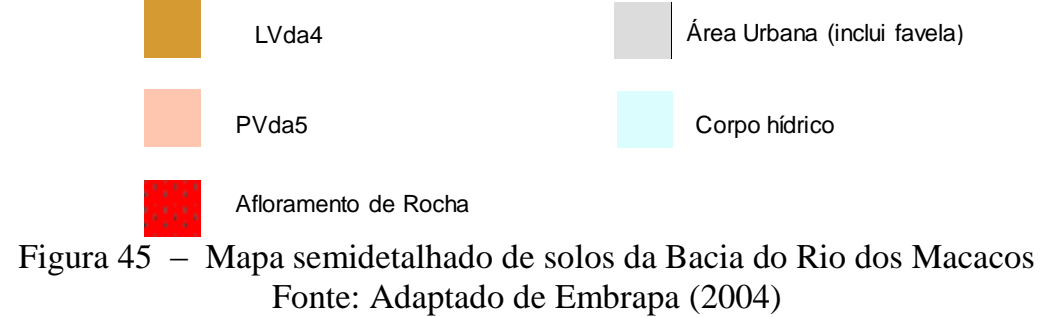

A unidade PVad5 apresenta classe do solo do tipo argissolo vermelhoamarelo distrófico típico, de textura média/argilosa ou média/muito argilosa, apresentando vegetação do tipo floresta tropical subcaducifólia e relevo forte ondulado (declividade entre $20 \%$ a $45 \%$ ). A floresta subcaducifólia é predominante no município do Rio de Janeiro, ocorrendo nas encostas mais secas e em pequenos maciços de baixa altitude, apresenta menor densidade e porte quando comparada a floresta subperenifólia. Essa unidade foi classificada pela Embrapa (2004) como de alta vulnerabilidade ambiental por apresentar elevada suscetibilidade à erosão.

Quanto à qualidade ambiental, o estudo realizado pela Embrapa (2004) também classifica as unidades PVad5 e LVad4 como terras conservadas, já que apresentam baixa interferência antrópica e cobertura de Mata Atlântica pouco alterada e/ou não alterada.

As regiões que apresentam afloramento de rocha possuem vulnerabilidade extremamente alta, condicionada por declividade e rochosidade. Tal classificação é justificada porque existe grande risco de acidentes geotécnicos devido à possibilidade de desagregação e queda de blocos rochosos. 
A impermeabilidade do material rochoso, associado à vegetação rupestre pouco densa, propicia à elevada concentração das águas de chuvas nas áreas imediatamente abaixo, incrementando os processos erosivos nestes locais. (Embrapa, 2004, p. 310)

Conforme pode ser visualizado na Figura 45, não há informações a respeito do solo da área urbana

\section{2 Modelagem Hidráulica e Hidrológica}

Um modelo é uma representação simplificada de um sistema complexo. Um modelo hidráulico hidrológico pode ser definido como uma representação matemática de um sistema que é um conjunto de processos físicos, químicos e/ou biológicos que ocorrem na superfície e/ou subsuperfície terrestre (Rennó, Soares, 2008; Xu, 2002).

A bacia hidrográfica é o objeto de estudo da maioria dos modelos hidráulicos e hidrológicos, reunindo as superfícies que captam e despejam água sobre um ou mais canais de escoamento que desembocam numa única saída. (Rennó, Soares, 2008; p.1)

Para Jajarmizadeh et al (2012), o conceito de modelagem em hidrologia envolve as relações de água, clima, solo e sua ocupação, mais do que isso, modelos hidráulicos hidrológicos incluem parâmetros temporais e espaciais. Segundo Xu (2002), o limite do modelo se confunde com os limites da bacia hidrográfica.

Usando o conceito de sistema, a construção do modelo deve ser dirigida a relacionar entradas e saídas, e não à representação exata dos seus detalhes, o que pode não ser significativo do ponto de vista prático ou pode não ser conhecido. No entanto, o conhecimento do sistema físico ajuda a desenvolver um bom modelo.

O principal objetivo da modelagem das bacias hidrográficas é a melhor compreensão dos fenômenos hidrológicos e de como mudanças na bacia podem afetar esses fenômenos, fornecendo informações valiosas para o estudo de previsão dos impactos potenciais de mudanças no uso da terra ou do clima. (Rennó, Soares, 2008, Todini, 2007; Xu, 2002)

Existem diversos tipos de modelos hidráulicos hidrológicos, podendo ser classificados sob diferentes aspectos. A escolha de tipo de modelo deve ser em função da existência de dados de entrada elementares e da necessidade da aplicação. 
De acordo com Rennó \& Soares (2008), as principais classificações dos modelos são quanto ao tipo de variáveis empregadas na modelagem (estocásticos ou determinísticos), o tipo de relações entre essas variáveis (empíricos ou baseados em processos), a forma de representação dos dados (discretos ou contínuos), a existência ou não de relações espaciais (pontuais ou distribuídos), e a existência de dependência temporal (estáticos ou dinâmicos).

Existem diversos modelos hidráulicos hidrológicos aplicados à drenagem urbana. Ellitot \& Trowsdale (2007) compararam os modelos MOUSE, MUSIC, P8, PURRS, RUNQUAL, SLAMM, STORMTac, SWMM, UVQ e WBM para parâmetros diversos e demonstraram que os modelos MOUSE e SWMM eram os modelos mais completos, sendo adequados para uma vasta gama de utilizações.

O software MOUSE foi criado pela corporação DHI Water \& Environment em 1985, de uso privado. Segundo próprio fabricante, o modelo utiliza equações físicas e empíricas, sendo a estrutura do modelo uma descrição simplificada do comportamento da fase terrestre do ciclo hidrológico.

O SWMM, Storm Water Management Model, é um modelo de simulação dinâmica largamente utilizado, criado pela EPA - United States Environmental Protection (Agência de Proteção Ambiental dos Estados Unidos) em 1971 e desde então vem sofrendo atualizações constantes, estando na versão 5.00.22. Ele é capaz de simular a quantidade e a qualidade do escoamento superficial, em um único evento chuvoso ou continuamente a longo prazo; como também o comportamento hidráulico das redes de drenagem.

O SWMM está disponível em versão português, sua última versão foi traduzida em 2012 pelo Laboratório de Eficiência Energética e Hidráulica em Saneamento da Universidade Federal da Paraíba (UFPB), fruto de um convênio entre a Eletrobras e a UFPB.

Ao contrário do MOUSE, o SWMM é de domínio público, sendo utilizado pela Fundação Instituto Rio Águas, órgão responsável pela infraestrutura de drenagem urbana da Prefeitura do Rio de Janeiro. Por todas as vantagens ora citadas, o modelo SWMM foi escolhido para ser utilizado no presente estudo.

O SWMM é capaz de simular o transporte através de sistemas de tubos, canais, dispositivos de armazenamento e tratamento, bombas e reguladores. $\mathrm{O}$ SWMM rastreia a quantidade e a qualidade do escoamento gerado dentro de cada bacia hidrográfica e a taxa de fluxo, profundidade de fluxo e qualidade da água em 
cada tubo e canal durante um período de simulação composto de vários passos de tempo.

O SWMM é um modelo de simulação discreto e distribuído. Ele calcula novos valores de suas variáveis de estado $^{2}$ ao longo de uma sequência de passos de tempo, em que em cada passo de tempo o sistema é submetido a um novo conjunto de entradas externas. À medida que suas variáveis de estado são atualizadas, outras variáveis de saída de interesse são computadas e relatadas.

Além dos modelos estudados por Ellitot \& Trowsdale (2007), pode-se citar outros modelos hidráulicos e hidrológicos de grande importância, tais como: HECRAS, HEC-HMS e DELFT-FEWS

Os modelos River Analysis System (HEC-RAS) e Hydrologic Modeling System (HEC-HMS) foram desenvolvidos pelo U.S. Army Corps of Engineers USACE (Corpo de Engenheiros do Exército dos Estados Unidos). O HEC-RAS é um software que permite executar cálculos hidráulicos para regimes de fluxo unidimensional permanente e não permanente. Já o HEC-HMS, foi projetado para simular os processos hidrológicos que ocorrem nas bacias hidrográficas, incluindo desde análises hidrológicas tradicionais, tais como, infiltração e hidrogramas unitários, até métodos que necessitam de simulação contínua, como por exemplo, a evapotranspiração. (USACE, 2016).

O modelo Delft Flood Early Warning System (DELFT-FEWS) foi desenvolvido pela organização Deltares, sendo bastante utilizado na Europa. Esse modelo é constituído por módulos projetados para a construção de um sistema de previsão hidrológica para requisitos específicos do usuário. (Deltares, 2017).

\section{2 .1}

\section{Discretização da bacia}

A bacia hidrográfica do Rio dos Macacos foi discretizada, obedecendo ao critério topográfico e de uso do solo. As áreas de vegetação foram segregadas das áreas urbanas, por apresentarem regime de chuvas e infiltração diferentes. Desta

\footnotetext{
${ }^{2}$ Variável de estado é o menor conjunto de variáveis que determina o estado de um sistema dinâmico. Se pelo menos " $n$ " variáveis são necessárias para descrever completamente o comportamento de um sistema dinâmico, então estas “n” variáveis são um conjunto de variáveis de estado.
} 
maneira, foram determinadas 24 sub-bacias, conforme pode ser visualizado na Figura 46.

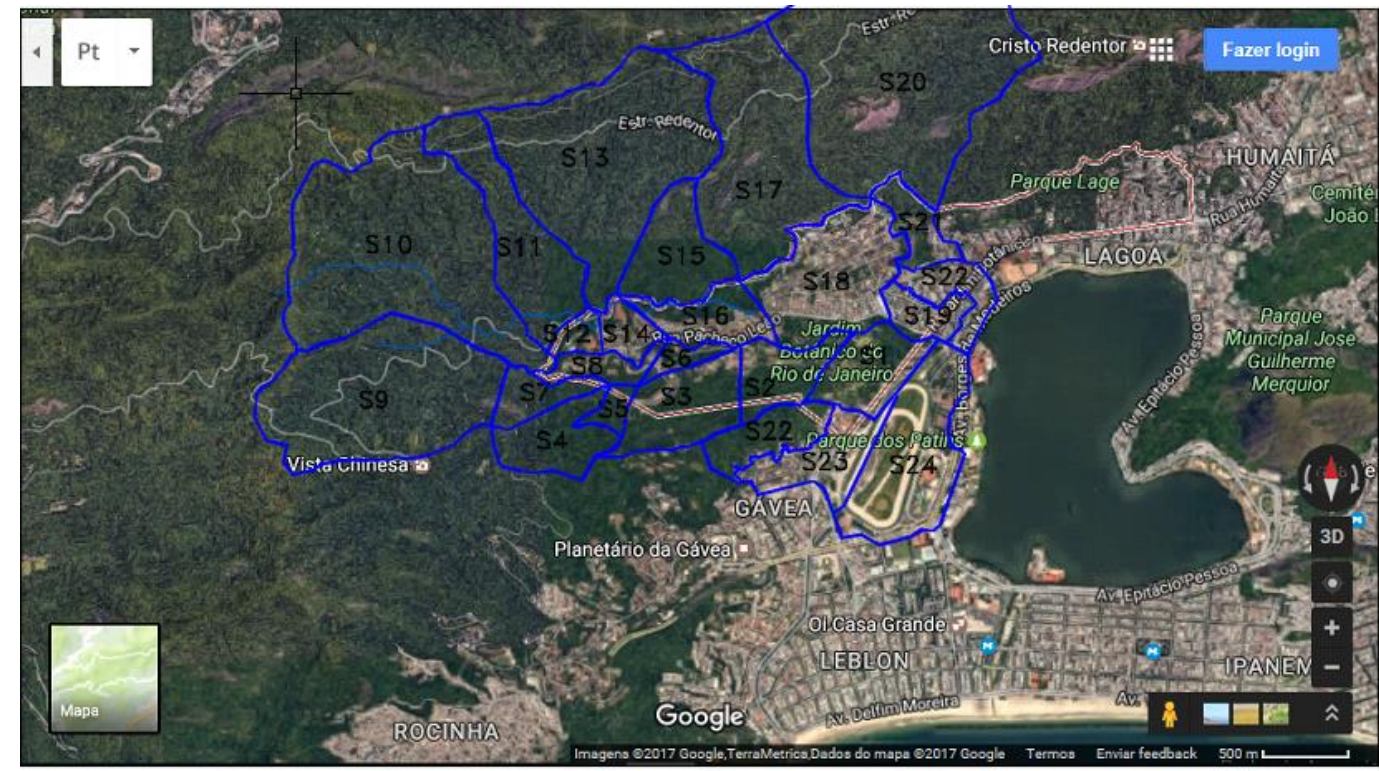

Fonte: Adaptado de Google Earth (2017)

Figura 46 - Divisão de sub-bacias

Para cada bacia foram inseridas as seguintes informações no software SWMM: área, largura, declividade, percentual de área impermeável, coeficiente de Manning das áreas impermeável e impermeável, armazenamento em depressão da área permeável e impermeável e modelo de infiltração.

As larguras das sub-bacias foram determinadas utilizando-se as equações (17), (18) e (19) descritas abaixo, as quais foram recomendadas e utilizadas pelos autores Rossman (2008), Collodel (2009) e Canholi (2013). Os resultados desses cálculos estão expostos na Tabela 19.

$$
\begin{gathered}
L_{e}=\frac{k_{c} \times \sqrt{A}}{1,12} \times\left[1-\sqrt{1-\left(\frac{1,128}{k_{c}}\right)^{2}}\right] \\
\mathrm{k}_{\mathrm{c}}=0,282 \times \frac{\mathrm{P}}{\sqrt{\mathrm{A}}} \\
W=\frac{A}{L_{e}}
\end{gathered}
$$

Onde,

W é a largura da sub-bacia (m); 
Le é a largura do retângulo equivalente (m);

$\mathrm{P}$ é o perímetro da bacia (m);

A é a área da bacia $\left(\mathrm{m}^{2}\right)$;

$\mathrm{k}_{\mathrm{c}}$ é o fator de compacidade (adimensional)

Tabela 19 - Cálculo da largura das sub-bacias

\begin{tabular}{|c|c|c|c|c|c|}
\hline Sub-bacia & $\begin{array}{l}\text { Perímetro } \\
\text { (m) }\end{array}$ & $\begin{array}{l}\text { Area total } \\
\qquad\left(\mathrm{m}^{2}\right)\end{array}$ & $\mathrm{Kc}$ & Le & $\mathrm{W}$ \\
\hline $\mathrm{S} 1$ & $2.138,67$ & $229.100,36$ & 1,26 & 298,52 & 767,45 \\
\hline $\mathrm{S} 2$ & $2.128,38$ & $192.104,52$ & 1,37 & 232,04 & 827,88 \\
\hline S3 & $2.540,33$ & $302.727,70$ & 1,30 & 320,17 & 945,51 \\
\hline $\mathrm{S} 4$ & $2.504,01$ & $228.006,52$ & 1,48 & 222,77 & $1.023,50$ \\
\hline S5 & $1.142,36$ & $50.048,26$ & 1,44 & 108,84 & 459,83 \\
\hline S6 & $1.442,64$ & $56.371,13$ & 1,71 & 89,81 & 627,66 \\
\hline S7 & $1.832,08$ & $120.685,55$ & 1,49 & 160,67 & 751,15 \\
\hline S8 & $2.049,11$ & $99.964,07$ & 1,83 & 109,99 & 908,86 \\
\hline S9 & $3.979,09$ & $939.219,27$ & 1,16 & 775,88 & $1.210,52$ \\
\hline $\mathrm{S} 10$ & $5.481,64$ & $1.302 .341,63$ & 1,35 & 616,04 & $2.114,05$ \\
\hline $\mathrm{S} 11$ & $3.802,27$ & $461.127,18$ & 1,58 & 287,44 & $1.604,28$ \\
\hline $\mathrm{S} 12$ & $1.032,11$ & $59.389,51$ & 1,19 & 174,48 & 340,38 \\
\hline $\mathrm{S} 13$ & $4.800,73$ & $1.113 .597,43$ & 1,28 & 632,97 & $1.759,32$ \\
\hline $\mathrm{S} 14$ & $1.517,37$ & $95.004,50$ & 1,39 & 159,35 & 596,21 \\
\hline $\mathrm{S} 15$ & $2.429,13$ & $292.255,13$ & 1,27 & 332,99 & 877,67 \\
\hline S16 & $2.417,88$ & $200.930,26$ & 1,52 & 200,36 & $1.002,84$ \\
\hline $\mathrm{S} 17$ & $4.793,26$ & $826.683,27$ & 1,49 & 420,74 & $1.964,84$ \\
\hline $\mathrm{S} 18$ & $3.395,51$ & $520.073,97$ & 1,33 & 403,95 & $1.287,47$ \\
\hline $\mathrm{S} 19$ & $1.700,83$ & $113.815,86$ & 1,42 & 167,58 & 679,17 \\
\hline $\mathrm{S} 20$ & $5.040,49$ & 1.377.320,61 & 1,21 & 806,95 & $1.706,83$ \\
\hline $\mathrm{S} 21$ & $3.579,99$ & $275.760,75$ & 1,92 & 171,47 & $1.608,26$ \\
\hline $\mathrm{S} 22$ & $2.362,49$ & $184.842,51$ & 1,55 & 186,99 & 988,52 \\
\hline $\mathrm{S} 23$ & $3.136,67$ & $238.937,68$ & 1,81 & 172,22 & $1.387,43$ \\
\hline $\mathrm{S} 24$ & $3.332,69$ & $523.971,38$ & 1,30 & 423,62 & $1.236,90$ \\
\hline
\end{tabular}

O percentual de áreas impermeáveis para cada sub-bacia foi definido com base em imagens de satélite do Google Earth e em plantas cadastrais do sistema de drenagem. Já os coeficientes n de Manning e as profundidades de armazenamento em depressão de áreas permeáveis e impermeáveis, foram definidos conforme orientação de Rossman (2008) e estão apresentados na Tabela 20 e na Tabela 21, respectivamente. 
Tabela 20 - Coeficiente $\mathrm{n}$ de Manning

\begin{tabular}{c|c}
\hline Superfície & Coeficiente de Manning, $\mathrm{n}$ \\
\hline Áreas impermeáveis & 0,01 \\
\hline Grama curta & 0,15 \\
\hline Floresta - vegetação rasteira leve & 0,40 \\
\hline Floresta - vegetação rasteira densa & 0,80 \\
\hline
\end{tabular}

Fonte: Rossman, 2008

Tabela 21 - Profundidade de armazenamento em depressões

\begin{tabular}{c|c}
\hline Superfície & $\begin{array}{c}\text { Profundidade de } \\
\text { armazenamento em depressões } \\
(\mathrm{mm})\end{array}$ \\
\hline Áreas impermeáveis & 1,905 \\
\hline Áreas permeáveis & 3,81 \\
\hline Serrapilheira & 7,62 \\
\hline
\end{tabular}

Fonte: Rossman (2008)

O modelo de infiltração será mais bem descrito no item 5.2.4. A Figura 47 apresenta como a bacia foi representada graficamente no software SWMM: os polígonos identificados por $\mathrm{S}$ representam as sub-bacias; os nós identificados por $\mathrm{N}$ representam o exutório das sub-bacias e os nós de entrada e de saída dos condutos; os trechos identificados por $\mathrm{T}$ representam os condutos; e, finalmente, o exutório da bacia é identificado por E. 


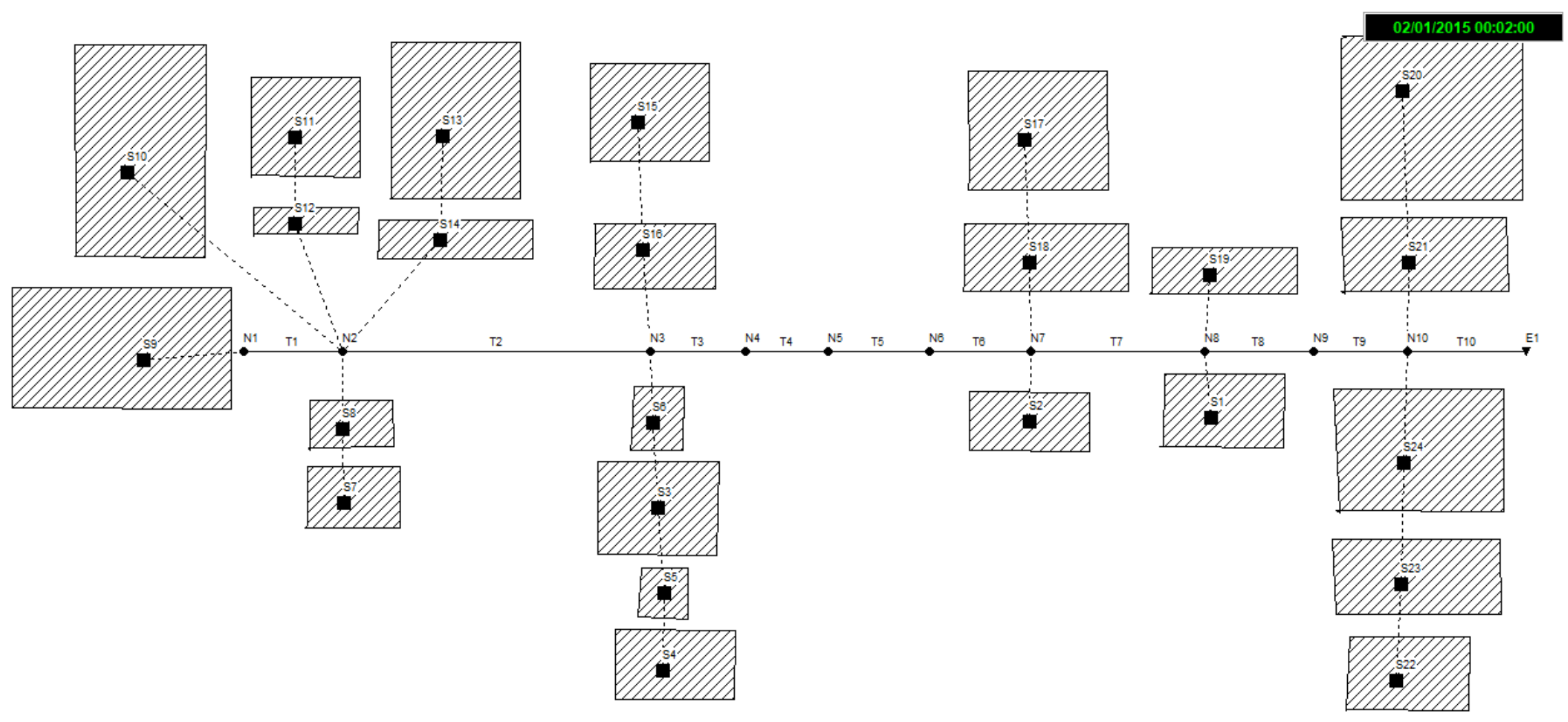

Figura 47 - Discretização da Bacia do Rio dos Macacos 


\section{Condutos}

Apenas o canal natural principal, Rio dos Macacos, foi considerado no estudo. A Figura 48 apresenta o perfil do Rio do Macacos, caracterizado pela alta declividade no início do corpo hídrico e baixa declividade no trecho final. Tal característica possibilita que haja erosão na parte alta devido à alta velocidade do escoamento; e que ocorra assoreamento nas partes mais baixas.

Através das plantas cadastrais da rede de drenagem existente, a microdrenagem foi analisada para avaliar seus pontos de deságue. Com base nisso, foram definidos os nós nos quais seriam os pontos de entrada de contribuição das sub-bacias para o canal - no total foram definidos 10 nós, 10 trechos de conduto e 1 exutório, conforme pode ser visualizado na Figura 47 e na Figura 48.

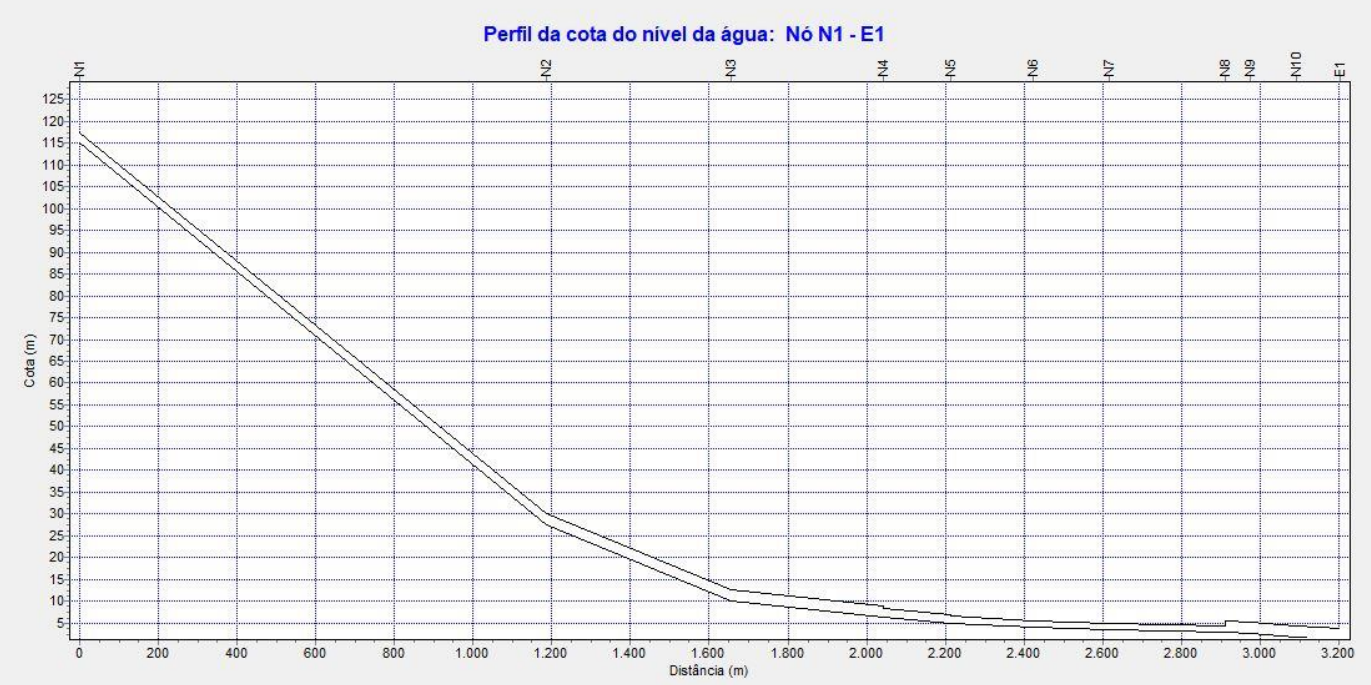

Figura 48 - Perfil do Rio dos Macacos

A Tabela 22 apresenta os dados de entrada de condutos, a saber: tipo (galeria ou canal), revestimento da superfície, dimensões e trechos. Tais informações foram baseadas na pesquisa de Lucas \& Cunha (2007) e em plantas cadastrais da rede de drenagem obtidas na Fundação Instituto Rio Águas. As plantas cadastrais são antigas, desta maneira foram utilizadas preferencialmente as informações mais atuais presentes no artigo publicado por Lucas \& Cunha (2007).

Lucas \& Cunha (2007) analisaram as alterações na morfologia do Rio dos Macacos e avaliaram a qualidade da água ao longo do curso d'água. A fim de analisar processos de erosão e deposição no canal, o estudo levantou as dimensões de algumas seções transversais durante o período de março de 2002 a fevereiro de 
2003. Foram consideradas as médias das profundidades obtidas a partir dessas medições do referido estudo.

Tabela 22 - Dados de entrada de condutos

\begin{tabular}{c|c|c|c|c|c|c}
\hline Seção & $\begin{array}{c}\text { Largura } \\
(\mathrm{m})\end{array}$ & $\begin{array}{c}\text { Profundidade } \\
\text { média }(\mathrm{m})\end{array}$ & $\begin{array}{c}\text { Tipo de } \\
\text { conduto }\end{array}$ & $\begin{array}{c}\text { Revestimento } \\
\text { do canal }\end{array}$ & Fonte & Trechos \\
\hline S1 & 4,7 & 2,5 & $\begin{array}{c}\text { Canal } \\
\text { Retangular }\end{array}$ & $\begin{array}{c}\text { Blocos e } \\
\text { matacões }\end{array}$ & $\begin{array}{c}\text { Lucas \& Cunha } \\
(2007)\end{array}$ & $\begin{array}{c}\text { T1, T2 e } \\
\text { T3 }\end{array}$ \\
\hline S2 & 4,35 & 1,92 & $\begin{array}{c}\text { Canal } \\
\text { Retangular }\end{array}$ & $\begin{array}{c}\text { Blocos e } \\
\text { matacões }\end{array}$ & $\begin{array}{c}\text { Lucas \& Cunha } \\
(2007)\end{array}$ & T4 \\
\hline S3 & 5,05 & 1,57 & $\begin{array}{c}\text { Canal } \\
\text { Retangular }\end{array}$ & $\begin{array}{c}\text { Blocos e } \\
\text { matacões }\end{array}$ & $\begin{array}{c}\text { Lucas \& Cunha } \\
(2007)\end{array}$ & T5 \\
\hline S5 & 4,18 & 1,39 & $\begin{array}{c}\text { Canal } \\
\text { Retangular }\end{array}$ & $\begin{array}{c}\text { Blocos e } \\
\text { matacões }\end{array}$ & $\begin{array}{c}\text { Lucas \& Cunha } \\
(2007)\end{array}$ & T6, T7 \\
\hline S6 & 10 & 3,27 & $\begin{array}{c}\text { Galeria } \\
\text { Concreto }\end{array}$ & $\begin{array}{c}\text { Plantas } \\
\text { Águas }\end{array}$ & T8 \\
\hline
\end{tabular}

\section{2 .3}

\section{Dados Pluviométricos}

Conforme estudo da Embrapa (2004), as áreas de maior altitude apresentam precipitações maiores quando comparadas as demais. Desta maneira, foram escolhidas duas equações de chuvas intensas: para áreas de maior altitude foi utilizada a equação de chuva intensa elaborada pela Fundação Instituto Rio Águas em 2013 obtida através dos dados do pluviômetro Capela Mayrink, equação (20), e para as demais, foi considerada a equação de chuva intensa elaborada pelo Professor Ulisses Alcântara em 1960 obtida a partir do pluviômetro Jardim Botânico, equação (21).

$$
\begin{gathered}
I=\frac{921,39 \times T_{R}{ }^{0,162}}{(t+15,46)^{0,73}} \\
I=\frac{1239 \times T_{R}^{0,15}}{(t+20)^{0,74}}
\end{gathered}
$$

Onde,

I é a intensidade pluviométrica $(\mathrm{mm} / \mathrm{h})$;

$\mathrm{T}_{\mathrm{R}}$ é o tempo de recorrência (anos); 
t é o tempo de duração, em minutos.

Para o presente estudo foi utilizado tempo de recorrência $\left(T_{R}\right)$ de 25 anos, conforme preconizado pela Fundação Instituto Rio Águas para o tipo de dispositivo canais de macrodrenagem.

Miguez et al (2012) obteve o tempo de concentração de 70 minutos para a bacia do Rio dos Macacos, através da fórmula de George Ribeiro, a qual é recomendada pela Fundação Instituto Rio Águas para elaboração de estudos e projetos na cidade do Rio de Janeiro.

O tempo de duração foi adotado como igual ao tempo de concentração da bacia hidrográfica para o cálculo da chuva de projeto, 70 minutos.

O SWMM exige que a chuva seja discretizada para simulação, desta maneira para determinar a precipitação em função do tempo (hietograma) foi utilizado o Método dos Blocos Alternados. O Gráfico 8 e o Gráfico 9 apresentam os hietogramas obtidos para os pluviômetros estudados.

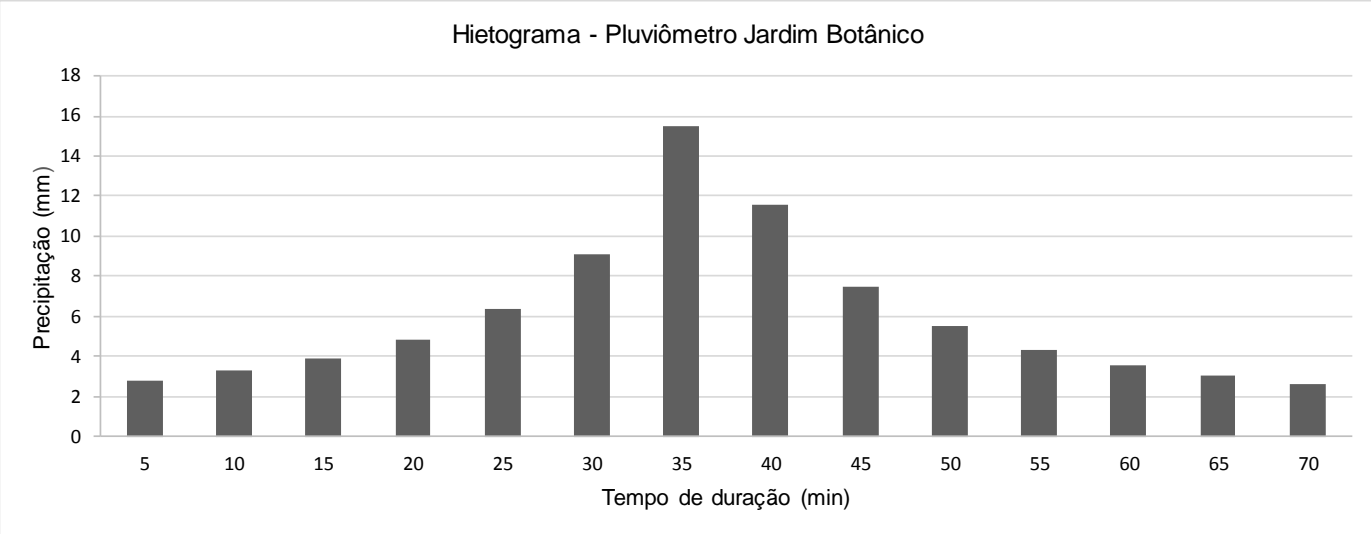

Gráfico 8 - Hietograma do pluviômetro Jardim Botânico $\operatorname{Tr}=25$ anos

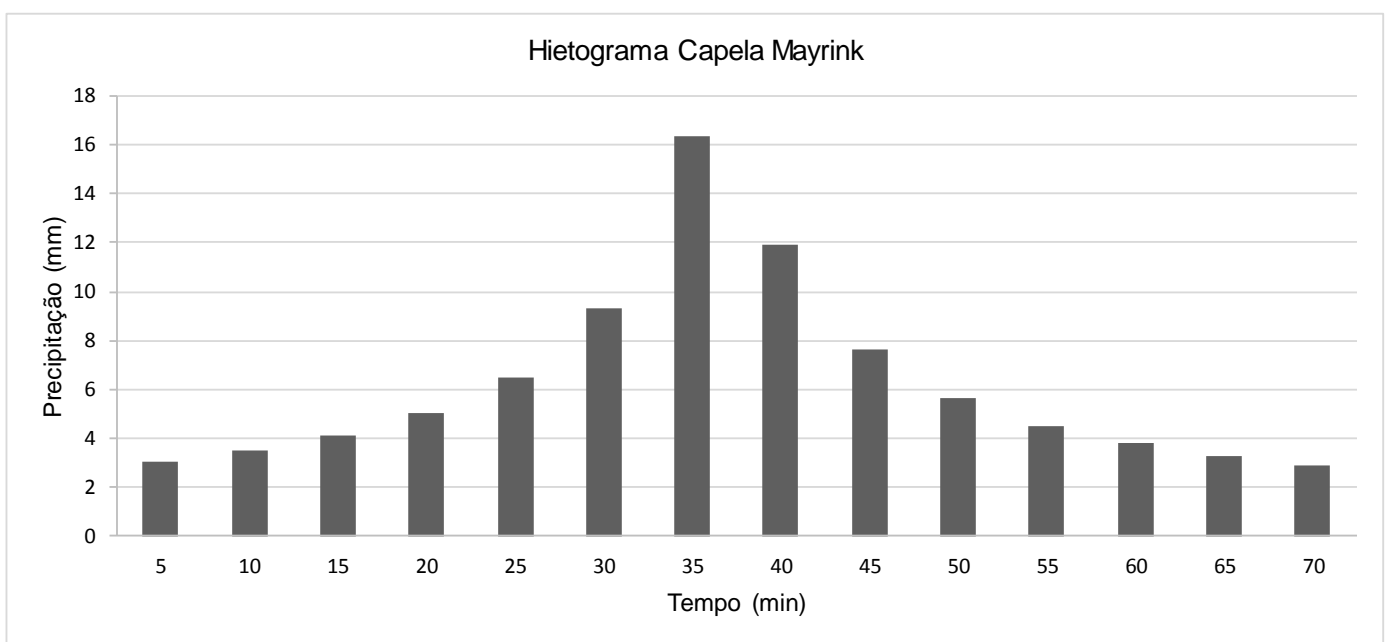

Gráfico 9 - Hietograma do pluviômetro Capela Mayrink $\operatorname{Tr}=25$ anos 


\subsection{4 Infiltração}

A infiltração é o processo de passagem de água da superfície para o solo da área permeável da bacia.

O software SWMM permite escolher entre três modelos de infiltração diferentes: Horton, Green Ampt e Curva Número do SCS (Soil Conservation Service). Foi utilizado o modelo de infiltração Curva Número do SCS, conforme orientação do documento Instruções Técnicas para Elaboração de Estudos Hidrológicos e Dimensionamento Hidráulico de Sistemas de Drenagem Urbana publicado pela Fundação Instituto Rio Águas em 2010. O método descrito a seguir é realizado exclusivamente pelo SWMM, a partir dos dados de entrada relatados neste subitem e ao longo de todo conteúdo apresentado no item 5.2.

Esse método determina o escoamento superficial da bacia hidrográfica, através do hidrograma triangular composto, de parâmetros de classificação hidrológica e de dados da cobertura do solo. De acordo com Canholi (2014), esse método é recomendável quando não há confiabilidade nos dados de campo.

O hidrograma triangular composto é obtido através da soma das ordenadas dos hidrogramas unitários para cada intervalo de discretização da chuva. Para cada intervalo é calculada a chuva efetiva através da equação (22) a qual é conhecida como Equação de Mockus. A Equação de Mockus apenas é válida para condição $\mathrm{P}>$ 2S. Caso contrário, $\mathrm{P}_{\mathrm{e}}=0$.

$$
P_{e}=\frac{\left(P+0,2 \times S_{d}\right)^{2}}{P+0,8 \times S_{d}}
$$

Onde:

$P_{e}$ é a Precipitação efetiva (mm);

P é a precipitação acumulada ( $\mathrm{mm})$;

$\mathrm{S}_{\mathrm{d}}$ é a capacidade máxima da camada superior do solo (mm);

O valor de Sd é determinado em função do tipo e uso do solo e das condições antecedentes de umidade e pode ser descrito pela equação abaixo.

$$
S_{d}=\frac{25400}{C N}-254
$$

Onde: 
CN é a curva de deflúvio, também denominada de curva número.

$\mathrm{O}$ valor de $\mathrm{CN}$ retrata as condições de cobertura do solo e foi estabelecido em uma escala de 1 a 100 , variando de coberturas totalmente impermeáveis a coberturas inteiramente permeáveis. Os solos foram classificados em quatro categorias de grupo hidrológico - A, B, C e D. Os valores de CN estão apresentados na Tabela 23.

A partir dos resultados obtidos, os hidrogramas para cada intervalo são determinados. Posteriormente, por convolução, é definido o hidrograma de cheia da bacia em análise cujo valor máximo é denominado vazão de pico, sendo adotado como vazão de projeto. (Fundação Instituto Rio Águas, 2010)

Tabela 23 - Valores do parâmetro CN

\begin{tabular}{|c|c|c|c|c|}
\hline \multirow{2}{*}{ Tipologia do uso do solo } & \multicolumn{4}{|c|}{ Grupo hidrológico } \\
\hline & A & $\mathrm{B}$ & $\mathrm{C}$ & $\mathrm{D}$ \\
\hline \multicolumn{5}{|l|}{ Uso residencial } \\
\hline \multicolumn{5}{|l|}{ Tamanho médio do lote impermeável $\%$} \\
\hline Até $500 \mathrm{~m}^{2}$ & 77 & 85 & 90 & 92 \\
\hline $1000 \mathrm{~m}^{2}$ & 61 & 75 & 83 & 87 \\
\hline $1500 \mathrm{~m}^{2}$ & 57 & 72 & 81 & 86 \\
\hline Estacionamentos pavimentados, telhados & 98 & 98 & 98 & 98 \\
\hline \multicolumn{5}{|l|}{ Ruas e estradas } \\
\hline Pavimentadas, com guias e drenagem & 98 & 98 & 98 & 98 \\
\hline Com cascalho & 76 & 85 & 89 & 91 \\
\hline De terra & 72 & 82 & 87 & 89 \\
\hline Áreas comerciais (85\% de impermeabilização) & 89 & 92 & 94 & 95 \\
\hline \multicolumn{5}{|l|}{ Espaços abertos, parques e jardins } \\
\hline Boas condições, cobertura de grama $>75 \%$ & 39 & 61 & 74 & 80 \\
\hline Condições médias, cobertura de grama $>50 \%$ & 49 & 69 & 79 & 84 \\
\hline \multicolumn{5}{|l|}{ Florestas } \\
\hline Condições ruins & 45 & 66 & 77 & 83 \\
\hline Médias condições & 36 & 60 & 73 & 79 \\
\hline Boas condições & 25 & 55 & 70 & 77 \\
\hline
\end{tabular}

Fonte: Adaptado de Fundação Instituto Rio Águas (2010) 


\section{2 .5 \\ Pavimento permeável}

\subsubsection{1}

\section{Dimensionamento hidráulico e mecânico}

Para o dimensionamento hidráulico e mecânico foram adotadas as seguintes premissas:

- O pavimento permeável proposto será aplicado apenas para tráfego de pedestres em calçadas;

- O concreto permeável será moldado no local.

- Por ausência de informações geotécnicas locais foi considerado: $C B R \geq 5 \%$; distância entre a face inferior da base do pavimento e lençol freático maior que 1 metro; e coeficiente de permeabilidade do solo igual a $10^{-5} \mathrm{~m} / \mathrm{s}$, o que corresponde a um solo de média permeabilidade, conforme classificação apresentada na Tabela 4.

\section{Revestimento}

Com base nos resultados obtidos do estudo experimental do concreto poroso e na utilização pretendida para o revestimento - aplicação em calçadas -, o traço T7 foi escolhido por apresentar melhor coeficiente de permeabilidade $-0,32 \mathrm{~cm} / \mathrm{s}$ (conforme Tabela 18), e resistência mecânica compatível com o uso proposto.

A ABNT NBR 16416:2015 exige que o revestimento tenha coeficiente de permeabilidade maior que $10^{-3} \mathrm{~m} / \mathrm{s}$ e, que em função do tipo de solicitação tráfego de pedestres, apresente resistência à tração na flexão de no mínimo $1 \mathrm{MPa}$. O traço T7 atende a esses requisitos, apresentando resistência à tração na flexão de 1,68 MPa aos 28 dias, índice de vazios 0,275 e coeficiente de permeabilidade $0,32 \mathrm{~cm} / \mathrm{s}$, conforme dados expostos na Tabela 18 .

Foi adotada espessura de $60 \mathrm{~mm}$ para o revestimento, conforme orientação da Tabela 6.

\section{Camada de Base (Reservatório)}

Para o dimensionamento hidráulico da base, foram calculados diferentes cenários de tempo de recorrência e foi adotado o tempo de duração da chuva de 120 minutos.

De acordo com a classificação do tipo de infiltração do pavimento permeável exposta na Tabela 1, tal permeabilidade permite que o pavimento seja do tipo infiltração total. 
Foi considerado que a relação entre as áreas de contribuição e permeável é igual a 2 .

Adotou-se como premissa a especificação do material brita 3 para construção da camada reservatório cuja compactação deve proporcionar um índice de vazios de $40 \%$, de acordo com a Tabela 3.

Desta maneira, através das equações (3), (4) e (21) foram obtidos os dados apresentados na Tabela 24 .

\begin{tabular}{c|c|c|c|c|c|c|c}
\hline \multicolumn{2}{c}{ Tabela 24 - Dimensionamento do reservatório } \\
\hline $\begin{array}{c}\mathrm{T}_{\mathrm{R}} \\
\text { (anos) }\end{array}$ & $\begin{array}{c}\text { Duração } \\
\text { da } \\
\text { chuva } \\
(\min )\end{array}$ & $\begin{array}{c}\text { Intensidade } \\
\text { Pluviométrica } \\
(\mathrm{mm} / \mathrm{h})\end{array}$ & $\begin{array}{c}\text { Coeficiente de } \\
\text { permeabilidade } \\
\text { do solo (m/h) }\end{array}$ & $\mathrm{R}$ & $\mathrm{n}$ & $\mathrm{H}(\mathrm{m})$ & $\begin{array}{c}\text { Tempo de } \\
\text { esvaziamento } \\
(\mathrm{h})\end{array}$ \\
\hline 10 & 120 & 45,2 & 0,036 & 2 & 0,40 & 0,27 & 3,0 \\
\hline 15 & 120 & 48,0 & 0,036 & 2 & 0,40 & 0,30 & 3,3 \\
\hline 20 & 120 & 50,1 & 0,036 & 2 & 0,40 & 0,32 & 3,6 \\
\hline $\mathbf{2 5}$ & $\mathbf{1 2 0}$ & $\mathbf{5 1 , 8}$ & $\mathbf{0 , 0 3 6}$ & $\mathbf{2}$ & $\mathbf{0 , 4 0}$ & $\mathbf{0 , 3 4}$ & $\mathbf{3 , 8}$ \\
\hline 50 & 120 & $\mathbf{5 7 , 5}$ & 0,036 & 2 & 0,40 & 0,40 & 4,4 \\
\hline 100 & 120 & 63,8 & 0,036 & 2 & 0,40 & 0,46 & 5,1 \\
\hline
\end{tabular}

Adotou-se como dimensão a altura da camada reservatório de $340 \mathrm{~mm}$ e tempo de esvaziamento de $3 \mathrm{~h} 48 \mathrm{~min}$, correspondente ao tempo de retorno de 25 anos. $\mathrm{O} \mathrm{T}_{\mathrm{R}}$ de 25 anos é utilizado pela Fundação Instituto Rio Águas para dimensionamento dos canais de macrodrenagem.

Considerando que o concreto permeável será aplicado em calçadas e sabendo-se que muitos dos locais estudados há circulação de bicicletas e entradas para carro, adotou-se de forma conservadora a categoria 2, a qual corresponde a uma camada de base mínima de $150 \mathrm{~mm}$, conforme Tabela 7.

Comparando-se a espessura de camada determinada pelo dimensionamento mecânico e hidráulico, adotou-se a maior entre elas, sendo de $340 \mathrm{~mm}$, obtida pelo critério hidráulico.

\section{Camada filtro}

Serão adotadas duas camadas de filtro localizadas abaixo do revestimento e da camada de base, a fim de separar as camadas e preservar a capacidade estrutural e hidráulica da base. 
Cada camada de filtro deverá ter espessura de $2,5 \mathrm{~cm}$ e poderá ser construída com brita do tipo 0 ou geocomposto.

\section{Estrutura do pavimento permeável}

A estrutura do pavimento permeável projetado para aplicação em calçadas para a área estudada está apresentada na Figura 49. As especificações das suas camadas foram utilizadas como dado de entrada para representar o pavimento no software SWMM.

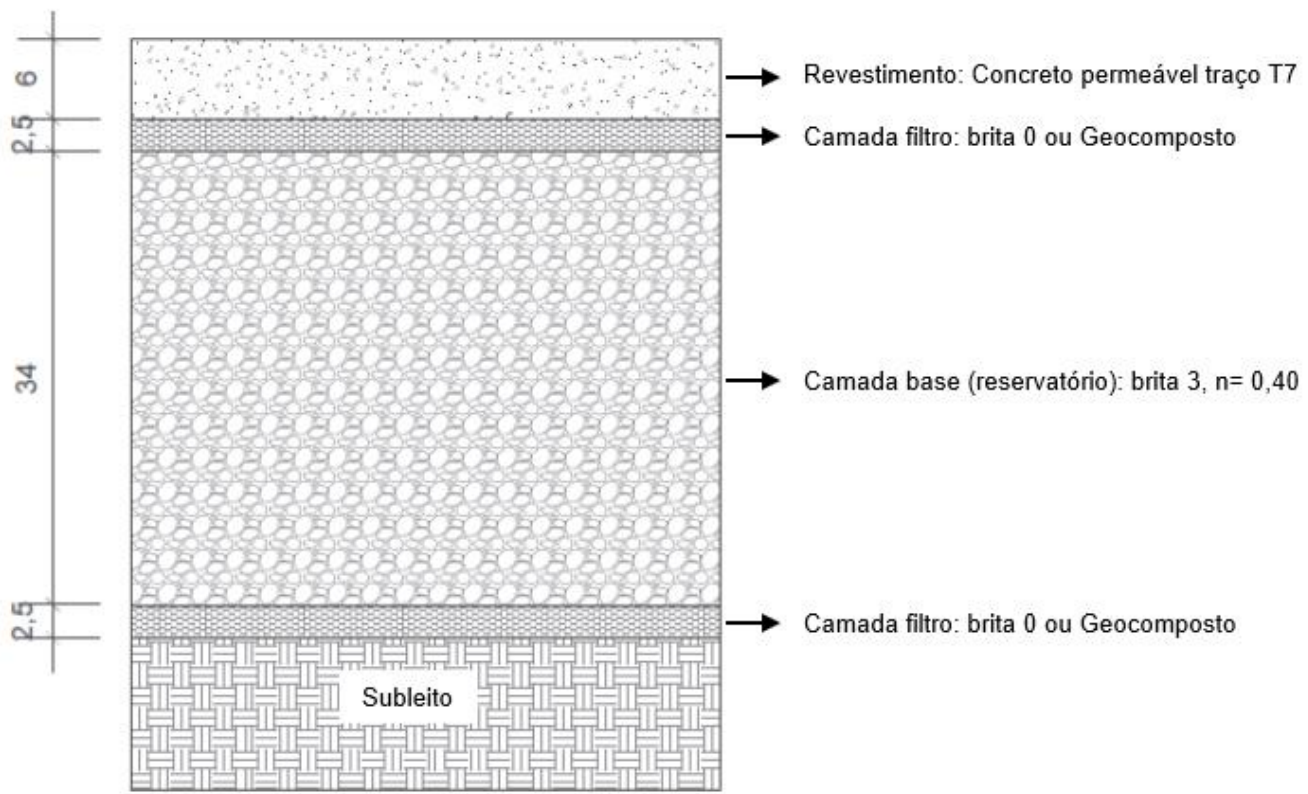

Figura 49 - Estrutura do pavimento permeável. Dimensões em cm.

\subsubsection{2}

\section{Definição das áreas de calçadas}

Além da estrutura do pavimento permeável, o SWMM exige para a modelagem hidráulica e hidrológica a definição das áreas para aplicação do pavimento permeável. Desta maneira, as áreas de calçadas e declividades das subbacias predominantemente urbanas S1, S14, S16, S18, S19, S21 e S23 foram levantadas, com base nas plantas cadastrais do sistema de drenagem do Jardim Botânico obtidas na Fundação Instituto Rio Águas e nas imagens de satélite.

Conforme já relatado no item 2.3.1, não é recomendável o uso de pavimentos permeáveis em terrenos de inclinação maior que 5\%, assim apenas foram consideradas as ruas com declividade menor ou igual a 5\% para simulação 
do modelo. Para as ruas com declividade entre $0 \%$ e $5 \%$, foi adotada a construção de pequenas barragens com orifícios, conforme apresentado na Figura 17.

A sub-bacia S1 apresenta área de aproximadamente 23 ha e é onde está localizado o Instituto de Pesquisas Jardim Botânico do Rio de Janeiro. A declividade média da bacia é de aproximadamente $1 \%$.

Nessa sub-bacia, foi possível aplicar os pavimentos permeáveis ao longo da Rua Jardim Botânico, cuja declividade da rua é aproximadamente 0\%, conforme Tabela 25. Foi aplicada em toda área de calçadas disponível na sub-bacia S1.

O trecho da Rua Jardim Botânico entre a Associação dos Amigos e a Rua Pacheco Leão é considerado como ponto crítico de alagamento, conforme demonstrado nas Figuras 41, 42 e 43.

\begin{tabular}{c|c|c|c|c}
\multicolumn{5}{c}{ Tabela 25-S1: Área de calçadas permeáveis } \\
\hline \multirow{2}{*}{ Sub-bacia } & Rua & Área $\left(\mathrm{m}^{2}\right)$ & $\begin{array}{c}\text { Área proposta para } \\
\text { calçadas permeáveis } \\
\left(\mathrm{m}^{2}\right)\end{array}$ & $\begin{array}{c}\text { Declividade } \\
(\%)\end{array}$ \\
\hline S1 & Rua Jardim Botânico & 3.660 & 3.660 & $0 \%$ \\
\hline \multicolumn{2}{|c|}{ Total } & 3.660 & 3.660 & \\
\hline
\end{tabular}

A sub-bacia S14 possui uso predominantemente residencial, apresenta área de aproximadamente 9,5 ha e é onde está localizado o Instituto Nacional de Matemática Pura e Aplicada (IMPA). A declividade média da bacia é de aproximadamente $14 \%$ e ela recebe toda contribuição da sub-bacia S13 a qual possui área de cerca de 111 ha, declividade média de $43 \%$ e cobertura vegetal.

Nessa sub-bacia, foi possível considerar os pavimentos permeáveis apenas ao longo das Ruas Orthom Melo e em parte da Rua Pacheco Leão, conforme Tabela 26, resultando na aplicação de pavimentos em cerca de $42 \%$ da área disponível.

Tabela 26 - S14: Área de calçadas permeáveis

\begin{tabular}{c|l|c|c|c}
\hline \multirow{3}{*}{ Sub-bacia } & \multicolumn{1}{|c|}{ Rua } & $\begin{array}{c}\text { Área } \\
\text { disponível } \\
\left(\mathrm{m}^{2}\right)\end{array}$ & $\begin{array}{c}\text { Área proposta para } \\
\text { calçadas permeáveis } \\
\left(\mathrm{m}^{2}\right)\end{array}$ & $\begin{array}{c}\text { Declividade } \\
(\%)\end{array}$ \\
\hline \multirow{5}{*}{ S14 } & $\begin{array}{l}\text { IMPA + Estrada Dona } \\
\text { Castorina }\end{array}$ & 916 & 0 & $11 \%$ \\
\cline { 2 - 5 } & Rua Orthom Melo & 303 & 0 & $6 \%$ \\
\cline { 2 - 5 } & \multirow{3}{*}{ Pacheco Leão } & 4.257 & 1.257 & $5 \%$ \\
\cline { 2 - 5 } & & 1.038 & 480 & $5 \%$ \\
\cline { 2 - 5 } & Total & 153 & 0 & $7 \%$ \\
\hline
\end{tabular}

A sub-bacia S16 apresenta área de aproximadamente 20 ha, possui uso predominantemente residencial e também abriga uma indústria têxtil. A declividade média da bacia é de aproximadamente $34 \%$ e ela recebe a contribuição da sub-bacia 
S15 a qual possui área de aproximadamente 29 ha, declividade média de $57 \%$ e cobertura vegetal.

Nessa sub-bacia foi possível aplicar os pavimentos permeáveis apenas em parte das Ruas Modesto Brocos, Marquês de Sabará, Pacheco Leão e ao longo da Rua Oliveira Castro, conforme Tabela 27. No total foi possível aplicar os pavimentos permeáveis em $7.744 \mathrm{~m}^{2}$, o que equivale a $68 \%$ da área total de calçadas.

Tabela 27 - S16: Área de calçadas permeáveis

\begin{tabular}{c|c|c|c|c}
\hline \multirow{3}{*}{ Sub-bacia } & Ruas & Área $\left(\mathrm{m}^{2}\right)$ & $\begin{array}{c}\text { Área proposta para } \\
\text { calçadas } \\
\text { permeáveis }\left(\mathrm{m}^{2}\right)\end{array}$ & $\begin{array}{c}\text { Declividade } \\
(\%)\end{array}$ \\
\hline \multirow{3}{*}{ S16 } & \multirow{2}{*}{ Rua Modesto Brocos } & 870 & 0 & $7 \%$ \\
\cline { 3 - 5 } & \multirow{3}{*}{ Rua Marques de Sabará } & 1.425 & 1.425 & $5 \%$ \\
\cline { 3 - 5 } & & 429 & 0 & $7 \%$ \\
\cline { 3 - 5 } & \multirow{2}{*}{ Rua Pacheco Leão } & 305 & 0 & $8 \%$ \\
\cline { 2 - 5 } & & 4.462 & 1.462 & $5 \%$ \\
\cline { 2 - 5 } & Rua Oliveira de Castro & 1.479 & 438 & $5 \%$ \\
\cline { 2 - 5 } & Total & 7.744 & 469 & $5 \%$ \\
\hline
\end{tabular}

A sub-bacia S18 apresenta área de aproximadamente 52 ha e também possui uso predominantemente residencial. A declividade média dessa sub-bacia é de aproximadamente $11 \%$ e ela recebe a contribuição da sub-bacia S17 a qual possui área de aproximadamente 83 ha, declividade média de $45 \%$ e cobertura vegetal.

Na S18 está localizado parte do trecho entre o número 650 da Rua Pacheco Leão e a Rua Jardim Botânico, em que a ocorrência de alagamentos é mais crítica (ver item 5.1), estando prevista a aplicação de pavimentos permeáveis.

No total foi possível aplicar os pavimentos permeáveis em $36.756 \mathrm{~m}^{2}$, o que equivale a $89 \%$ da área total de calçadas. Todas as ruas e as suas respectivas áreas de calçadas propostas para a aplicação dos pavimentos estão descritas na Tabela 28. 
Tabela 28 - S18: Área de calçadas permeáveis

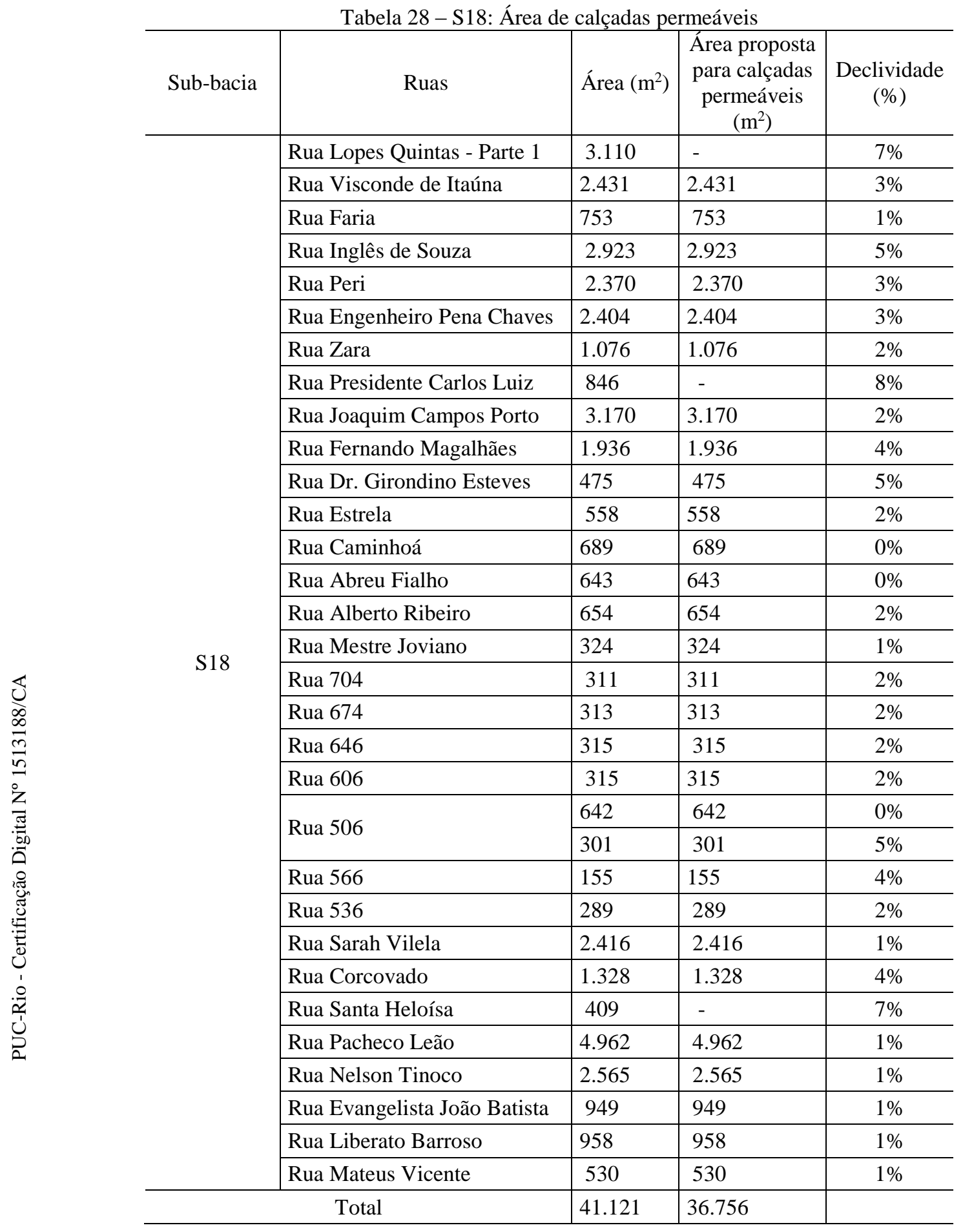

A sub-bacia S19 apresenta área de aproximadamente 11 ha e também possui uso predominantemente residencial. A declividade média desta sub-bacia é de apenas $3 \%$.

Na S19 estão localizados alguns dos pontos críticos de alagamento, conforme descrito no item 5.1:

- Parte final do trecho entre o número 650 da Rua Pacheco Leão e a Rua Jardim Botânico; 
- Rua Visconde de Carandaí;

- Rua Von Martius;

- Rua 86;

- Parte final da Rua Jardim Botânico entre a Rua Pacheco Leão e a Rua Lopes Quintas;

Nessa sub-bacia foi possível aplicar os pavimentos permeáveis em toda área disponível de calçadas, $7.990 \mathrm{~m}^{2}$, conforme pode ser visualizado na Tabela 29.

Tabela 29 - S19: Área de calçadas permeáveis

\begin{tabular}{c|l|c|c|c}
\hline \multirow{2}{*}{ Sub-bacia } & \multicolumn{1}{|c|}{ Ruas } & $\begin{array}{c}\text { Área } \\
\left(\mathrm{m}^{2}\right)\end{array}$ & $\begin{array}{c}\text { Área proposta para } \\
\text { calçadas permeáveis }\left(\mathrm{m}^{2}\right)\end{array}$ & $\begin{array}{c}\text { Declividade } \\
(\%)\end{array}$ \\
\hline \multirow{5}{*}{ S19 } & 2.253 & 2.253 & $3 \%$ \\
\cline { 2 - 5 } & $\begin{array}{l}\text { Rua Lopes Quintas } \\
\text { Rua Saturnino de Brito - }\end{array}$ & 132 & 132 & $3 \%$ \\
\cline { 2 - 5 } & Rua Pacheco Leão & 1.813 & 1.813 & $1 \%$ \\
\cline { 2 - 5 } & Rua Visconde de Carandaí & 831 & 831 & $0 \%$ \\
\cline { 2 - 5 } & Rua 86 & 642 & 642 & $0 \%$ \\
\cline { 2 - 5 } & Rua Jardim Botânico & 1.566 & 1.566 & $4 \%$ \\
\cline { 2 - 5 } & Rua Von Martius & 752 & 752 & \\
\hline
\end{tabular}

A sub-bacia S21 apresenta aproximadamente 28 ha e é ocupada por cobertura vegetal em cerca de $48 \%$ da área, e no restante tem uso predominantemente residencial. A declividade média dessa sub-bacia é de aproximadamente $8 \%$ e recebe a contribuição da sub-bacia S20, a qual possui cerca de 138 ha, declividade média de $29 \%$ e cobertura vegetal.

$\mathrm{Na}$ S21 estão alguns dos locais críticos de ocorrência de inundação, conforme descrito no item 5.1:

- Rua General Garzon;

- Avenida Lineu de Paula Machado, entre a Rua General Garzón e a Rua Saturnino de Brito.

No total foi possível aplicar os pavimentos permeáveis em $5.166 \mathrm{~m}^{2}$, o que equivale a $65 \%$ do total de calçadas. Todas as ruas e as áreas de calçadas propostas para a aplicação dos pavimentos estão descritas na Tabela 30. 
Tabela 30 - S21: Área de calçadas permeáveis

\begin{tabular}{c|l|c|c|c}
\hline \multirow{3}{*}{ Sub-bacia } & \multicolumn{1}{|c|}{ Ruas } & Área $\left(\mathrm{m}^{2}\right)$ & $\begin{array}{c}\text { Área proposta para } \\
\text { calçadas permeáveis } \\
\left(\mathrm{m}^{2}\right)\end{array}$ & $\begin{array}{c}\text { Declividade } \\
(\%)\end{array}$ \\
\hline \multirow{5}{*}{ S21 } & Rua Faro & 1.603 & - & $8 \%$ \\
\cline { 2 - 5 } & Rua Visconde Da Graça & 1.212 & - & $8 \%$ \\
\cline { 2 - 5 } & Rua Jardim Botânico & 755 & 755 & $2 \%$ \\
\cline { 2 - 5 } & Rua Saturnino de Brito & 1.092 & 1.092 & $0 \%$ \\
\cline { 2 - 5 } & $\begin{array}{l}\text { Avenida Lineu de Paula } \\
\text { Machado }\end{array}$ & 2.182 & 2.182 & $0 \%$ \\
\cline { 2 - 5 } & Rua General Garzon & 1.136 & 1.136 & 0 \\
\hline
\end{tabular}

A sub-bacia S23 possui aproximadamente 24 ha e apresenta uso predominantemente residencial. A declividade média desta sub-bacia é de aproximadamente $2 \%$ e recebe a contribuição da sub-bacia S22, a qual possui cerca de 19 ha, declividade média de $53 \%$ e cobertura vegetal.

Nesta sub-bacia foi possível aplicar a solução dos pavimentos permeáveis em 70\% das áreas disponíveis de calçadas, conforme apresentado na Tabela 31.

Tabela 31 - S23: Área de calçadas permeáveis

\begin{tabular}{|c|c|c|c|c|}
\hline Sub-bacia & Ruas & Área $\left(\mathrm{m}^{2}\right)$ & $\begin{array}{c}\text { Área proposta para } \\
\text { calçadas permeáveis }\left(\mathrm{m}^{2}\right)\end{array}$ & $\begin{array}{c}\text { Declividade } \\
(\%)\end{array}$ \\
\hline \multirow{13}{*}{$\mathrm{S} 23$} & \multirow{5}{*}{ Rua Jequitibá } & 324 & - & $19 \%$ \\
\hline & & 240 & - & $13 \%$ \\
\hline & & 528 & 528 & $2 \%$ \\
\hline & & 180 & & $17 \%$ \\
\hline & & 90 & - & $10 \%$ \\
\hline & \multirow{3}{*}{ Rua Major Rubens Vaz } & 2.376 & 2.376 & $0 \%$ \\
\hline & & 655 & 655 & $5 \%$ \\
\hline & & 532 & - & $17 \%$ \\
\hline & Rua dos Otis & 1.500 & - & $1 \%$ \\
\hline & Praça Santos Dumont & 1.750 & 1.750 & $0 \%$ \\
\hline & \multirow{2}{*}{ Rua das Acácias } & 384 & - & $23 \%$ \\
\hline & & 345 & - & $9 \%$ \\
\hline & Rua Jardim Botânico & 3.034 & 3.034 & $0 \%$ \\
\hline \multicolumn{2}{|r|}{ Total } & 11.939 & 8.343 & \\
\hline
\end{tabular}




\section{6 \\ Resultados do Estudo de Caso}

\section{1}

\section{Atenuação do Escoamento Superficial}

Para cada sub-bacia em que os pavimentos permeáveis de concreto foram aplicados em calçadas (S1, S14, S16, S18, S19, S21 e S23) e para a bacia do Rio dos Macacos foram plotados os hidrogramas de cheia dos cenários antes e após a aplicação dos pavimentos permeáveis, considerando tempo de retorno de 25 anos. Os resultados da modelagem obtidos através do software SWMM podem ser visualizados através dos hidrogramas apresentados no Gráfico 10 ao Gráfico 17.

O Gráfico 10 apresenta os hidrogramas obtidos para a sub-bacia S1. Na subbacia $\mathrm{S} 1$, os pavimentos permeáveis de concreto foram propostos para $3.660 \mathrm{~m}^{2} \mathrm{de}$ calçadas, o que equivale a 1,6\% da área total da sub-bacia de 23 ha. Através da comparação dos hidrogramas dos cenários antes e após a aplicação dos pavimentos, tem-se os seguintes resultados:

- Redução de cerca de $9 \%$ do volume de escoamento superficial, passando de 3.062 para $2.783 \mathrm{~m}^{3}$;

- A primeira vazão de pico foi mitigada em aproximadamente de $64 \%$, de 1130 para 410 l/s. Todavia não houve alteração do tempo de pico que foi de 10 minutos;

- Houve aumento da segunda vazão de pico em 9\%, de 455 para 494 1/s. No entanto, não houve alteração do tempo do segundo pico, permanecendo em 74 minutos.

O Gráfico 11 apresenta os hidrogramas obtidos para a sub-bacia S14 onde os pavimentos permeáveis foram propostos para $1.737 \mathrm{~m}^{2}$ de calçadas o que equivale a $0,1 \%$ da área total de 120 ha, soma da área da sub-bacia S14 a da contribuinte S13. Com base na análise dos hidrogramas dos cenários antes e após a aplicação dos pavimentos, tem-se os seguintes resultados:

- Redução de $1,4 \%$ do volume de escoamento superficial, passando de 26.592 para $26.231 \mathrm{~m}^{3}$; 
- A primeira vazão de pico foi reduzida em aproximadamente de $17 \%$, de 4.039 para 3.351 1/s. E ainda, o tempo de pico aumentou de 10 para 20 minutos. Portanto, o tempo de pico foi menor e mais lento;

- Também ocorreu redução da segunda vazão de pico em 4,4\%, de 4.995 para $4.775 \mathrm{l} / \mathrm{s}$, e seu tempo de pico aumentou em 2 minutos, de 74 para 76 minutos.

O Gráfico 12 exibe os hidrogramas obtidos para a sub-bacia S16 na qual os pavimentos permeáveis foram aplicados em cerca de $5.273 \mathrm{~m}^{2}$ de calçadas o que significa $1,1 \%$ da área total de 49 ha, área da sub-bacia S16 somada a da contribuinte S15. À luz dos hidrogramas dos cenários antes e após a aplicação dos pavimentos, tem-se os resultados abaixo:

- Mitigação de 4,4\% do volume de escoamento superficial, passando de 20.031 para $19.152 \mathrm{~m}^{3}$;

- Redução da vazão de pico em aproximadamente de 33\%, de 6.973 para 4.670 l/s. E ainda, o tempo de pico aumentou de 10 para 26 minutos, atenuando o escoamento superficial, com menor vazão de pico e tempo de pico mais lento.

O Gráfico 13 ilustra os hidrogramas obtidos para a sub-bacia S18, na qual os pavimentos permeáveis foram aplicados cerca de $36.756 \mathrm{~m}^{2}$ de calçadas o que significa 2,7\% da área total de 134,7 ha, soma da área da sub-bacia S18 e sua contribuinte S17. Analisando-se os hidrogramas dos cenários antes e após a aplicação dos pavimentos, foram obtidos os seguintes resultados:

- O volume de escoamento superficial foi reduzido em $11,5 \%$, passando de 53.125 para $46.984 \mathrm{~m}^{3}$;

- A vazão de pico sofreu uma redução de cerca de $32 \%$, de 15.430 para 10.434 1/s. Adicionalmente, o tempo de pico aumentou de 14 para 30 minutos, portanto houve atenuação significativa do escoamento superficial, com menores vazão de pico e tempo de pico.

O Gráfico 14 mostra os hidrogramas obtidos para a sub-bacia S19 onde os pavimentos permeáveis foram aplicados em cerca de $7.990 \mathrm{~m}^{2}$ de calçadas o que significa 7\% da sua área total de apenas 11 ha. Com base na análise dos hidrogramas dos cenários antes e após a aplicação dos pavimentos, tem-se os seguintes resultados:

- Houve redução do volume de escoamento superficial em 9,6\%, passando de 9.608 para $8.681 \mathrm{~m}^{3}$;

- A vazão de pico reduziu em 9,8\%, de 4.295 para 3.878 1/s, o tempo de pico aumentou de 14 para 20 minutos, desta forma a vazão de pico foi 
atenuada e o tempo de escoamento foi aumentado, resultando em um escoamento superficial mais lento e de menor magnitude.

O Gráfico 15 apresenta os hidrogramas obtidos para a sub-bacia S21. Nessa sub-bacia os pavimentos permeáveis foram aplicados em $5.166 \mathrm{~m}^{2}$ de calçadas, o que representa $0,3 \%$ da área total de 165 ha, resultado da soma da área da sub-bacia S21 com a sua contribuinte S20. Comparando-se os hidrogramas dos cenários antes e após a aplicação dos pavimentos, tem-se os resultados abaixo:

- O volume de escoamento superficial foi reduzido em cerca de $4 \%$, passando de 29.930 para $28.792 \mathrm{~m}^{3}$;

- A primeira vazão de pico foi reduzida em $69 \%$, de 7.028 para 2.175 1/s, e o tempo de pico aumentou apenas em 2 minutos, de 10 para 12. Houve significativa redução da primeira vazão de pico de chuva, todavia a redução do volume de escoamento superficial foi pouco significativa;

- A segunda vazão de pico foi elevada em 0,8\%, de 4.772 para 4.812 1/s, porém o tempo de pico não foi alterado, permanecendo em 74 minutos.

O Gráfico 16 ilustra os hidrogramas obtidos para a sub-bacia S23, na qual foram propostos $8.343 \mathrm{~m}^{2}$ de calçadas para aplicação dos pavimentos permeáveis o que equivale a $1,7 \%$ da área total de 47 ha, soma da área da sub-bacia S23 e sua contribuinte S22. Com base nos hidrogramas dos cenários antes e após a aplicação dos pavimentos, os resultados obtidos foram:

- O volume de escoamento superficial foi reduzido em aproximadamente $12 \%$, passando de 33.701 para $29.771 \mathrm{~m} 3$;

- A vazão de pico foi reduzida em $18 \%$, de 13.774 para 11.280 1/s, e o tempo de pico aumentou apenas em 8 minutos, de 24 para 16.

O Gráfico 17 mostra o resultado do impacto da aplicação dos pavimentos permeáveis na vazão do exutório da Bacia do Rio dos Macacos. No total os pavimentos permeáveis foram aplicados em $68.925 \mathrm{~m}^{2}$ de calçadas, o que equivale a $0,7 \%$ da área total da bacia em estudo.

Através da análise dos hidrogramas dos cenários antes e após a aplicação dos pavimentos permeáveis, pode-se inferir que:

- O volume de escoamento superficial foi atenuado em aproximadamente $4 \%$, passando de 169.300 para $161.857 \mathrm{~m} 3$;

- Aos 16 minutos, a primeira vazão de pico que antes era de 25.478 1/s foi amortecida para 15.947 1/s, o que representa uma redução de $37 \%$; 
- Observa-se também que a vazão do escoamento superficial é amortecida até 46 minutos após o início do evento chuvoso, momento no qual os hidrogramas dos cenários estudados encontram-se e passam a ter comportamentos semelhantes. Todavia as vazões do hidrograma do cenário após são ligeiramente superiores ao cenário antes da aplicação dos pavimentos permeáveis.

De acordo com Miguez et al (2012), as vazões no exutório da bacia do Rio dos Macacos são reduzidas, ao compará-las com as vazões que são geradas nas encostas a montante da bacia. Desta maneira, Miguez et al (2012) chegou à conclusão de que grande parte do escoamento superficial gerado fica represado na bacia, ocasionando inundação das áreas urbanas. Através da modelagem hidráulica e hidrológica realizada, o presente estudo também foi capaz de constatar tal fato.

Observa-se que a vazão máxima do exutório obtida para a bacia do Rio dos Macacos pelo software SWMM está similar a obtida por Miguez et al (2012). 


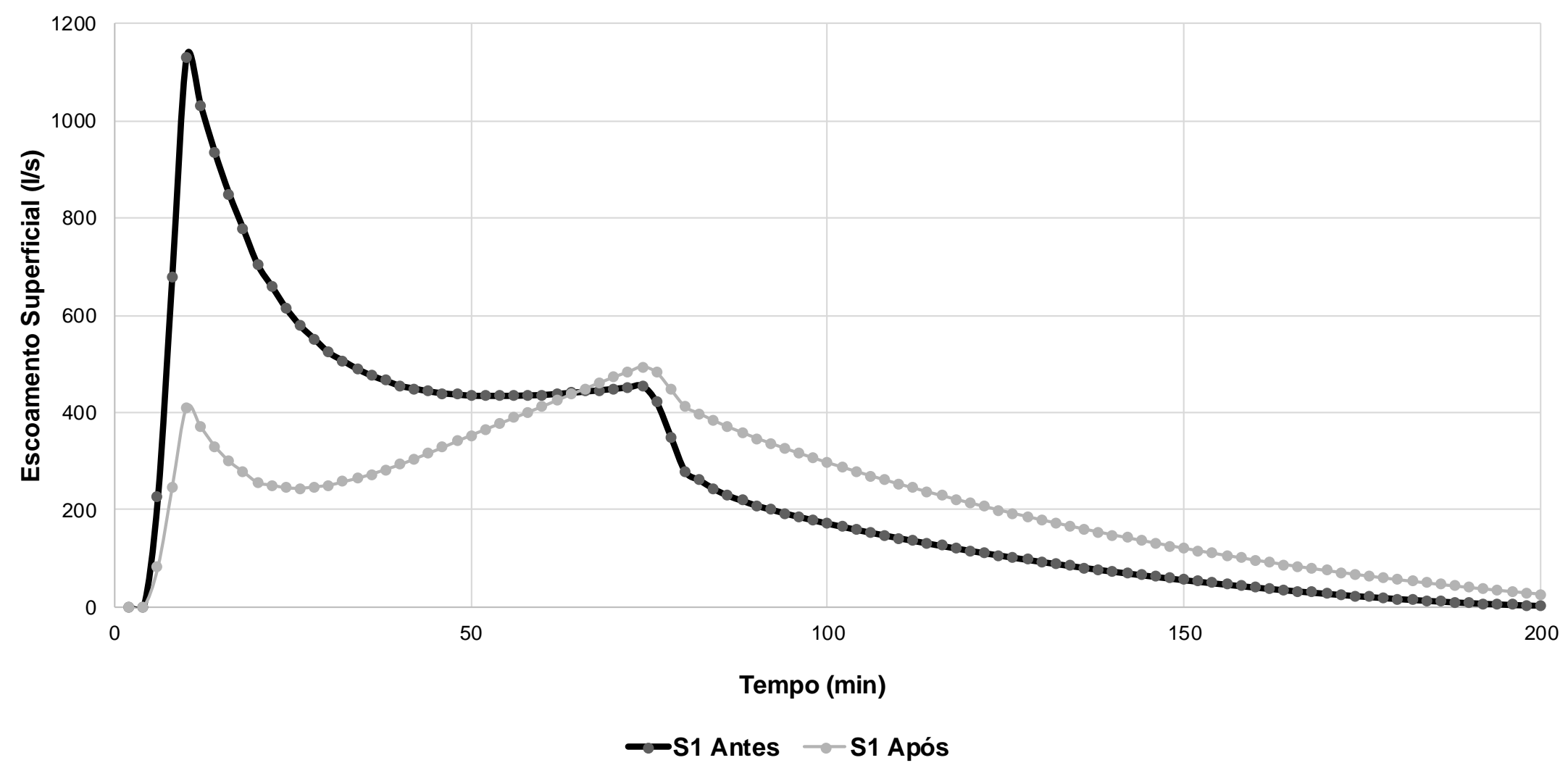

Gráfico 10 - Hidrograma da Sub-bacia S1 


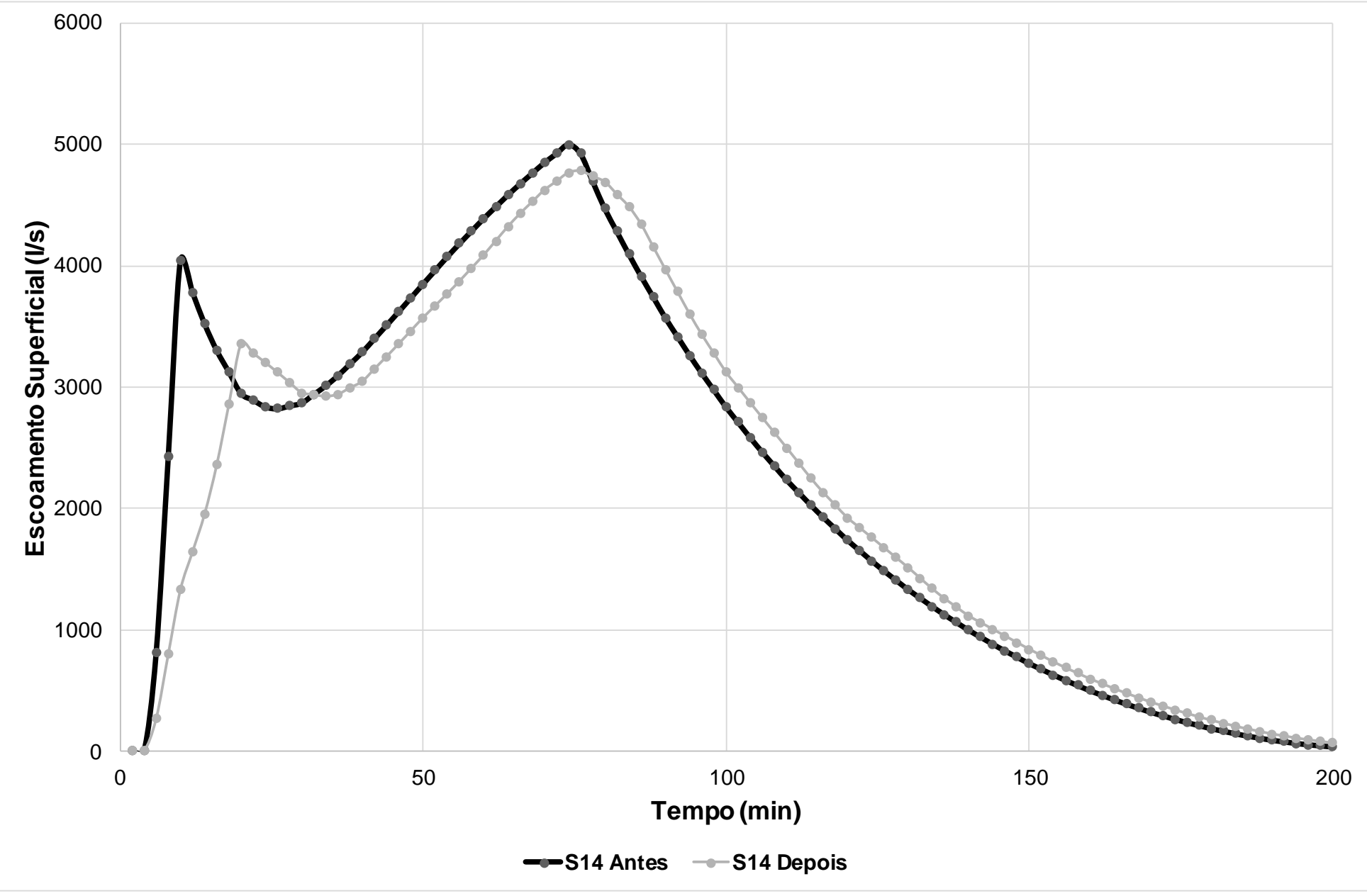

Gráfico 11 - Hidrograma da Sub-bacia S14 


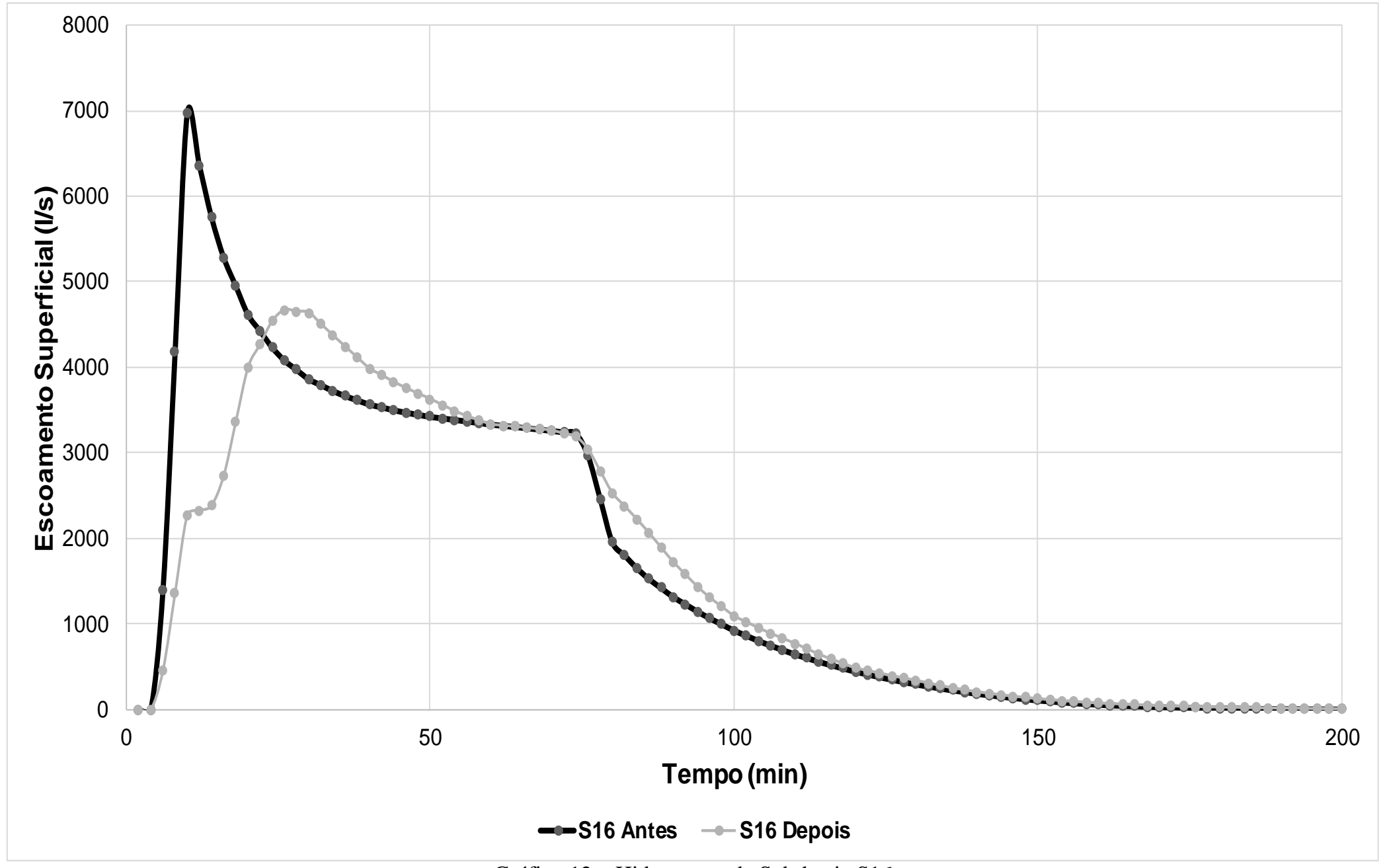

Gráfico 12 - Hidrograma da Sub-bacia S16 


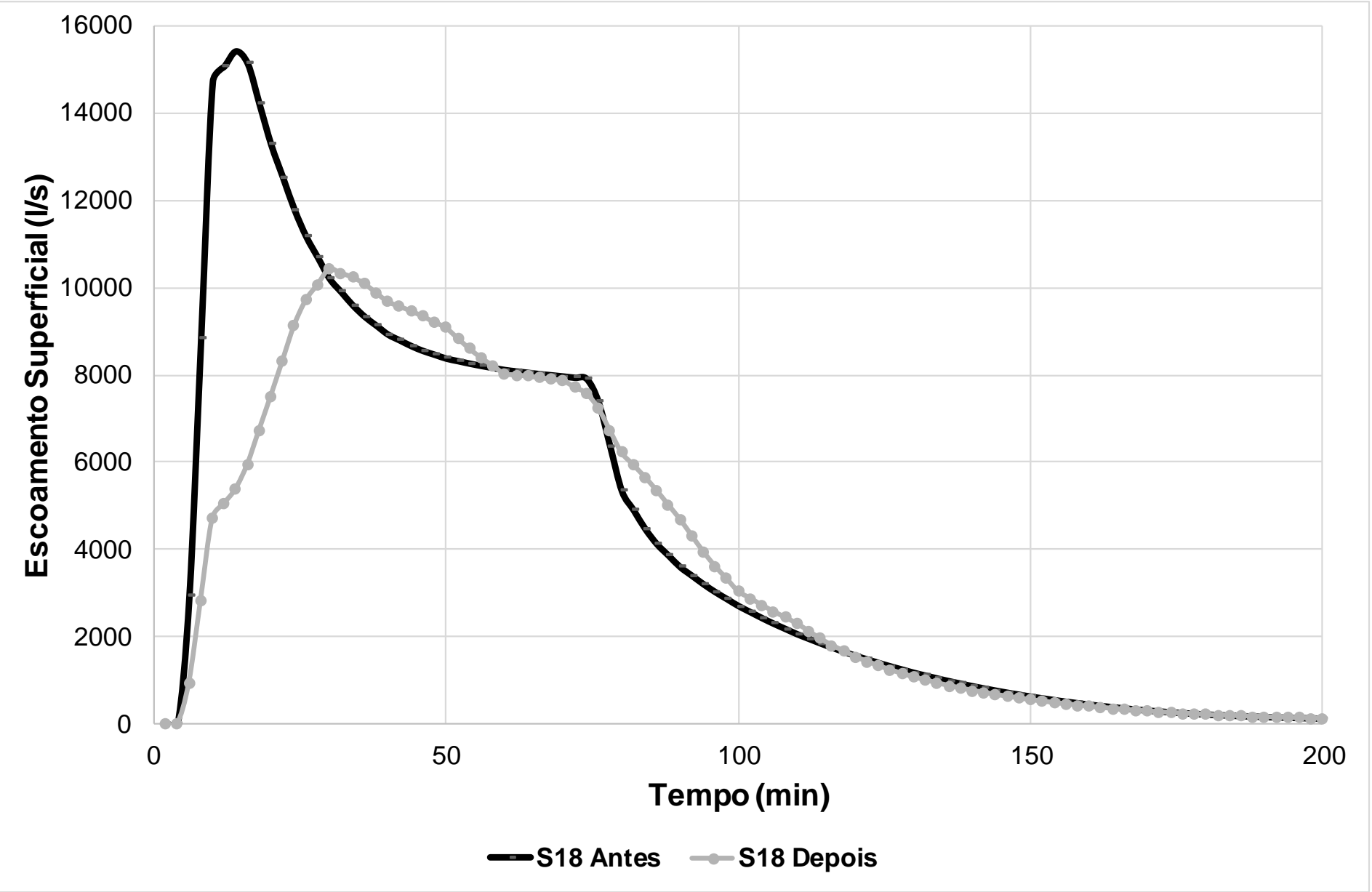

Gráfico 13 - Hidrograma da Sub-bacia S18 


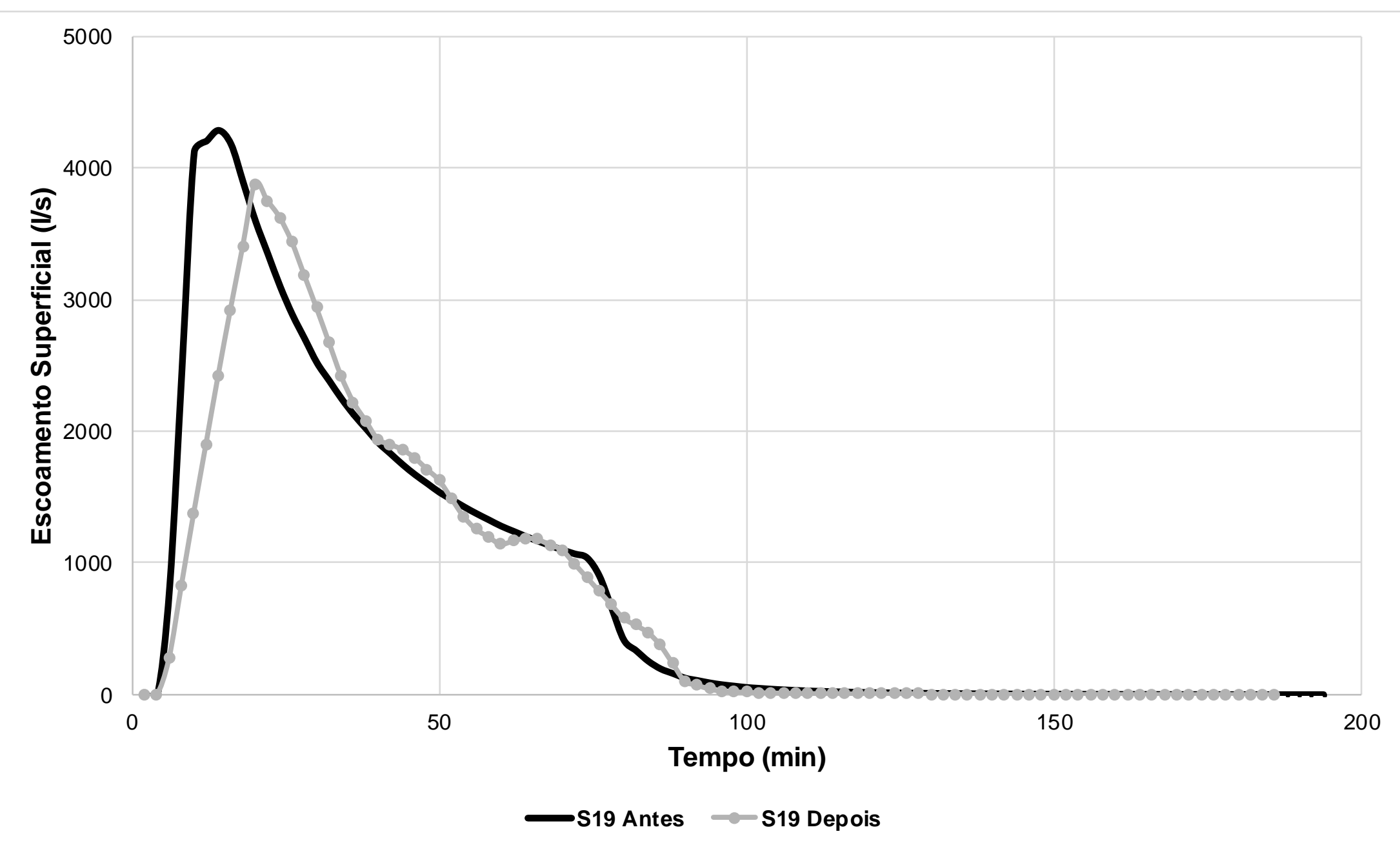

Gráfico 14 - Hidrograma da Sub-bacia S19 


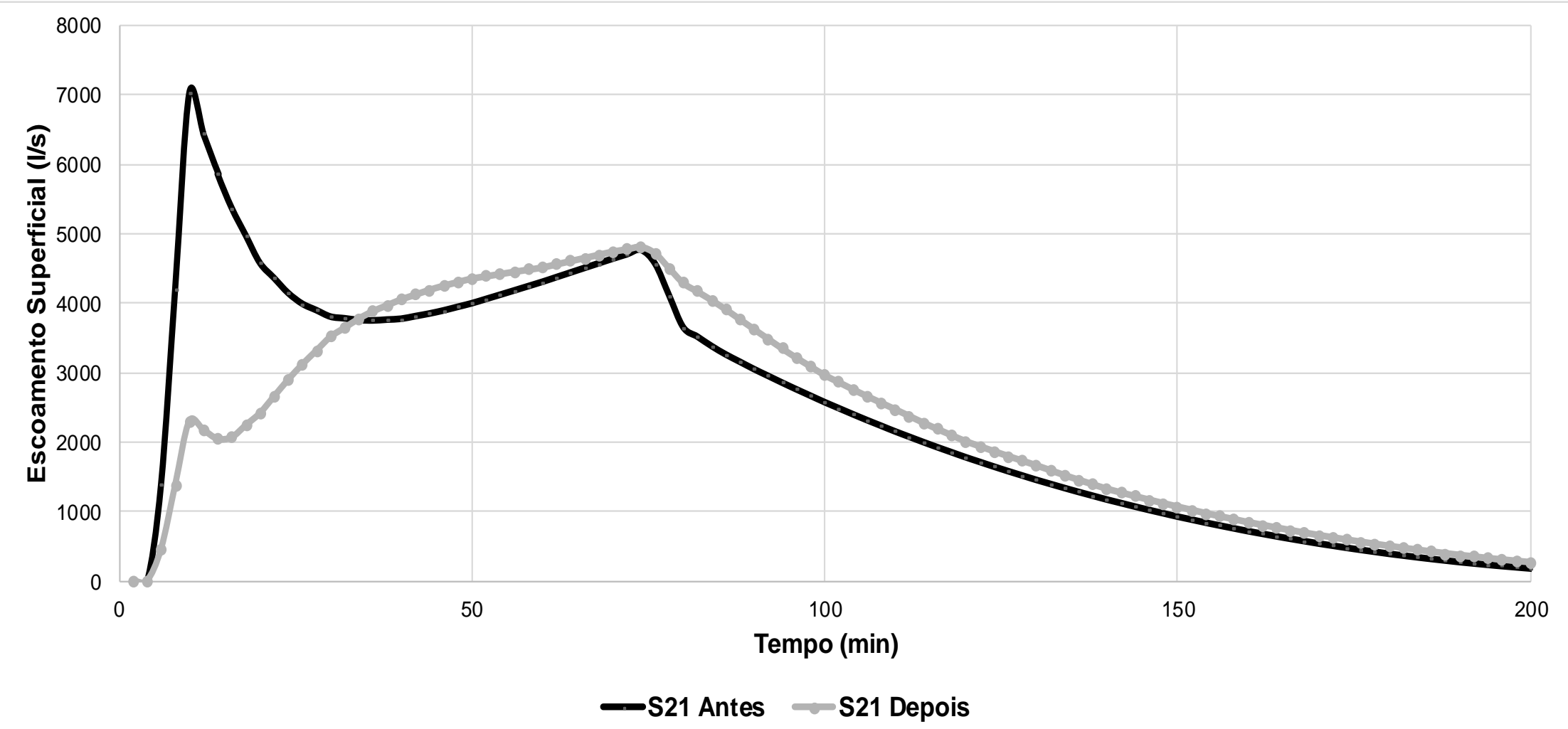

Gráfico 15 - Hidrograma da Sub-bacia S21 


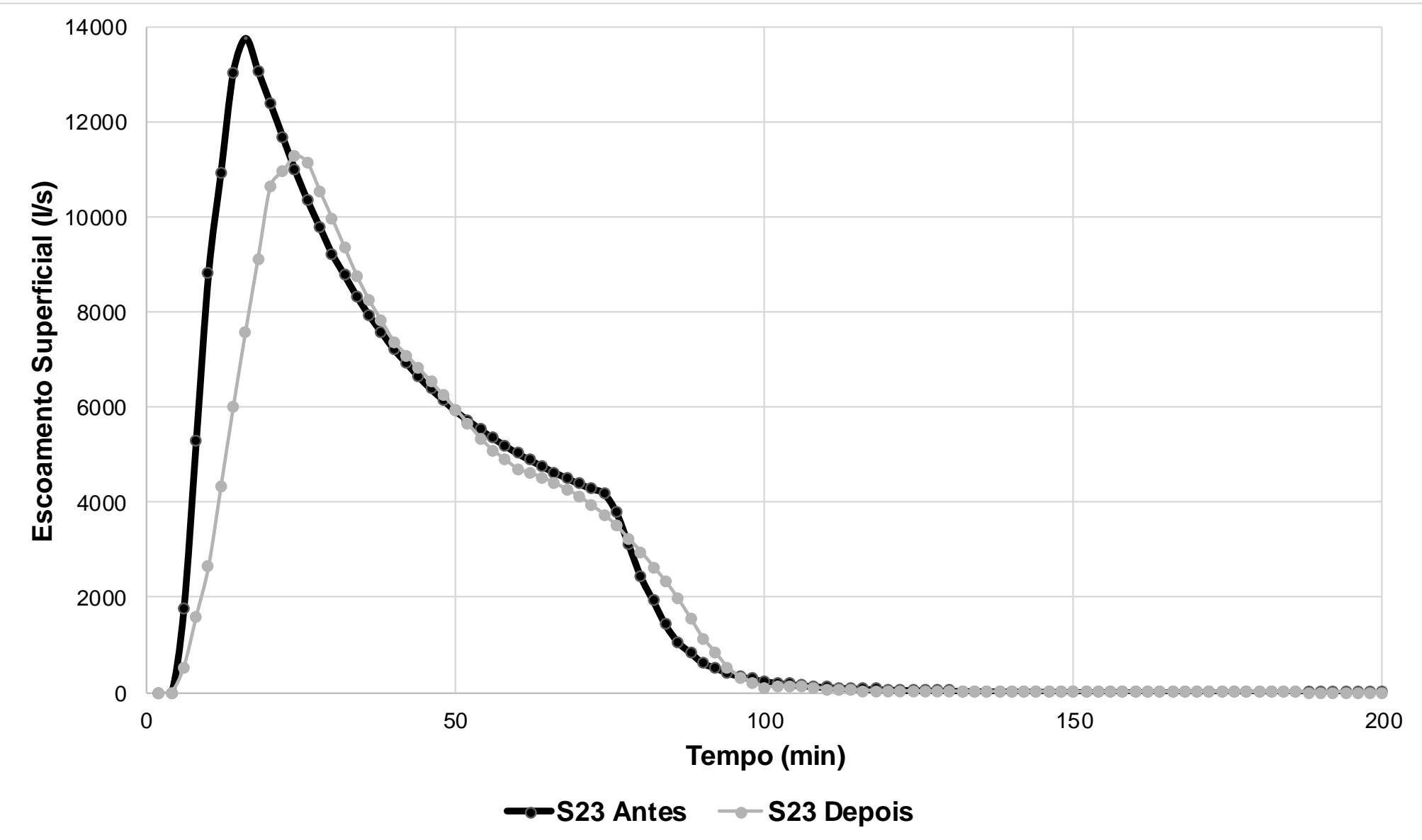

Gráfico 16 - Hidrograma da Sub-bacia S23 


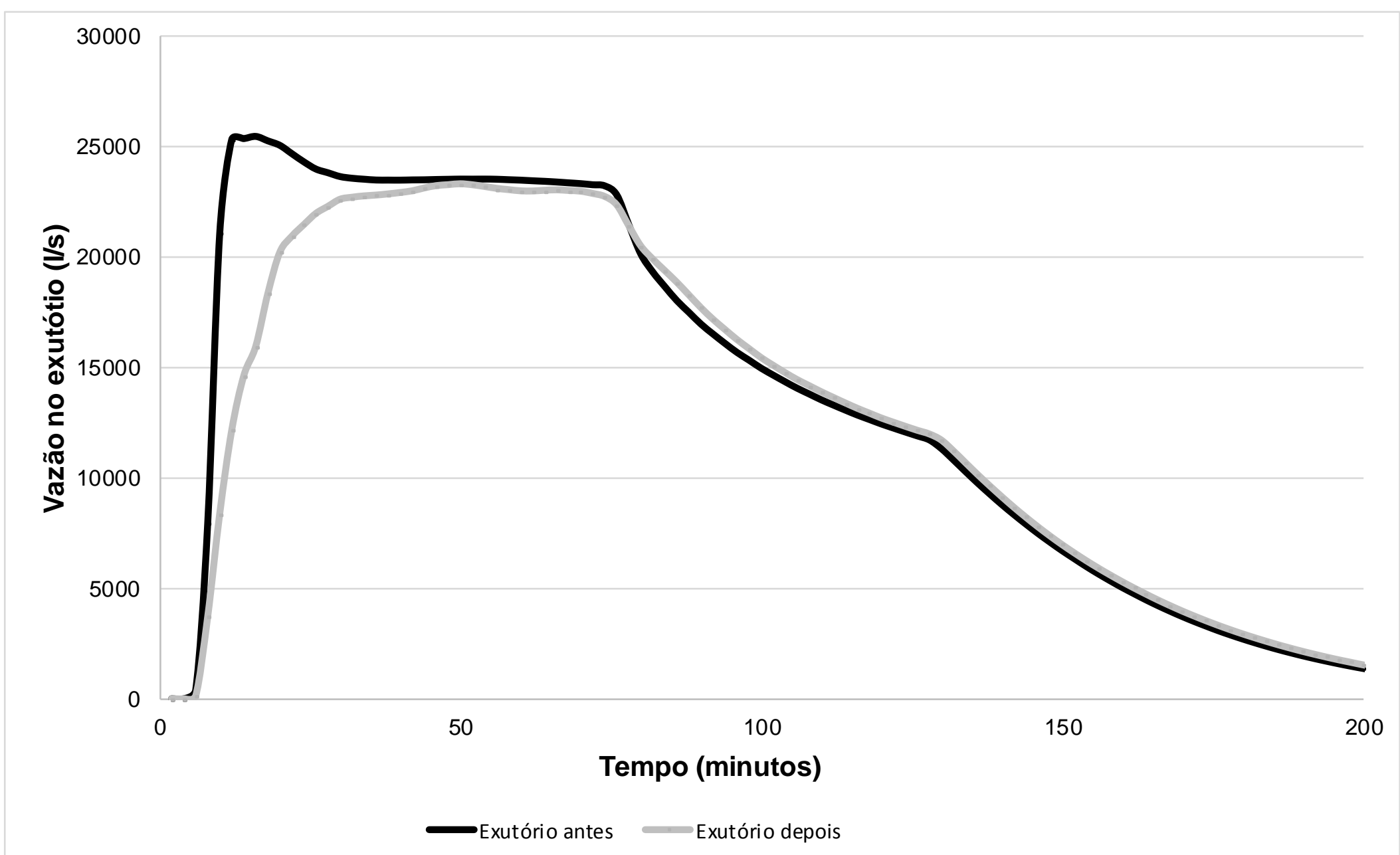

Gráfico 17 - Hidrograma do exutório da Bacia do Rio dos Macacos 


\section{2 \\ Análise de custo}

Foi realizada uma análise de custos diretos da solução proposta para as calçadas das sub-bacias urbanas da Bacia do Rio dos Macacos.

Os custos diretos englobam custos de mão de obra, materiais e equipamentos e seus valores estão fundamentados no Sistema de Custos de Obras - SCO RIO, data base julho de 2017, publicados pela Prefeitura do Rio de Janeiro. O SCO RIO disponibiliza os custos de mão-de-obra sem encargos sociais (desonerado).

Ressalta-se que o valor de $\mathrm{R}$ foi adotado igual a 2, conforme apresentado na Tabela 24, o que significa que em $1 \mathrm{~m}^{2}$ de calçada deve ser construído $0,33 \mathrm{~m}^{2}$ de pavimento permeável, de acordo com o exemplo exposto na Figura 18.

Para a elaboração da composição de custos foi considerada que a camada filtro será constituída por geotêxtil. O resultado foi o custo total de $\mathrm{R} \$ 62,29$ por metro quadrado de pavimento permeável, segundo detalhado na Tabela 32.

Portanto foi determinado o custo direto total de $\mathrm{R} \$ 4.293 .355,00$ para implantar a solução proposta de $68.925 \mathrm{~m}^{2}$ de pavimento permeável, conforme detalhado para cada sub-bacia na Tabela 33.

Observa-se que se trata de uma estimativa de custos preliminar, desta forma deverão ser analisadas as peculiaridades locais para uma estimativa mais precisa. 
Tabela 32 - Custo do metro quadrado do pavimento de concreto permeável

\begin{tabular}{|c|c|c|c|c|c|c|}
\hline Etapa & Item de serviço & Descrição & Un & $\begin{array}{c}\text { Custo } \\
(\mathbf{R} \$)\end{array}$ & Qtde & $\begin{array}{l}\text { Total } \\
(\mathbf{R} \$)\end{array}$ \\
\hline $\begin{array}{l}\text { Demolição do } \\
\text { pavimento } \\
\text { existente }\end{array}$ & SC 04.10.0100 (/) & $\begin{array}{l}\text { Demolição, com equipamento de ar comprimido, de passeio cimentado com espessura até } 10 \mathrm{~cm}, \\
\text { inclusive afastamento lateral dentro do canteiro de serviços. }\end{array}$ & $\mathrm{m} 2$ & 8,00 & 0,33 & 2,67 \\
\hline \multirow{3}{*}{$\begin{array}{l}\text { Escavação e } \\
\text { Bota-fora }\end{array}$} & MT 09.05.0050 (/) & $\begin{array}{l}\text { Escavação mecânica, em material de } 1^{\mathrm{a}} \text { categoria (areia, argila ou piçarra), utilizando Retro- } \\
\text { Escavadeira }\end{array}$ & $\mathrm{m} 3$ & 5,33 & 0,15 & 0,80 \\
\hline & TC 04.05.0150 (/) & $\begin{array}{l}\text { Transporte de carga de qualquer natureza; exclusive as despesas de carga e descarga tanto da espera } \\
\text { do caminhão como de servente ou equipamento auxiliar, em alta velocidade }(\mathrm{Vm}=50 \mathrm{Km} / \mathrm{h}) \text {, em } \\
\text { Caminhão de Carroceria Fixa a óleo diesel, com capacidade útil de } 7,5 \mathrm{t} \text {. }\end{array}$ & $\mathrm{t} \times \mathrm{km}$ & 0,60 & 18,90 & 11,34 \\
\hline & TC 09.05.0700 (/) & $\begin{array}{l}\text { Disposição final de materiais e resíduos de obras em locais de operação e disposição final } \\
\text { apropriados, autorizados e/ou licenciados pelos órgãos de licenciamento e de controle ambiental, } \\
\text { medida por tonelada transportada, sendo comprovada conforme legislação pertinente. }\end{array}$ & $\mathrm{t}$ & 14,24 & 0,27 & 3,84 \\
\hline $\begin{array}{c}\text { Camada } \\
\text { Reservatório }\end{array}$ & $\begin{array}{l}\text { BP } 04.05 .0025(/) \\
\text { modificado }\end{array}$ & Base de brita 3, inclusive fornecimento dos materiais, medida após compactação. & $\mathrm{m}^{3}$ & 103,87 & 0,22 & 23,31 \\
\hline Camada de Filtro & DR 64.05.0100 (/) & $\begin{array}{l}\text { Manta Bidim ou similar tipo OP-30 em drenos subterrâneos, gaviões, filtros de transição, drenos } \\
\text { profundos ou valetas. Fornecimento e colocação. }\end{array}$ & $\mathrm{m}^{2}$ & 5,57 & 0,33 & 1,86 \\
\hline \multirow{4}{*}{ Revestimento } & МAT033700 & Cimento Portland, tipo 320, saco de 50K.g & $\mathrm{kg}$ & 0,32 & 6,30 & 2,02 \\
\hline & MAT018450 & Brita $0(9,5$ a $6,3 \mathrm{~mm})$ & $\mathrm{m}^{3}$ & 99,65 & 0,05 & 4,59 \\
\hline & ET 04.20.0200 (/) & $\begin{array}{l}\text { Preparo mecânico de concreto, compreendendo a mistura e o amassamento em betoneira, exclusive } \\
\text { materiais, considerando produção normal. }\end{array}$ & $\mathrm{m}^{3}$ & 46,39 & 0,06 & 2,78 \\
\hline & ET 04.25.0403 (A) & $\begin{array}{l}\text { Lançamento de concreto em peças sem armadura, inclusive a colocação, o adensamento e o } \\
\text { acabamento, exclusive o transporte (TC 05.10.0050), considerando a produção normal. }\end{array}$ & $\mathrm{m}^{3}$ & 36,99 & 0,06 & 2,22 \\
\hline $\begin{array}{l}\text { Barragem com } \\
\text { orifício }\end{array}$ & ET 04.30.0100 (A) & $\begin{array}{l}\text { Concreto simples dosado racionalmente para uma resistência mínima característica a compressão } \\
\text { de } 11 \mathrm{MPa} \text {, inclusive materiais, preparo, lançamento, colocação e adensamento, exclusive transporte. }\end{array}$ & $\mathrm{m}^{3}$ & 277,60 & 0,02 & 6,87 \\
\hline \multicolumn{6}{|c|}{ Custo direto total por metro quadrado $\left(\mathrm{R} \$ / \mathrm{m}^{2}\right)$} & 62,29 \\
\hline
\end{tabular}


Tabela 33 - Custo direto total da solução proposta

\begin{tabular}{c|c|c|c|c|c|c}
\hline $\begin{array}{c}\text { Sub- } \\
\text { Bacia }\end{array}$ & $\begin{array}{c}\text { Área da } \\
\text { sub-bacia } \\
\left(\mathbf{m}^{2}\right)\end{array}$ & $\begin{array}{c}\text { Sub-bacia } \\
\text { Contribuinte }\end{array}$ & $\begin{array}{c}\text { Área total } \\
\left(\mathbf{m}^{2}\right)\end{array}$ & $\begin{array}{c}\text { Área de } \\
\mathbf{c}(c ̧ a d a s \\
\left(\mathbf{m}^{2}\right)\end{array}$ & $\begin{array}{c}\text { Área de } \\
\text { calçadas em } \\
\text { relação a área } \\
\text { total (\%) }\end{array}$ & $\begin{array}{c}\text { Custo } \\
\text { direto } \\
(\mathbf{R} \mathbf{\$})\end{array}$ \\
\hline S1 & 229.100 & - & 229.100 & 3.660 & $1,6 \%$ & 227.981 \\
\hline S14 & 95.005 & S13 & 1.208 .602 & 1.737 & $0,1 \%$ & 108.188 \\
\hline S16 & 200.930 & S15 & 493.185 & 5.273 & $1,1 \%$ & 328.467 \\
\hline S18 & 520.074 & S17 & 1.346 .757 & 36.756 & $2,7 \%$ & 2.289 .537 \\
\hline S19 & 113.816 & - & 113.816 & 7.990 & $7,0 \%$ & 497.701 \\
\hline S21 & 275.761 & S20 & 1.653 .081 & 5.166 & $0,3 \%$ & 321.769 \\
\hline S23 & 238.938 & S22 & 477.875 & 8.343 & $1,7 \%$ & 519.712 \\
\hline TOTAL: BACIA RIO DOS & $\mathbf{9 . 8 0 4 . 2 7 9}$ & $\mathbf{6 8 . 9 2 5}$ & $\mathbf{0 , 7 \%}$ & $\mathbf{4 . 2 9 3 . 3 5 5}$ \\
\hline
\end{tabular}




\section{7 \\ Conclusões}

Sobre os resultados do estudo experimental do concreto permeável, pode-se concluir que o consumo de cimento e do fator água cimento para amostras com faixa de agregados variando de 6,3 a 2,4 $\mathrm{mm}$ (T1 a T5), elevou gradativamente a resistência mecânica do concreto e, simultaneamente, proporcionou maior índice de vazios e permeabilidade. Nos traços T1 a T5, tal resultado pode ser explicado devido à quantidade insuficiente de área de pasta de cimento para promover a ligação dos grãos, a qual também não permitia uma compactação eficiente devido ao atrito entre os agregados. Desta maneira, o aumento do volume de pasta proporcionou aumento das resistências mecânicas e do índice de vazios, proporcionando maior permeabilidade. No entanto, embora apresentando resistência mecânica suficiente para aplicação em calçadas, o coeficiente de permeabilidade dos traços T1 a T5 ficou abaixo do recomendado pela norma ABNT NBR16416:2015.

Ao alterar os diâmetros dos agregados para faixa de agregados de 9,5 a 6,3 mm no traço T6, obteve-se um concreto de maior permeabilidade e menor resistência. Todavia as resistências mecânicas encontradas ainda estão de acordo com os critérios estabelecidos para tráfego de pedestres, conforme norma ABNT NBR16416:2015.

A fim de melhorar ainda mais a permeabilidade no traço $\mathrm{T} 7$ aumentou-se o fator água cimento, mantendo-se as demais características de T6, e obteve-se um concreto permeável de maior permeabilidade e de menores resistências mecânicas. No entanto, mais uma vez, as resistências mecânicas encontradas não impedem o uso do concreto estudado em calçadas. Portanto, para simulação dos pavimentos permeáveis no software SWMM foi escolhido este último traço, por apresentar maior permeabilidade e resistência adequada ao uso pretendido no estudo.

No que tange ao estudo de caso no Bairro Jardim Botânico, pode-se concluir que por se tratar de uma bacia urbana consolidada e cujas ruas apresentam alta declividade, as áreas disponíveis para aplicação em calçadas foram pouco 
significativas em relação a área total da bacia. Soma-se a esse quadro, a característica natural da bacia do Rio dos Macacos, a qual possui a contribuição de sub-bacias de grande área, que apesar de apresentarem cobertura vegetal o que possibilitaria maior infiltração, possuem elevado índice pluviométrico e alta declividade, o que dificulta o processo de absorção de água pelo solo e faz com que a chuva chegue mais rápido na parte mais baixa da bacia, a qual apresenta ocupação urbana e consequentemente, solo impermeabilizado, elevando o escoamento superficial da bacia.

Mesmo diante deste cenário, o uso do pavimento permeável de concreto foi capaz de atenuar o escoamento superficial no exutório da Bacia do Rio dos Macacos, para o tempo de recorrência de 25 anos. A construção de $68.925 \mathrm{~m}^{2} \mathrm{de}$ pavimento permeável de concreto seria capaz de atenuar 37\% da primeira vazão de pico, todavia apenas cerca de $4 \%$ do volume do escoamento superficial seria reduzido. A estimativa preliminar resultou em um custo direto de $\mathrm{R} \$ 62,29$ por metro quadrado, totalizando um custo de $\mathrm{R} \$ 4.293 .355,00$ para execução dos pavimentos permeáveis de concreto propostos.

Ressalta-se que foram estabelecidas premissas para a elaboração do modelo hidráulico e hidrológico as quais podem mudar os resultados obtidos, sendo estas, o coeficiente de permeabilidade, que foi adotado conservadoramente como $10^{-5}$ $\mathrm{m} / \mathrm{s}$, CBR maior que 5\% e assumido que o nível do lençol freático está a uma distância maior que $1 \mathrm{~m}$ da base dos pavimentos. Desta maneira, tais premissas devem ser confirmadas, caso haja interesse em implantar a solução proposta.

Para trabalhos futuros, podem ser modeladas outras soluções para a Bacia do Rio dos Macacos, além da aplicação do pavimento permeável de concreto, tais como a dragagem do trecho de baixa declividade do Rio dos Macacos, reservatórios, telhados verdes, entre outros. Ademais, com intuito de aumentar a precisão da simulação, podem ser utilizadas geotecnologias para aprimorar a caracterização da bacia hidrográfica.

Quanto ao estudo do concreto permeável, para trabalhos futuros pode ser estudada a inclusão de aditivos no traço T7, a fim de melhorar a sua resistência e permeabilidade e, desta maneira, possibilitar o uso do pavimento em categorias de tráfego leve e médio. 


\section{8 Referências Bibliográficas}

ABNT NBR 6118: Projeto de Estruturas de Concreto - Procedimento. Rio de Janeiro, 2014.

ABNT NBR 7211. Agregados para concreto - Especificação. Rio de Janeiro, 2009.

ABNT NBR 11578: Cimento Portland Composto- Especificação. Rio de Janeiro, 1991.

ABNT NBR 16416: Pavimentos Permeáveis de Concreto - Requisitos e Procedimentos. Rio de Janeiro, 2015.

ASSOCIAÇÃO BRASILEIRA DE CIMENTO PORTLAND - ABCP. Guia Básico de Utilização do Cimento Portland. Boletim Técnico. São Paulo, 2002. ASSOCIAÇÃO BRASILEIRA DE CIMENTO PORTLAND - ABCP. Manual de Pavimento Intertravado: Passeio Público. São Paulo, 2010.

BALLARD, W. B. et al. The SuDS Manual. Londres, Inglaterra, 2007

BALLARD, W. B. et al. The SuDS Manual. Londres, Inglaterra, 2015

BATEZINI, R. Estudo Preliminar de Concretos Permeáveis como Revestimento de Pavimentos para Áreas de Veículos Leves. Dissertação de Mestrado. São Paulo, 2013.

BEECHAM, S. Water Sensitive Urban Design - Greater Adelaide RegionTechnical Manual. Austrália, 2010

BHUTTA, R. A. M.; TSURUTA, K; MIRZA, J. Evaluation of high-performance porous concrete properties. Construction and Building Materials. Vol. 13 pag 6773. Malásia, 2012

BONICELli, A.; ARGUELlES, G.; M., PUMAREJO, L. G. F. Improving Pervious Concrete Pavements for Achieving More Sustainable Urban Roads. Procedia Engineering. Vol. 161 pag 1568-1573. Colômbia, 2016. 
CANHOLI, A. Drenagem Urbana e Controle de Enchentes. 2.ed. São Paulo. Editora Oficina de Textos. 2014. 278p.

CANHOLI, J. F. Medidas de Controle in Situ do Escoamento Superficial em Áreas Urbanas: Análise de Aspectos Técnicos e Legais. Dissertação de Mestrado. São Paulo, 2013.

COLLODEL, M. G. Aplicação do Modelo Hidrológico SWMM na avaliação de diferentes níveis de detalhamento da bacia hidrográfica submetidas ao processo de transformação chuva-vazão. Universidade de São Paulo. São Carlos, 2009.

COMPANHIA SIDERÚRGICA NACIONAL - CSN. Disponível em http://www.csn.com.br/conteudo_eni.asp?idioma=1\&conta=46\&tipo=59833 Acesso em 01 jan 18.

CHANDRAPPA, P. K.; BILIGIRI A. K, Pervious concrete as a sustainable pavement material - Research. Findings and future prospects: A state-of-theart review. India. 2016.

CHINDAPRASIRT, P.et al. Cement paste characteristics and porous concrete properties. Construction and Building Materials Vol. 22 pag 894-901. Japão, 2008 .

DELTARES. Disponível em: <http://oss.deltares.nl/web/delft-fews/home> . Acesso em 20 dez 2017

DEPARTAMENTO NACIONAL DE INFRAESTRUTURA DE TRANSPORTES - DNIT. Manual de Pavimentação. Rio de Janeiro, 2006.

Elliot, A. H.; TROWSDAlE, S. A. A Review of Models for Low Impact Urban Stormwater. Environmental Modeling \& Software. Vol 22 pag 394-405. Nova Zelândia, 2007

EMPRESA BRASILEIRA DE PESQUISA AGROPECUÁRIA - EMBRAPA. Mapeamento Pedológico e Informações Úteis ao Planejamento Ambiental do Município do Rio de Janeiro. Rio de Janeiro, RJ, 2004

FERGUSON, B. K. Porous Pavements. 1. Florida, Estados Unidos: CRC Press, 2005. 577p. 
FIELD, R.; MASTERS, H.; SINGER, M. Status of Porous Pavement Research. Water Research, Vol 15, página 849-858, Estados Unidos, 1982.

FOLHA DE SÃO PAULO Disponível em: http://fotografia.folha.uol.com.br/galerias/42576-enchente-no-rio-de-janeiro\#foto594894. Acesso em: 24junho 2017

FUNDAÇÃO InSTITUTO RIO ÁGUAS. Plano Municipal de Saneamento Básico da Cidade do Rio de Janeiro. Rio de Janeiro, 2015.

FUNDAÇÃO INSTITUTO RIO ÁGUAS. Instruções Técnicas para Elaboração de Estudos Hidrológicos e Dimensionamento Hidráulico de sistemas de Drenagem Urbana. Rio de Janeiro, 2010.

GOOGLE EARTH. Disponível em < https://www.google.com.br/intl/pt-PT/earth/, 2017. Acesso em: 30 junho 2017

GOUDIE, A. The human impact on the natural environment, 3rd ed. The MIT Press, Cambridge, Massachusetts, 1990.

GLOBO. Disponível em < http://g1.globo.com/Noticias/Rio/0,,MUL15596085606,00.html> Acesso em: 24 junho 2017

GLOBO. Disponível em <http://g1.globo.com/Noticias/Rio/0,,MUL1559608$5606,00-$

COMPARE+O+EFEITO+DESTE+TEMPORAL+COM+O+DE+OUTROS+QUE +ATINGIRAM+O+RIO.html>Acesso em: 24 junho 2017

JAJARMIZADEH, M; HARUN, S.; SALAPOUR, M. A Review on Theorical Considerations and Types of Models in Hydrology. Journal of Environmental Science and Technology. Vol 5 pag 249-261. Malásia, 2012.

HUNT, F. W.; COLLINS, A. K. Permeable pavement: Research update and design implication, in Urban Waterway Series, North Carolina State University, Carolina do Norte, Estados Unidos, 2008

INTERPAVE. Permeable pavements. Guide to the design, construction and maintenance of concrete permeable pavements, sixth edition, Leicester, Reino Unido, 2010. 
INSTITUTO BRASILEIRO DE GEOGRAFIA E ESTATÍTICA-IBGE. Disponível em<http://www.ibge.gov.br/home/estatistica/economia/perfilmunic/2013/defaultta b_pdf.shtm> Acesso em: 14 setembro 2016

INSTITUTO BRASILEIRO DE GEOGRAFIA E ESTATÍTICA-IBGE. Censo Demográfico 2010. Rio de Janeiro, 2011.

JAIN, A. K.; CHOUHAN, S. J. Effect of Shape of Aggregate on Compressive Strength and Permeability Properties of Pervious Concrete. International Journal of Advanced Engineering Research and Studies. Vol.1 pag 120-126. India, 2011.

KHATTAB, E. A.; EL NOUHY, H. A.; ABDEL-HAMEED, G. D. Assessment of Porous Concrete Properties as a Function of Mix Proportions. World Applied Sciences Journal. Vol. 24 pag 751-758. Egito, 2013.

KEVERn, J. et al. Pervious Concrete Construction: Methods and Quality Control. Nashville, Estados Unidos, 2006.

KIM, J. Y.; GADDAFI, A.; YOSHITAKE, I. Permeable Concrete Mixed with Various Admixture. Materials and Design, Vol. 100 página 110-119, Denver, Estados Unidos, 2016.

LIAN, C.; ZHUGE, Y. The Relationship Between Porosity and Strength for Porous Concrete. Construction and Building Materials. Austrália, 2011

LIAN, C.; ZHUGE, Y.; BEECHAM, S. The Properties of Porous Concrete. Tese de doutorado. Austrália, 2011. Página 2

LUCAS, L. M.; CUNHA, S. B. Rede de Drenagem Urbana em Área Tropical: Mudanças na Morfologia do Canal e Níveis de Poluição das Águas - Rio dos Macacos - Rio de Janeiro - RJ. GEOUSP - Espaço e Tempo, № 22, pag. 39 - 64. São Paulo, 2007

MIGUEZ, M. G; REZENDE, O. M, VEROL, A. P. Interações entre o Rio dos Macacos e a Lagoa Rodrigo de Freitas sob a Ótica dos Problemas de Drenagem Urbana e Ações Integradas de Revitalização Ambiental. Oceanologia Australis, Vol. 16, pag. 615-650. Setembro, 2012.

MOREIRA, A. S. Os africanos livres e as relações de trabalho na Fábrica de Pólvora da Estrela, RJ (c.1831- c.1870). Dissertação (Mestrado) - Instituto de 
Filosofia e Ciências Humanas, Universidade Estadual de Campinas, Campinas, 2005.

Mullaney, J; LUCKE, T. Practical Review of Pervious Pavement Designs. Austrália, 2013

MUlligan, A.M. Attainable Compressive Strength of Pervious Concrete Paving Systems. Dissertação de Mestrado. Florida, Estados Unidos, 2003

PERVIOUS PAVEMENT. Disponível em <http://www.perviouspavement.org/> Acesso em: 15 janeiro 2017.

RENNÓ, C. D; SOARES, J. V. Conceitos básicos de modelagem hidrológica. INPE, Santa Maria, 2008.

ROSSMAN, L. A. Storm Management Model, Version 5.0: User's Manual. Environment Protection Agency. Cincinnati, OH. 2008

SANTOS, M. A Urbanização Brasileira. 5.ed. São Paulo: Editora da Universidade de São Paulo, 2005. 176p.

SECRETARIA MUNICIPAL DE URBANISMO - SMU. Nota Técnica $\mathbf{n}^{\mathbf{0}}$ 12: Zona Sul a Imagem do Carioca. Rio de Janeiro, 2003.

SONEBI M.; BASSUONI, M.; YAHIA, A. Pervious Concrete: Mix Design Properties and Applications. RILEM Technical Letters PAG 109-115. Canadá, 2016.

TÉCHNE PINI. Disponível em <http://techne17.pini.com.br/engenhariacivil/190/artigo288015-1.aspx >. Acesso em:16 abril 2017

TENNIS, D. P; LEMING, L. M, AKERS, J. D. Pervious Concrete Pavements, EB302.02, Portland Cement Association, Skokie, Illinois, and National Ready Mixed Concrete Association, Silver Spring, Maryland, Estados Unidos, 2004, 36 pages.

THOMAZ, S. C. E. Escória de Alto Forno - Parte 1 - Fabricação. Notas de aula. Rio de Janeiro, 2002. Disponível em: http://aquarius.ime.eb.br/ webde2/prof/ethomaz/cimentos_concretos/escoria_fabri cacao.pdf. Acesso em: 29 maio 2017. 
TODINI, E. Hydrologic cacthment modelling: past, present and future. Hydrology \& Earth System Sciences. Pag 468-482. Italy,2007.

TOMAZ, P. Pavimento Poroso. Curso de Manejo de Águas Pluviais. 2009.

UDFCD - URBAN DRAINAGE AND FLOOD CONTROL DISTRICT. Urban Storm Drainage Criteria Manual Volume 3, Stormwater Best Management Practices. Colorado, Estados Unidos. 2010.

USACE- U.S. ARMY CORPS OF ENGINEERS. HEC-RAS River Analysis System. Hydraulic Reference Manual. Estados Unidos, 2016

VON DER WEID, E. O bonde como elemento de expansão urbana no Rio de Janeiro. Fundação Casa Rui Barbosa. Rio de Janeiro, 1997.

XU, C. Textbook of Hydrologic Models. Suécia, 2002. 168p

YANG, J. JIANG, G. Experimental study on properties of pervious concrete pavement materials. Cement and Concrete Research. Vol. 33 pag 381-386. Beijing, China, 2002. 